\title{
Still living with mortality: the longevity risk transfer market after one decade
}

\author{
D. Blake*, A. J. G. Cairns, K. Dowd and A. R. Kessler
}

[Presented to the Institute and Faculty of Actuaries, Edinburgh, 29 January 2018]

\begin{abstract}
This paper updates Living with Mortality published in 2006. It describes how the longevity risk transfer market has developed over the intervening period, and, in particular, how insurance-based solutions - buy-outs, buy-ins and longevity insurance - have triumphed over capital markets solutions that were expected to dominate at the time. Some capital markets solutions - longevity-spread bonds, longevity swaps, $q$-forwards and tail-risk protection - have come to market, but the volume of business has been disappointingly low. The reason for this is that when market participants compare the index-based solutions of the capital markets with the customised solutions of insurance companies in terms of basis risk, credit risk, regulatory capital, collateral and liquidity, the former perform on balance less favourably despite a lower potential cost. We discuss the importance of stochastic mortality models for forecasting future longevity and examine some applications of these models, e.g. determining the longevity risk premium and estimating regulatory capital relief. The longevity risk transfer market is now beginning to recognise that there is insufficient capacity in the insurance and reinsurance industries to deal fully with demand and new solutions for attracting capital markets investors are now being examined - such as longevity-linked securities and reinsurance sidecars.
\end{abstract}

\section{Keywords}

Longevity Risk; Buy-Outs; Buy-Ins; Longevity Insurance; Longevity Bonds; Longevity Swaps; q-Forwards; Tail-Risk Protection; Basis Risk; Credit Risk; Regulatory Capital; Collateral; Liquidity; Stochastic Mortality Models; Longevity Risk Premium; Longevity-Linked Securities; Reinsurance Sidecars

\section{Introduction}

\subsection{Background}

1.1.1. A little over a decade ago, the longevity risk transfer market started. This is now a global market, but it began in the UK in 2006. To coincide with the setup of this market, the British Actuarial Journal published Living with Mortality (Blake et al., 2006a). That paper examined the problem of longevity risk - the risk surrounding uncertain aggregate mortality - and discussed the ways in which life insurers, annuity providers and pension plans could manage their exposure to this

*Correspondence to: David Blake, Pensions Institute, Cass Business School, City University of London, 106 Bunhill Row, London EC1Y 8TZ, UK. Tel: +44 (0) 207040 5143. E-mail: D.Blake@city.ac.uk 
risk. In particular, it focused on how they could use mortality-linked securities and over-the-counter contracts - some existing and others still hypothetical - to manage their longevity risk exposures. It provided a detailed analysis of two such securities - the Swiss Re mortality bond issued in December 2003 and the European Investment Bank (EIB)/BNP Paribas longevity bond announced in November 2004. It then looked at the universe of hypothetical mortality-linked securities - other forms of longevity bonds, swaps, futures and options - and investigated their potential uses. It also addressed implementation issues and drew lessons from the experience with other derivative contracts. Particular attention was paid to the issues involved with the construction and use of mortality indices, the management of the associated credit risks and possible barriers to the development of markets for these securities. The paper concluded that these implementation difficulties were essentially teething problems that would be resolved over time, and so leave the way open to the development of a flourishing market in a brand new class of capital market securities. ${ }^{1}$

1.1.2. In the event, the EIB/BNP longevity bond did not attract sufficient demand to get launched. The Swiss Re mortality bond, known as Vita, ${ }^{2}$ was followed by broadly similar bonds from both Swiss Re and other issuers, but the overall size of the issuance was fairly small. Swiss Re also pioneered the successful issuance of a longevity-spread bond, known as Kortis, ${ }^{3}$ but again the size of the issue was small. Investment banks, such as J. P. Morgan and Société Générale, introduced some innovative derivatives contracts $-q$-forwards and tail risk protection - but, so far, only a few of these contracts have been sold. Overall, then, the demand for the capital market solutions that have been proposed for hedging longevity risk has been disappointingly low.

1.1.3. By contrast, the solutions offered by the insurance industry have been much more successful. The key examples are the buy-out, the buy-in and longevity insurance. In other words, pension plan trustees, sponsors and advisers preferred dealing with risk by means of insurance contracts which fully removed the risk concerned and were not yet comfortable with capital market hedges that left some residual basis risk.

\subsection{Focus of This Paper}

The present paper provides a review of the developments in longevity risk management over the last decade or so. In particular, we focus on the ways in which pension plans and life insurers have managed their exposure to longevity risk, on why capital market securities failed to take off in the way that was anticipated 10 years ago, and what solutions for managing longevity risk might become available in the future.

\subsection{Layout of This Paper}

The paper is organised as follows. Section 2 quantifies the potential size of the longevity risk market globally. Section 3 discusses the different stakeholders in the market for longevity risk transfers. Sections 4 and 5, respectively, examine the structure of the successful insurance-based and capital market solutions that have been brought to market since 2006. The distinction between index and

1 As originally suggested in Blake \& Burrows (2001), Dowd (2003) and Blake et al. (2006b).

2 http://www.artemis.bm/deal_directory/vita-capital-ltd/

Disclaimer: the web links in the footnotes were active at the time of the sessional meeting and the authors take no responsibility for the ongoing maintenance of these links.

${ }^{3}$ http://www.artemis.bm/deal_directory/kortis-capital-ltd/ 
customised hedges and the issue of basis risk are investigated in section 6, while section 7 looks at credit risk, regulatory capital and collateral and section 8 discusses liquidity. Stochastic mortality models are crucial to the design and pricing of longevity risk transfer solutions and these are reviewed in section 9, while some applications that use these models are considered in section 10 . Section 11 reviews the developments in the longevity de-risking market since 2006. Section 12 looks at potential future risk transfer solutions that involve the capital markets and section 13 concludes.

\section{Quantifying the Potential Size of the Longevity Risk Market}

2.1. Michaelson \& Mulholland (2014) recently estimated the potential size of the global longevity risk market for pension liabilities at between $\$ 60$ trn and $\$ 80$ trn, comprising:

(i) The accumulated assets of private pension systems in the Organisation for Economic CoOperation and Development (OECD) were $\$ 32.1 \mathrm{trn},{ }^{4}$ arising from: pension funds $(67.9 \%)$, banks and investment companies $(18.5 \%)$, insurance companies $(12.8 \%)$ and employers' book reserves $(0.8 \%)$ at year-end 2012 (OECD, 2013).

(ii) The US social security system had unfunded obligations for past and current participants of \$24.3trn, as of the end of 2013 (Social Security Administration (SSA), 2013).

(iii) The aggregate liability of US State Retirement Systems was an additional \$3trn, as of the end of 2012 (Morningstar, 2013), which does not capture the liabilities of countless US local and municipal pension systems.

(iv) There are public social security systems in 170 countries (excluding the USA) that provide oldage benefits of some sort for which reliable size estimates are not readily available but which are certainly substantial. ${ }^{5}$

2.2. Michaelson \& Mulholland (2014) then estimated the size of the longevity risk underlying these liabilities. Each additional year of unanticipated life expectancy at age 65 - roughly equivalent to a $0.8 \%$ increase in mortality improvements or a $13 \%$ reduction in mortality rates ${ }^{6}$ - can increase pension liabilities by $4-5 \%{ }^{7}$ (Swiss Re Europe, 2012). Risk Management Solutions (RMS) estimated the standard deviation of a sustained shock to annual mortality improvements (lasting 10 years or more) relative to expectations at around $0.80 \%$. Michaelson and Mulholland use this estimate to calculate the effect of a longevity tail event (i.e. a 2.5 standard deviation event) which corresponds to a $2 \%$ change in trend $(0.80 \% \times 2.5=2 \%)$ and, in turn, implies that longevity-related liabilities could increase by $10-12.5 \%$ as a result of unforeseen mortality improvements. Given aggregate global pension liabilities of $\$ 60-80 \operatorname{trn}$, these could, in the extreme, turn out to be between $\$ 6 \operatorname{trn}$ and $10 \operatorname{trn}$ higher.

2.3. Pigott $\&$ Walker (2016) also estimate that private sector longevity risk exposure is of the order of $\$ 30 \mathrm{trn}^{8}{ }^{8}$ This is concentrated in the US $(\$ 14.460 \mathrm{trn})$, the UK $(\$ 2.685 \mathrm{trn})$, Australia $(\$ 1.639 \mathrm{trn})$, Canada (\$1.298trn), Holland (\$1.282trn), Japan $(\$ 1.221 \mathrm{trn})$, Switzerland (\$0.788trn), South Africa $(\$ 0.306 \mathrm{trn})$, France $(\$ 0.272$ trn), South America $(\$ 0.251$ trn), Germany $(\$ 0.236$ trn) and Hong Kong (\$0.110trn).

${ }^{4}$ Revised to \$38trn at the end of 2016 (OECD(2017) Global Pension Statistics).

5 Social Security Administration: http://www.ssa.gov/policy/docs/progdesc/ssptw/

${ }^{6}$ Own calculations, based on England \& Wales mortality forecasts for males aged 65.

7 Corresponding to $2 \%$ and $0 \%$ real discount rates, respectively.

${ }^{8}$ Derived from Aon Hewitt calculations, based on data from the OECD and European Insurance and Occupational Pensions Authority (EIOPA). 
Pigott and Walker argue that only the UK, USA, Canada and Holland currently have the conditions for a longevity risk transfer market to develop. These conditions include: low interest rates (in part due to government quantitative easing programmes in response to the 2007-2008 Global Financial Crisis (GFC)) which, by increasing the present value of more distant pension payments, has exposed the real extent of longevity risk in pension plans; inflation uplifting of pensions in payment further increases longevity risk; frequent updating by the actuarial profession of longevity projections; the introduction of market-consistent valuation methods; increased accounting transparency of pension assets and liabilities; and increased intervention powers by the regulator. Collectively, these factors have focussed the minds of plan trustees and sponsors and encouraged them to look for solutions with their advisers.

2.4. The other markets do not currently have the right conditions for the following reasons:

- Australia: Most sponsors of pension plans bear little or no longevity risk; individuals often take a lump sum or buy term (20-year) annuities at retirement, then rely on the state, although a lifetime annuity market is beginning to emerge.

- Japan: Corporate sponsors of pension plans and insurers do not bear longevity risk, since individuals buy term annuities at retirement; however, there is a growing market for long-term annuities in Japan purchased from Australia. ${ }^{9}$

- Switzerland: Individuals are incentivised but not required to annuitise; the market is small, but may open up in the future.

- Germany: Occupational plan liabilities are often written onto company balance sheets as book reserves, so there is little resource or incentive to de-risk, despite longevity risk being as significant a risk as it is in other countries.

- France: A very small market, although French insurers and reinsurers are active in other markets.

- South Africa and South America: Hampered by lack of or unreliable historical mortality data and poor experience data; in Chile, which has a rapidly growing lifetime annuities market, the government effectively underwrites annuity providers which therefore have no incentive to hedge their longevity risk exposure. ${ }^{10}$

\section{Stakeholders in the Longevity Risk Transfer Market}

\subsection{Classes of Stakeholders}

Figure 1 shows the participants in the longevity risk transfer market. In this section, we examine the various classes of stakeholders in this market.

\subsection{Hedgers}

3.2.1. One natural class of stakeholders are hedgers, those who have a particular exposure to longevity risk and wish to lay off that risk. For example, defined benefit (DB) pension funds and annuity providers stand to lose if mortality improves by more than anticipated, while life insurance

9 Richard Gluyas (2017) Challenger rides tidal wave of Japanese interest in Australian annuities, The Weekend Australian, 24 April: 'sales of Australian dollar annuities in Japan are estimated to be worth about \$A30 billion a year - about seven times the size of the entire annuities market in Australia'.

${ }^{10}$ See Zelenko (2014) 

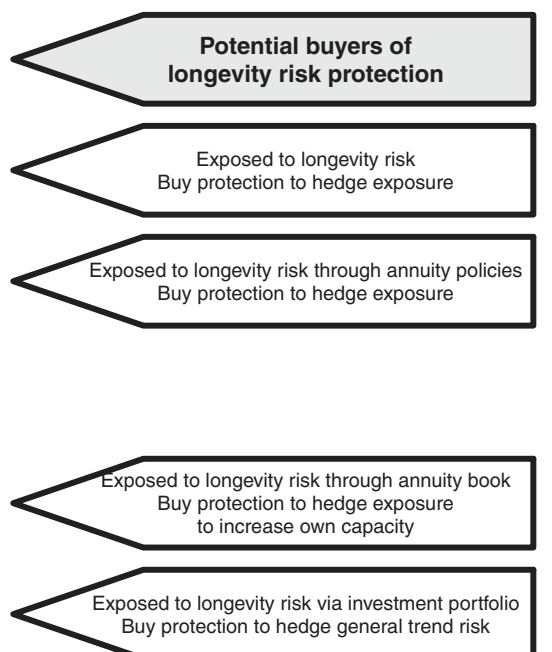
Buy protection to hedge general trend risk
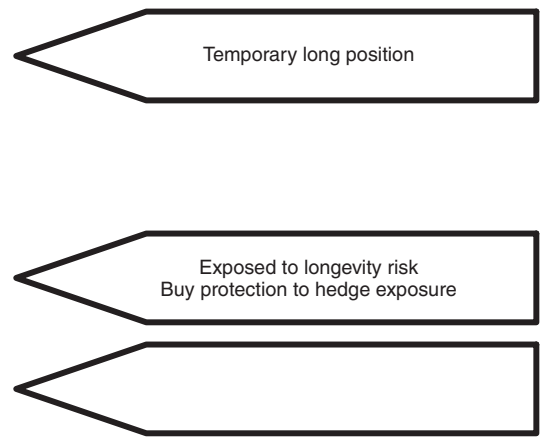

Protection of pension members and policyholders
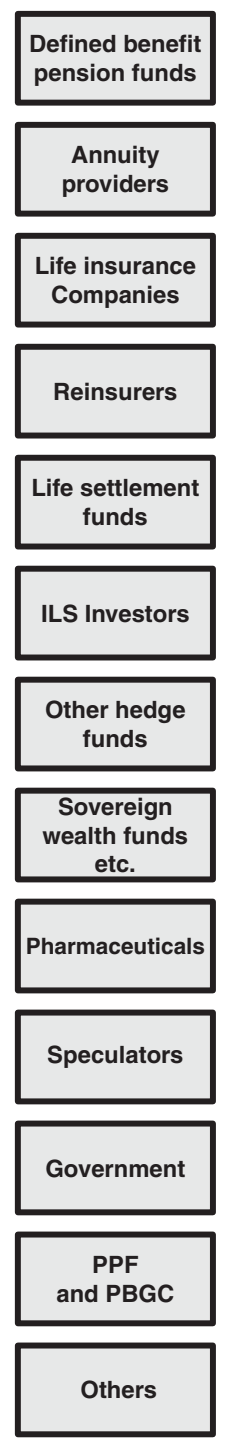

Regulators
Potential sellers of Iongevity risk protection
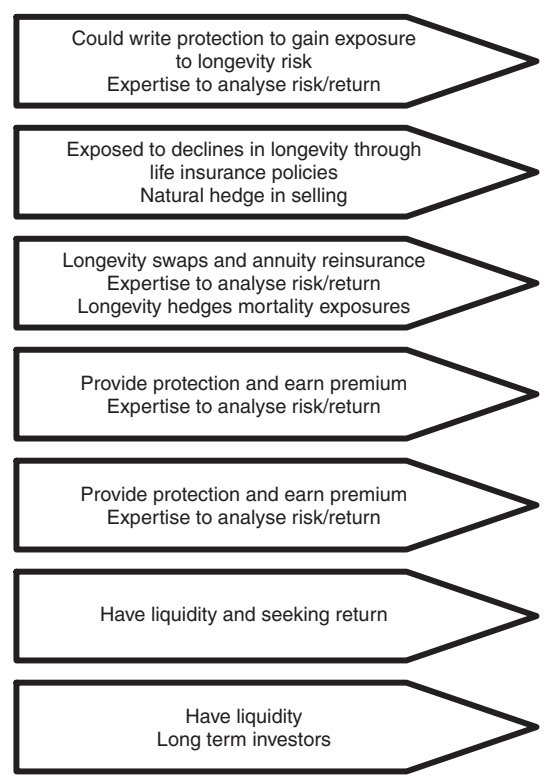

Benefits from increased longevity

Potential issuer of longevity-linked instruments
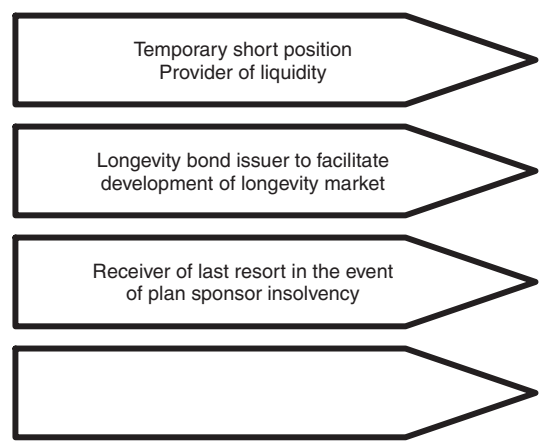

Orderly and fair markets

Figure 1. Participants in the Longevity Risk Transfer Market

Source: Adapted from Loeys et al. (2007, Chart 10); PPF, Pension Protection Fund, PBGC, Pension Benefit Guaranty Corporation. 
companies stand to gain, and vice versa. These offsetting exposures imply that annuity providers and life assurers, for example, can hedge each other's longevity risks. ${ }^{11}$ Alternatively, parties with unwanted exposure to longevity risk might pay other parties to lay off some of their risk. For instance, a life office might hedge its longevity risk using a reinsurer or by selling it to capital market institutions.

3.2.2. As another possibility, pharmaceutical companies benefit if people live longer, since they (and the health service) need to spend more on medicines as they get older, especially for those in poor health. Also there is a continuous stream of new medical treatments that prolong life. The pharmaceutical companies could potentially issue longevity-linked debt to finance their research and development programmes which, if sufficiently attractive for pension funds to hold, could be issued at a lower cost than conventional fixed maturity debt. In other words, pharmaceutical companies benefit if longevity increases and could put on a counterbalancing position by issuing longevity bonds. ${ }^{12}$ While they have been approached about this possibility, no pharmaceutical company has yet issued such debt. The principal reasons appear to be that the finance directors have not been made sufficiently aware of the potential benefits of such an issue - and in any case are more concerned that the millions of dollars being spent on drug trials will bring a sufficient return to shareholders - and because, in practice, the short-term correlation between company profits and longevity is probably not strong enough to persuade finance directors to issue longevity bonds.

\subsection{Specialist and General Investors}

There are specialist investors in this market, such as life settlement ${ }^{13}$ investors, premium finance investors, ${ }^{14}$ and insurance-linked securities (ILS) investors. ${ }^{15}$ Depending on their existing exposures, these investors could either buy longevity protection or sell it and earn a premium. General investors include short-term investors, such as hedge funds and private equity investors and long-term investors, such as sovereign wealth funds, endowments and family offices. Provided expected returns are acceptable, such investors might be interested in acquiring an exposure to longevity risk, since it has a low correlation with standard financial market risk factors. The combination of a low beta and a potentially positive alpha should therefore make mortality-linked securities attractive investments in diversified portfolios.

\subsection{Speculators and Arbitrageurs}

A market in longevity-linked securities might attract speculators: short-term investors who trade their views on the direction of individual security price movements. The active involvement of speculators is important for creating market liquidity as a by-product of their trading activities, and is in fact essential to the success of traded futures and options markets. However, liquidity also

11 In many cases, annuity providers and life assurers are part of the same life office, in which case the annuity and life books provide at least a partial 'natural hedge'.

12 This possibility was first suggested in Dowd (2003).

13 A life settlement is the US name for a traded life policy.

14 Premium finance investors provide funding for those wishing to buy life settlements and similar types of policies.

15 Insurance-linked securities are financial instruments whose values depend typically on the occurrence of prescribed high severity, low probability insurance loss events. The typical events covered are natural catastrophes, such as hurricanes and earthquakes, and the values of the ILSs will depend on the value of the property losses if such events occur. ILSs are commonly known as catastrophe or CAT bonds. 
depends on the frequency with which new information about the market materialises and this is currently sufficiently low that there is negligible speculator interest in the longevity market at the present time. Arbitrageurs seek to profit from any pricing anomalies in related securities. For arbitrage to be a successful activity, it is essential that there are well-established pricing relationships between the related securities: periodically, prices get out of line which creates profit opportunities which arbitrageurs exploit. ${ }^{16}$ However, the longevity market is currently not sufficiently well developed for arbitrage opportunities to exist.

\subsection{Governments}

3.5.1. Governments have many potential reasons to be interested in markets for longevity-linked securities. They might wish to promote such markets and assist financial institutions that are exposed to longevity risk (e.g. they might issue longevity bonds that can be used as instruments to hedge longevity risk). ${ }^{17}$

3.5.2. Governments might also be interested in managing their own exposure to longevity risk. They are a significant holder of this risk in their own right via pay-as-you-go state pensions, pensions to former public sector employees and their obligations to provide health care for the elderly. At a higher level, governments are affected by numerous other economic factors, some of which partially offset their own exposure to longevity risk (for example income tax on private pensions continues to be paid as people live longer).

\subsection{Regulators}

3.6.1. Financial regulators have two main stated aims: (i) the enhancement of financial stability through the promotion of efficient, orderly and fair markets and (ii) ensuring that retail customers get a fair deal. ${ }^{18}$ The two financial regulators in the UK responsible for delivering on these aims are the Prudential Regulatory Authority (PRA) and the Financial Conduct Authority (FCA).

3.6.2. The PRA has a duty to ensure that the financial system is protected against systemic risks and longevity risk is a potential example of such a risk. This, in turn, requires that carriers of such risks, such as life insurance companies, issue sufficient regulatory capital to protect themselves from insolvency with a high degree of probability. The FCA's duty is to ensure that customers get competitive and fairly priced annuity products, for example, and that becomes more difficult if providers of these products cannot easily or economically hedge the longevity risk contained in them. ${ }^{19}$

16 Classic examples are currencies and commodities, such as gold, which are traded in two different markets at different prices. Arbitrageurs will buy in the cheaper market and immediately sell in the dearer market, making an arbitrage profit if the price difference exceeds any transaction costs. The key difference between arbitrageurs and speculators is that the former seek to make a profit without taking on any risks (or at least minimising the risks they need to take), whereas the latter seek to make a profit from explicitly assuming risks.

17 As proposed in Blake et al. (2014).

18 As specified in the Financial Services and Markets Act 2000.

19 Hedging allows the issuer of an annuity to reduce its exposure to longevity risk which in turn allows it to offer its products at more competitive prices (i.e., closer to the actuarially fair price), since less regulatory capital needs to be posted. 
3.6.3. Another interested regulator is The Pensions Regulator (TPR) which acts as gatekeeper to the UK's pension lifeboat, the Pension Protection Fund (PPF). ${ }^{20}$ TPR wants to reduce the probability that large companies (in particular) are bankrupted by their pension funds (Harrison \& Blake, 2016). As "insurer of last resort," the Government is also potentially the residual holder of this risk in the event of default by the PPF. The PPF and Government have a strong incentive to help companies hedge their exposure to longevity risk, which would reduce the likelihood of claims on the PPF. The PPF faces the systematic risk that longevity projections go up generally for plans (without diversifying away between plans), which (i) pushes some plans into the PPF and (ii) increases existing PPF liabilities. $^{21}$

\subsection{Other Stakeholders}

Other domestic stakeholders include healthcare providers and insurers, providers of equity release (or reverse or lifetime) mortgages and securities managers and organised exchanges, all of which would benefit from a new source of fee income. Members of both DB and defined contribution (DC) plans have an interest in protecting their current and future pension entitlements, although the risks in the two types of plan are different. In the case of DB, the security of the plan itself is at stake, with the member facing the risk of lower (e.g. PPF) benefits if the plan sponsor becomes insolvent. In the case of DC, the member is exposed either to the vagaries of the individual annuities market or to the risk of drawing down benefits too quickly and surviving longer than expected. Finally, individuals with state pensions are ultimately not immune from increases in the government's budget deficit that arise from increases in life expectancy: (i) state pensions could fall (in real terms) for current pensioners, (ii) the state pension age could increase even further than currently planned for future pensioners and (iii) all current and future generations of tax payers are ultimately liable for the increased cost. Longevity risk is a global phenomenon, so there will be similar stakeholders in other countries where this problem is prevalent.

\section{Successful Insurance-Based Solutions}

\subsection{Overview}

The traditional solution for dealing with unwanted longevity risk in a DB pension plan or an annuity book is to sell the liability via an insurance or reinsurance contract. This is known as a pension buyout (or pension termination) or, in an insurance context, a group/bulk annuity transfer. More recently, pension buy-ins and longevity insurance (the insurance term for a longevity swap) have been added to the list of insurance-based solutions for transferring longevity risk. Insurance solutions are generally classified as "customised indemnification solutions," since the insurer fully indemnifies the hedger against its specific risk exposure. These solutions can also be thought of as "at-the-money"

${ }^{20}$ A statutory fund established by the UK Pensions Act 2004 "to provide compensation to members of eligible defined benefit pension plans, when there is a qualifying insolvency event in relation to the employer, and where there are insufficient assets in the pension plan to cover the Pension Protection Fund level of compensation."

21 The same would apply, mutatis mutandis, to the US equivalent of the PPF, namely the Pension Benefit Guaranty Corporation (PBGC). 
hedges, since the hedge provider is responsible for any increase in the liability above the current best estimate assumption on a pound-for-pound basis.

\subsection{Pension Buy-outs}

4.2.1. The most common traditional solution for DB pension plans is a full pension buy-out, implemented by a regulated life assurer. The procedure can be illustrated using the following simple example.

4.2.2. Consider Company $\mathrm{ABC}$ with pension plan assets $(A)$ of 85 and pension plan liabilities $(L)$ of 100 , valued on an "ongoing basis" 22 by the plan actuary; this implies a deficit of 15 . ABC approaches life assurer XYZ to effect a pension buy-out. On a full "buy-out basis," the insurer values the pension liabilities at 120, a premium of 20 to the plan actuary's valuation, implying a buyout deficit of 35. The insurer, subject to due diligence, offers to take on both the plan assets $A$ and plan liabilities $L$ provided the company contributes 35 from its own resources (or from borrowing) to cover the buy-out deficit. Following the acquisition, the insurer implements an asset transition plan which involves exchanging certain assets, e.g. cash or equities for bonds or loans, and implementing interest rate and inflation swaps to hedge the interest-rate and inflation risk associated with the pension liabilities. ${ }^{23}$

4.2.3. The advantages to the company are that the pension liabilities are completely removed from its balance sheet. In the case where the company does not have the cash resources to pay the full cost of the buy-out, the pension deficit (on a buy-out basis) is often replaced by a loan which, unlike fluctuating pension liabilities, is an obligation that is readily understood by investment analysts and shareholders. The company avoids volatility in its profit and loss account coming from the pension plan, ${ }^{24}$ the payment of levies to the PPF, administration fees on the plan and the potential drag on its enterprise value arising from the pension plan. The advantage of a buy-out to the pension trustees and plan members is that pensions are now secured in full (subject to the credit risk of the life assurer).

4.2.4. There is a potential disadvantage in terms of timing. Once a buy-out has taken place, it cannot generally be renegotiated if circumstances change and the buy-out price is lower in the future, say, because an increase in long-term interest rates leads to the discount rate used to value pension liabilities also increasing. There is also a potential risk that the buy-out company itself becomes insolvent in which case the pensioners would have no recourse to the PPF. However, since buy-out

22 In the UK, this would be consistent with Section 28 of FRS 102 (The Financial Reporting Standard applicable in the UK and Republic of Ireland) or the International Accounting Standard IAS 19.

${ }^{23}$ Traditional UK insurers running annuity books interpret UK regulatory capital requirements as restricting them to invest in government and investment-grade corporate bonds and related derivatives.

${ }^{24}$ This volatility is generated by the way in which accounting standards treat DB pension liabilities in a market-consistent way as the present discounted value of projected future pension payments. The required discount rates are related to the market yield on a class of traded bonds (such as AA-rated corporate bonds) of appropriate term. If market conditions are such that this yield is volatile, then the value of the pension liabilities will be similarly volatile, even though the projected stream of future pension payments might have changed very little. Further, if the loan has a shorter duration than the pension cashflows, it will have a lower balance sheet sensitivity to interest rate changes. 
companies are established as insurance companies with solvency capital requirements, ${ }^{25}$ this risk should, in practice, be very low in countries like the UK.

\subsection{Pension Buy-ins}

4.3.1. Buy-ins are insurance transactions that involve the bulk purchase of annuities by the pension plan to hedge the risks associated with a subset of the plan's liabilities, typically associated with retired members. The annuities become an asset of the plan and cover the specific mortality characteristics of the plan's membership in terms of age, gender and pension amount - but the individual members do not receive annuity certificates.

4.3.2. Buy-ins are often part of the journey to a full buy-out. They can be thought of as providing a "de-risking" of the pension plan in economic terms. If purchased in phases, they enable the plan to smooth out annuity rates over time and avoid a spike in pricing at the time it decides to proceed directly to a full buy-out. Buy-ins also offer the sponsor the advantage of full immunisation of a portion of the pension liabilities for a lower up-front cash payment relative to a full buy-out although the recent introduction of deferred premium payments for both buy-ins and buy-outs has helped to spread costs for both types of product. ${ }^{26}$

4.3.3. Since the annuity contract purchased in a buy-in is an asset of the pension plan, rather than an asset of the plan member, the pension liability remains on the balance sheet of the sponsor. Plan members are therefore still exposed to the risk of sponsor insolvency if the plan is in deficit and (indirectly) to the risk of insurance company insolvency unless the buy-in deal has been fully collateralised.

\subsection{Longevity Insurance or Insurance-Based Longevity Swaps}

4.4.1. The third successful solution is the longevity insurance contract or insurance-based longevity swap. This is effectively an insurance version of the capital-markets-based longevity swap (discussed in the next section), which transfers longevity risk only. ${ }^{27} \mathrm{~A}$ typical structure involves the buyer of the swap paying a pre-agreed fixed set of cash flows to the swap provider and receiving in exchange a floating set of cash flows linked to the realised mortality experience of the swap buyer, the latter being used to pay the pensions for which the swap buyer is liable. No assets are transferred and the pension plan typically retains the investment risks associated with the asset portfolio. Longevity swaps have the advantage that they remove longevity risk without the need for an upfront payment by the sponsor and allow the pension plan trustees to retain control of the asset allocation.

4.4.2. The first publicly announced longevity swap took place in April 2007 between Swiss Re and Friends' Provident, a UK life insurer. It was a pure longevity risk transfer and was not tied to another

${ }^{25}$ See section 7.2 for more details.

${ }^{26}$ See paragraph 11.52 .

${ }^{27}$ It is important to note that contingent beneficiaries would also be covered by the swap and so marital status and spouse age risks would be passed on. Additional data on these would be sought at the time of seeking cover, e.g. by writing to members and asking them if they are married and, if so, the age of the spouse. But divorce and remarriage can still occur before the spouse pension comes into payment. 


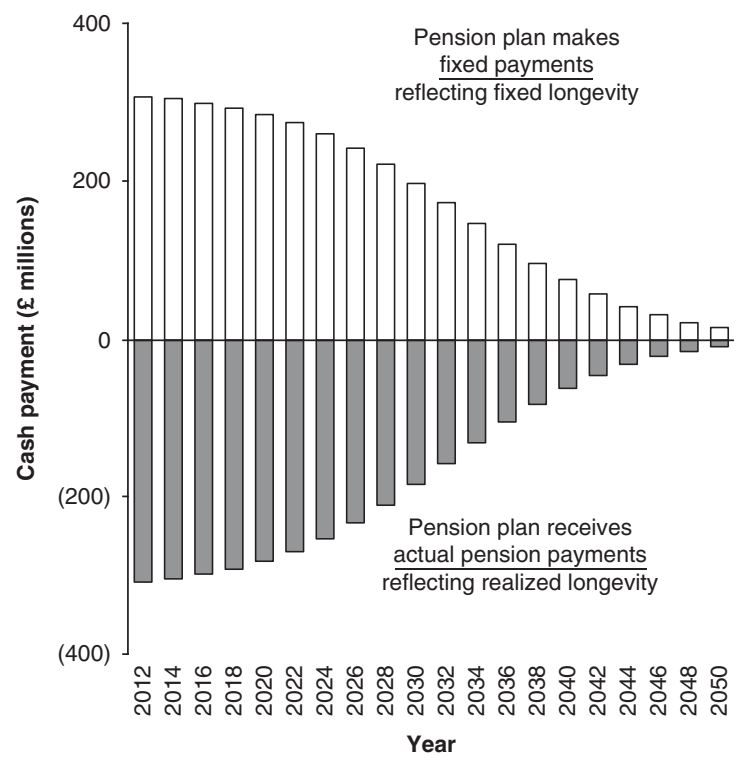

Figure 2. A longevity swap involves the regular exchange of actual realised pension cash flows and pre-agreed fixed cash flows

Source: Coughlan (2007a).

financial instrument or transaction. The swap was based on Friends' Provident's $£ 1$.7bn book of 78,000 pension annuity contracts written between July 2001 and December 2006. Friends' Provident retains administration of policies. Swiss Re makes payments and assumes longevity risk in exchange for an undisclosed premium.

4.4.3. In any longevity swap, the hedger of longevity risk (e.g. a pension plan or insurer) receives from the longevity swap provider the actual payments ${ }^{28}$ it must pay to pensioners and, in return, makes a series of fixed payments to the hedge provider. ${ }^{29}$ In this way, if pensioners live longer than expected, the higher pension amounts that the pension plan must pay are offset by the higher payments received from the provider of the longevity swap. The swap therefore provides the pension plan with a long-maturity, customised cash flow hedge of its longevity risk.

4.4.4. Figure 2 shows the set of cash flows in a typical longevity swap involving a pension plan wishing to hedge its longevity risk exposure. The plan makes a set of pre-agreed fixed payments (each payment is based on an amount-weighted survival rate (Dowd et al., 2006; Dawson et al., 2010)) and receives the actual pension payments it needs to make (these will be based on its realised longevity experience).

28 Before the swap is implemented, it is common to simplify benefits where possible, e.g. by reducing the overall number of pension increase tranches, simplifying partial payments in month of death, and, in a UK context, simplifying what happens when the pensioner passes GMP age. (Between April 1978 and April 1997, members of UK contracted-out pension plans accrued a notional SERPS (State Earnings Related Pension Scheme) pension which is called the Guaranteed Minimum Pension (GMP). The GMP was originally payable from age 60 for women and age 65 for men, although European Union equality legislation requires plans to introduce equal treatment for men and women in their plans in respect of the GMP.)

${ }^{29}$ It is possible that the swap is set up to cover inflation increases (possibly up to a limit), in which case the fixed payments are fixed in real rather than in nominal terms. 


\section{Successful Capital Markets Solutions}

\subsection{Overview}

In this section, we analyse the small number of capital market securities that have been successfully launched since 2006: longevity-spread bonds, longevity swaps, $q$-forwards, $S$-forwards and tail-risk protection (or longevity bull call spreads). The key feature of these is that most are index rather than customised solutions. ${ }^{30}$

\subsection{Longevity-Spread Bonds}

5.2.1. In December 2010, Swiss Re issued an 8-year catastrophe-type bond linked to longevity spreads. To do this, it used a special purpose vehicle, Kortis Capital, based in the Cayman Islands. ${ }^{31}$ The Kortis bond is designed to hedge Swiss Re's own exposure to longevity risk. ${ }^{32}$ It had a very small nominal value of just $\$ 50 \mathrm{~m}$, which clearly meant that it was designed to test the water for a new type of capital market instrument.

5.2.2. The bond holders received quarterly coupons equal to 3-month LIBOR plus a margin. In exchange, they were exposed to the risk that the difference between the annualised mortality improvement in English \& Welsh males aged 75-85 over a period of 8 years and the corresponding improvement in US males aged $55-65$ is significantly larger than anticipated. The mortality improvements were measured over 8 years from 1 January 2009 to 31 December 2016. The bonds matured on 15 January $2017,,^{33}$ although there was an option to extend the maturity to 15 July 2019. The principal was at risk if the Longevity Divergence Index Value (LDIV) exceeded the attachment point or trigger level of $3.4 \%$ over the risk period. The exhaustion point, at or above which there would be no return of principal, is $3.9 \%$. The principal would be reduced by the principal reduction factor (PRF) if the LDIV lies between $3.4 \%$ and $3.9 \%$.

5.2.3. The LDIV is derived as follows. Let $m^{y}(x, t)$ be the male death rate at age $x$ and year $t$ in country $y$. This is defined as the ratio of deaths to population size for the relevant age and year. Annualised mortality improvements over $n$ years are defined as:

$$
\text { Improvement } t_{n}^{y}(x, t)=1-\left[\frac{m^{y}(x, t)}{m^{y}(x, t-n)}\right]^{\frac{1}{n}}
$$

The annualised mortality improvement index for each age group is found by averaging the annualised mortality improvements across ages $x_{1}$ to $x_{2}$ in the group:

$$
\operatorname{Index}(y)=\frac{1}{1+x_{2}-x_{1}} \sum_{x=x_{1}}^{x=x_{2}} \text { Improvement } t_{n}^{y}(x, t)
$$

${ }^{30}$ The J. P. Morgan-Canada Life swap discussed in section 5.3 is one of the few examples of a customised capital markets solution.

$31 \mathrm{http}: / /$ www.swissre.com/media/news_releases/Swiss_Re_completes_first_longevity_trend_bond_transferring_ USD_50_million_of_longevity_trend_risk_to_the_capital_markets.html

${ }^{32}$ It is important to recognise that the Kortis bond is not a true longevity bond in the sense that it hedges the longevity trend in a particular population. Rather it transfers the risk associated with the spread (or difference) between the longevity trends for two different population groups, rather than the trends themselves.

${ }^{33}$ The payoff of the bond depends on population mortality data for 2016 for England \& Wales (now published) and the US (not yet published at the time of writing). 
Table 1. Estimated Loss Probabilities for the Swiss Re Longevity-Spread Bond

\begin{tabular}{lcc}
\hline \hline LDIV $(\%)$ & PRF $(\%)$ & Exceedance Probability $(\%)$ \\
\hline 3.4 & 0 & $5.31^{(1)}$ \\
3.5 & 20 & 4.32 \\
3.6 & 40 & 3.48 \\
3.7 & 60 & 2.82 \\
3.8 & 80 & 2.28 \\
3.9 & 100 & $1.81^{(2)}$ \\
Expected loss & 3.27 & \\
\hline \hline
\end{tabular}

Note: ${ }^{(1)}$ attachment probability; ${ }^{(2)}$ exhaustion probability.

Source: Standard and Poor's (2010) Presale information: Kortis Capital Ltd. Tech. Report.

In the case of the Kortis bond, $n$ is equal to 8 years. The LDIV is defined as:

$$
L D I V=\operatorname{Index}\left(y_{2}\right)-\operatorname{Index}\left(y_{1}\right)
$$

where $y_{2}$ is the England \& Wales population aged 75-85 and $y_{1}$ is the US population aged 55-65. The PRF is calculated as follows:

$$
P R F=\frac{L D I V-\text { Attachment point }}{\text { Exhaustion point-Attachment point }}
$$

with a minimum of $0 \%$ and a maximum of $100 \%$.

5.2.4. Proceeds from the sale of the bond were deposited in a collateral account at the AAA-rated International Bank for Reconstruction and Development (i.e. the World Bank). If there is a largerthan-expected difference between the mortality improvements of 75-85 year old English \& Welsh males and those of 55-65 year old US males, part of the collateral will be sold to make payment to Swiss Re and, as a consequence, the principal of the bond would be reduced. The exposure that Swiss Re wished to hedge comes from two different sources. For example, Swiss Re is the counterparty in a $£ 750$ m longevity swap with the Royal County of Berkshire Pension Fund which was executed in 2009, and so is exposed to high-age English \& Welsh males living longer than anticipated. It has also reinsured a lot of US life insurance policies and is exposed to middle-aged US males dying sooner than expected. The longevity-spread bond provided a partial hedge for both tail exposures.

5.2.5. Standard \& Poor's rated the bond BB + which took into account the possibility that investors would not receive the full return of their principal. This rating was determined using two models developed by RMS which was appointed as the calculation agent for the bonds. ${ }^{34}$

5.2.6. Table 1 shows estimated loss probabilities for the bond using the RMS models. Figure 3 presents a fan chart of the projected LDIV showing the $98 \%$ confidence interval.

5.2.7. This was the first time that the risk of individuals living longer than expected has been traded in the form of a bond. Investors had been reluctant to hold longevity risk long term, but short-term bonds might make bearing the risk more acceptable. The bond therefore represented a significant

34 See section 9.4 for more details. 


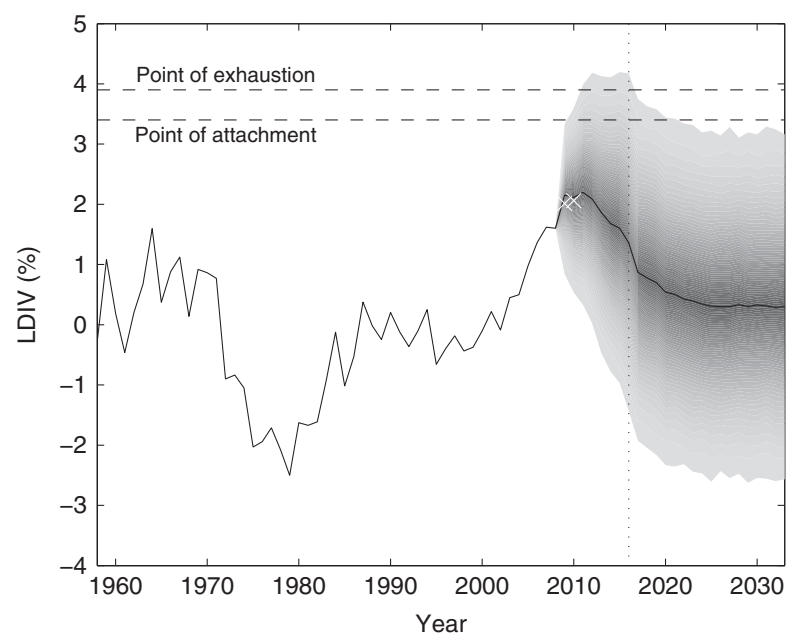

Figure 3. Fan chart of the projected LDIV showing the $98 \%$ confidence interval Source: Hunt \& Blake (2015, Figure 8).

breakthrough for capital market solutions. Nevertheless, there appears to have been very little trading in the bond and no further examples of the bond have so far been issued.

\subsection{Capital-Markets-Based Longevity Swaps}

5.3.1. The first capital-markets-based longevity swap took place in July 2008 between J. P. Morgan and Canada Life in the UK (Trading Risk, 2008). The contract was a 40 -year maturity $£ 500 \mathrm{~m}$ longevity swap that was linked to the actual mortality experience of the 125,000-plus annuitants in the annuity portfolio that was being hedged. This transaction brought capital markets investors into the longevity market for the very first time, as the longevity risk was passed from Canada Life to J. P. Morgan and then directly on to investors.

5.3.2. This has become the archetypal longevity swap upon which other transactions are based. Insurance companies, such as Rothesay Life, have adapted its structure and collateralisation terms to an insurance format.

5.3.3. It is important to note that the J. P. Morgan - Canada Life swap was a customised swap, since it was linked to the actual mortality experience of the hedger. All insurance-based longevity swaps in the UK have also been customised swaps to date. However, such swaps are harder to price ${ }^{35}$ and are potentially more illiquid than index-based swaps which are based on the mortality experience of a reference population, such as the national population. Most longevity swaps sold into the capital markets are index-based. These issues are discussed in more detail in section 8 .

35 Although pension plans tend to have good quality data in terms of pension amount, birth date, postcode etc, they also tend to have less mortality experience data and have their own idiosyncratic socio-economic and geodemographic characteristics that need careful assessment and calibration. 


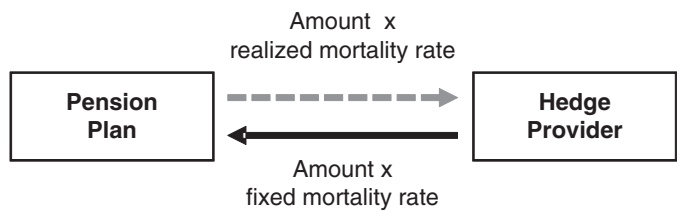

Figure 4. A $q$-forward exchanges fixed mortality for realised mortality at the maturity of the contract Source: Coughlan et al. (2007b, Figure 1)

\section{4. q-Forwards (or Mortality Forwards) and S-Forwards (or Survivor Forwards)}

5.4.1. A mortality forward rate contract is referred to as a " $q$-forward" because the letter " $q$ " is the standard actuarial symbol for a mortality rate. It is the simplest type of instrument for hedging longevity (and mortality) risk (Coughlan et al., 2007b). ${ }^{36,37}$

5.4.2. The first capital markets transaction involving a $q$-forward took place in January 2008. The hedger was buy-out company Lucida (Lucida, 2008; Symmons, 2008). The $q$-forward was linked to a longevity index based on England \& Wales national male mortality for a range of different ages. The hedge was provided by J. P. Morgan and was novel not just because it involved a longevity index and a new kind of product, but also because it was designed as a hedge of value rather than a hedge of cash flow. In other words, it hedged the value of an annuity liability, ${ }^{38}$ not the actual individual annuity payments.

5.4.3. Formally, a $q$-forward is a contract between two parties in which they agree to exchange an amount proportional to the actual realised mortality rate of a given population (or sub-population), in return for an amount proportional to a fixed mortality rate that has been mutually agreed at inception to be payable at a future date (the maturity of the contract). In this sense, a $q$-forward is a swap that exchanges fixed mortality for the realised mortality at maturity, as illustrated in Figure 4. The variable used to settle the contract is the realised mortality rate for that population in a future period. In the case of hedging longevity risk in a pension plan using a $q$-forward, the plan will receive the fixed mortality rate and pay the realised mortality rate (and hence, over the term of the contract, locks in the future mortality rate it has to pay whatever happens to actual rates). The counterparty to this transaction, typically an investment bank, has the opposite exposure, paying the fixed mortality rate and receiving the realised rate.

5.4.4. The fixed mortality rate at which the transaction takes place defines the "forward mortality rate" for the population in question. If the $q$-forward is fairly priced, no payment changes hands at the inception of the trade, but at maturity, a net payment will be made by one of the two parties (unless the fixed and actual mortality rates happen to be the same). The settlement that takes place at maturity is based on the net amount payable and is proportional to the difference between the fixed mortality rate (the transacted forward rate) and the realised reference rate. If the reference rate in the

36 See also: http://www.llma.org/files/documents/Technical_Note_q_Forward_Final.pdf; http://www.llma. org/files/documents/SampleTermSheet_-_q-Forward_Final.pdf; http://www.llma.org/files/documents/q-forward_ Example_Sheet_Version_Update.xlsm

37 Although $q$-forwards are simple in concept, using them can be complex and multi-population modelling is essential (see paragraph 9.3.1).

38 Or a significant part of it, if not fully. 
Table 2. An Illustrative Term Sheet for a Single $q$-forward to Hedge Longevity Risk

\begin{tabular}{ll}
\hline \hline Notional Amount & GBP 50,000,000 \\
\hline Trade date & 31 December 2008 \\
Effective date & 31 December 2008 \\
Maturity date & 31 December 2018 \\
Reference year & 2017 \\
Fixed rate & 1.2000\% \\
Fixed amount payer & J. P. Morgan \\
Fixed amount & Notional amount $\times$ fixed rate $\times 100$ \\
Reference rate & LifeMetrics graduated initial mortality rate for 65-year-old males in the reference year for \\
& England \& Wales national population \\
& Bloomberg ticker: LMQMEW65 Index $<$ GO $>$ \\
Floating amount payer & ABC Pension Fund \\
Floating amount & Notional amount $\times$ reference rate $\times 100$ \\
Settlement & Net settlement $=$ fixed amount - floating amount \\
\hline \hline
\end{tabular}

Source: Coughlan et al. (2007b, Table 1).

reference year is below the fixed rate (implying lower mortality than predicted), then the settlement is positive, and the pension plan receives the settlement payment to offset the increase in its liability value. If, on the other hand, the reference rate is above the fixed rate (implying higher mortality than predicted), then the settlement is negative and the pension plan makes the settlement payment to the hedge provider, which will be offset by the fall in the value of its liabilities. In this way, the net liability value is hedged ${ }^{39}$ regardless of what happens to mortality rates. The plan is protected from unexpected changes in mortality rates.

5.4.5. Table 2 presents an illustrative term sheet for a $q$-forward transaction, based on a reference population of 65 -year-old males from England \& Wales. The $q$-forward payout depends on the value of the LifeMetrics Index for the reference population on the maturity date of the contract. The particular transaction shown is a 10-year $q$-forward contract starting on 31 December 2008 and maturing on 31 December 2018. It is being used by ABC Pension Fund to hedge its longevity risk over this period; the hedge provider is J. P. Morgan. The hedge is a "directional hedge" and will help the pension fund hedge its longevity risk so long as the mortality experience of the pension fund and the index change in the same direction.

5.4.6. On the maturity date, J. P. Morgan (the fixed-rate payer or seller of longevity risk protection) pays ABC Pension Fund (the floating-rate payer or buyer of longevity risk protection) an amount related to the pre-agreed fixed mortality rate of $1.2000 \%$ (i.e. the agreed forward mortality rate for 65-year-old English \& Welsh males for 2018). In return, ABC Pension Fund pays J. P. Morgan an amount related to the reference rate on the maturity date. The reference rate is the most recently available value of the LifeMetrics Index. Settlement on 31 December 2018 will therefore be based on the LifeMetrics Index value for the reference year 2017, on account of the 10-month lag in the availability of official data. The settlement amount is the difference between the fixed amount (which depends on the agreed forward rate) and the floating amount (which depends on the realised reference rate).

39 Or a significant part of it, if not fully. 
Table 3. An Illustration of $q$-Forward Settlement for Various Outcomes of the Realised Reference Rate

\begin{tabular}{|c|c|c|c|}
\hline $\begin{array}{l}\text { Reference Rate } \\
\text { (Realised Rate) (\%) }\end{array}$ & Fixed Rate (\%) & $\begin{array}{l}\text { Notional } \\
\text { (GBP) }\end{array}$ & $\begin{array}{l}\text { Settlement } \\
\text { (GBP) }\end{array}$ \\
\hline 1.0000 & 1.2000 & $50,000,000$ & $10,000,000$ \\
\hline 1.1000 & 1.2000 & $50,000,000$ & $5,000,000$ \\
\hline 1.2000 & 1.2000 & $50,000,000$ & 0 \\
\hline 1.3000 & 1.2000 & $50,000,000$ & $-5,000,000$ \\
\hline
\end{tabular}

Source: Coughlan et al. (2007b, Table 1): A positive (negative) settlement means the hedger pays (receives) the net settlement amount.

5.4.7. Table 3 shows the settlement amounts for four realised values of the reference rate and a notional contract size of $£ 50 \mathrm{~m}$. If the reference rate in 2017 is lower than the fixed rate (implying lower mortality than anticipated at the start of the contract), the settlement amount is positive and ABC Pension Fund receives a payment from J. P. Morgan that it can use to offset an increase in its pension liabilities. If the reference rate exceeds the fixed rate (implying higher mortality than anticipated at the start of the contract), the settlement amount is negative and ABC Pension Fund makes a payment to J. P. Morgan which will be offset by a fall in its pension liabilities.

5.4.8. It is important to note that the hedge illustrated here is structured as a "value hedge," rather than as a "cash flow hedge." A value hedge aims to hedge the value of the hedger's liabilities at the maturity date of the swap. So although the swap has a duration of only 10 years, it nevertheless hedges that portion of the longevity risk in the hedger's cash flows beyond 10 years that are reflected in mortality rates at time 10 . This is achieved by exchanging a single payment at maturity. By contrast, a cash flow hedge hedges the longevity risk in each one of the hedger's cash flows and net payments are made period by period as in Figure 2. The J. P. Morgan-Canada Life longevity swap is an example of a cash flow hedge, while the J. P. Morgan-Lucida $q$-forward is an example of a value hedge. The capital markets are more familiar with value hedges, whereas cash flow hedges are more common in the insurance world. Value hedges are particularly suited to hedging the longevity risk of younger members of a pension plan, since it is much harder to estimate with precision the pension payments they will receive when they eventually retire. The world's first swap for non-pensioners (i.e. involving deferred members) took place in January 2011 when J. P. Morgan executed a value hedge in the form of a 10-year $q$-forward contract with the Pall (UK) pension fund.

5.4.9. The importance of $q$-forwards rests in the fact that they form basic building blocks from which other more complex, life-related derivatives can be constructed. When appropriately designed, a portfolio of $q$-forwards can be used to replicate and to hedge the longevity exposure of an annuity or a pension liability, or to hedge the mortality exposure of a life assurance book. We now provide an example.

5.4.10. A series of $q$-forward contracts, with different ages and maturities, can be combined to hedge a longevity swap. Initially assume that there is a complete market in these contracts for all ages and maturities. Suppose the contract involves swapping at time $t$ a fixed cashflow, $\tilde{S}(t)$, for the realised survivor index, $S(t, x)$, where $x$ is the age of the group being hedged at the inception of the swap. The fixed leg can be hedged using zero-coupon fixed-income bonds. The floating leg can be hedged approximately as follows. First, note that we can approximate the survivor index by expanding the 
cashflow in terms of the fixed legs of a set of $q$-forwards and their ultimate net payoffs (see Cairns et al., 2008):

$$
\begin{aligned}
S(t, x)= & (1-q(0, x)) \times(1-q(1, x+1)) \times \ldots \times(1-q(t-1, x+t-1)) \\
= & \prod_{i=0}^{t-1}\left(1-q_{F}(0, i, x+i)-\Delta(i, x+i)\right) \\
\approx & \prod_{i=0}^{t-1}\left(1-q_{F}(0, i, x+i)\right) \\
& \quad-\sum_{i=0}^{t-1} \Delta(i, x+i) \prod_{j=0, j \neq i}^{t-1}\left(1-q_{F}(0, j, x+j)\right)
\end{aligned}
$$

where $\Delta(i, x+i)=q(i, x+i)-q_{F}(0, i, x+i)$ and $q_{F}(0, i, x+i)=q$-forward mortality rate (the fixed rate). Here, $\Delta(i, x+i)$ is the net payoff on the $q$-forward per unit at time $i+1$.

5.4.11. It follows that an approximate hedge (assuming interest rates are constant and equal to $r$ per annum) for $S(t, x)$ can be achieved by holding:

- $-(1+r)^{-(t-1)} \prod_{j=0, j \neq 1}^{t-1}\left(1-q_{F}(0, j, x+j)\right)$ units of the 1-year $q$-forward;

- $-(1+r)^{-(t-2)} \prod_{j=0, j \neq 1}^{t-1}\left(1-q_{F}(0, j, x+j)\right)$ units of the 2-year $q$-forward;

- ...

- $-\prod_{j=0, j \neq t-1}^{t-1}\left(1-q_{F}(0, j, x+j)\right)$ units of the $t$-year $q$-forward.

5.4.12. In calculating these hedge quantities, we take account of the fact that, for example, the payoff at time 1 on the 1 -year $q$-forward will be rolled up to time $t$ at the risk-free rate of interest. Hence, the required payoff at time $t$ needs to be multiplied by the discount factor $(1+r)^{-(t-1)}$. In a stochastic interest environment, a quanto derivative would be required. This is one that delivers a number of units, $\mathrm{N}$, of a specified asset, where $N$ is derived from a reference index that is different from the asset being delivered. In this context, $N$ equals $-\Delta(i, x+i) \prod_{j=0, j \neq i}^{t-1}\left(1-q_{F}(0, j, x+j)\right)$, and we deliver, at time $i+1, N$ units of the fixed-interest zero-coupon bond maturing at time $t$, with a price $P(i+1, t)$ at time $i+1$ per unit.

5.4.13. In the real world, a complete market in $q$-forward contracts does not exist and the hedge would have to be constructed from $q$-forward contracts with a more limited range of reference ages (e.g. 10-year age buckets) and maturities (e.g. out to 20 years at most). Nevertheless, the complete market hedge serves as a benchmark against which we can measure the effectiveness of hedges using a smaller number of $q$-forwards.

5.4.14. A related contract is the " $S$-forward" or "survivor" forward contract, which is based on the survivor index, $S(t, x)$, which itself is derived from the more fundamental mortality rates. An " $S$-forward" is the basic building block of a longevity (survivor) swap first discussed in Dowd (2003). A longevity swap is composed of a stream of $S$-forwards with different maturity dates. It could be used, for example, for covering early cashflows, in conjunction with a $q$-forward at time 10 to (partially) cover the later cashflows. ${ }^{40}$

${ }^{40}$ See also: http://www.llma.org/files/documents/Technical_Note_S_Forward_Final.pdf; http://www.llma. org/files/documents/SampleTermSheet___S-Forward_Final.pdf; http://www.llma.org/files/documents/S-forward_ Example_Sheet_Version_Update.xlsm 
Table 4. Exposure Vector: Relative Weighting of Cohorts Over Time

\begin{tabular}{lcccccccccc}
\hline \hline Cohort & Year 1 & Year 2 & Year 3 & $\ldots$ & Year 15 & Year 16 & Year 17 & $\ldots$ & Year 54 & Year 55 \\
\hline Male 65 & 1000 & 995 & 985 & $\ldots$ & 590 & 565 & 535 & $\ldots$ & 65 & 55 \\
Male 66 & 980 & 975 & 960 & $\ldots$ & 505 & 485 & 450 & $\ldots$ & 45 & 40 \\
$\ldots$ & $\ldots$ & $\ldots$ & $\ldots$ & $\ldots$ & $\ldots$ & $\ldots$ & $\ldots$ & $\ldots$ & $\ldots$ & $\ldots$ \\
Female 99 & 125 & 120 & 115 & $\ldots$ & 20 & 10 & 5 & $\ldots$ & 0 & 0 \\
\hline \hline
\end{tabular}

Source: Michaelson \& Mulholland (2014, Exhibit 1).

\subsection{Tail-Risk Protection (or Longevity Bull Call Spread)}

5.5.1. To date there have been at least five publicly announced deals involving tail risk protection. The first two involved Aegon: one in 2012 was executed by Deutsche Bank and another in 2013 by Société Générale. The second two involved Delta Lloyd and Reinsurance Group of America (RGA $\mathrm{Re}$ ) in 2014 and 2015, respectively. The most recent occurred in December 2017 between NN Life and Hannover Re and is similar to the Société Générale deal discussed below.

5.5.2. Société Générale's tail risk protection structure was described in Michaelson \& Mulholland (2014). ${ }^{41}$ It is an index-based hedge using national population mortality data, but with minimal basis risk, ${ }^{42}$ and is designed around the following set of principles (pp.30-31):

In general, capital markets will be most effective in providing capital against the most remote pieces of longevity risk, called tail risk. This can be accomplished by creating "out-of-themoney" hedges against extreme longevity outcomes featuring option-like payouts that will occur if certain predefined thresholds are breached. These hedges would be capable of alleviating certain capital requirements to which the (re)insurers are subject, thereby enabling additional risk assumption.

However, a well-constructed hedge programme must perform a delicate balancing act to be effective. On the one hand, it must provide an exposure that sufficiently mimics the performance of the underlying portfolio so as not to introduce unacceptable amounts of basis risk; while, on the other hand, it must simplify the modelling and underwriting process to a level that is manageable by a broad base of investors. Further, the hedge transaction must compress the $60+$ year duration of the underlying retirement obligations to an investment horizon that is appealing to institutional investors.

5.5.3. Basis risk will reduce hedge effectiveness and this will, in turn, reduce the allowable regulatory capital relief. ${ }^{43}$ However, basis risk with this product can be minimised if the hedger can customise three features of the hedge exposure:

- The hedger is able to select the age and gender of the "cohorts" (also known as model points) they want in the reference exposure. For example, the hedger selects an exposure totalling 70 cohorts males and females aged 65-99 - to cover all the retired lives in the pension plan.

\footnotetext{
41 See, also, Cairns \& El Boukfaoui (2018) for a more detailed description.

42 See section 6.3 .

43 See section 7.2.
} 
Table 5. Experience Ratio Matrix

\begin{tabular}{lcccccccccc}
\hline \hline Cohort & Year 1 & Year 2 & Year 3 & $\ldots$ & Year 15 & Year 16 & Year 17 & $\ldots$ & Year 54 & Year 55 \\
\hline Male 65 & $90 \%$ & $89 \%$ & $88 \%$ & $\ldots$ & $81 \%$ & $80 \%$ & $80 \%$ & $\ldots$ & $75 \%$ & $75 \%$ \\
Male 66 & $89 \%$ & $88 \%$ & $87 \%$ & $\ldots$ & $80 \%$ & $79 \%$ & $79 \%$ & $\ldots$ & $75 \%$ & $75 \%$ \\
$\ldots$ & $\ldots$ & $\ldots$ & $\ldots$ & $\ldots$ & $\ldots$ & $\ldots$ & $\ldots$ & $\ldots$ & $\ldots$ & $\ldots$ \\
Female 99 & $77 \%$ & $77 \%$ & $76 \%$ & $\ldots$ & $75 \%$ & $75 \%$ & $75 \%$ & $\ldots$ & $75 \%$ & $75 \%$ \\
\hline \hline
\end{tabular}

Source: Michaelson \& Mulholland (2014, Exhibit 2).

- The hedger is able to choose the "exposure vector," i.e. the "relative weighting" of each cohort over time. This will equal the anticipated annuity payments for each cohort in each year of the risk period (see Table 4 for an example).

- The hedger is able to select an "experience ratio matrix," based on an experience study of its underlying book of business. For each cohort, in each year of the risk period, a fixed adjustment is applied to the national-population mortality rate to adjust for anticipated differences between the mortality profile of the hedger's book of business and the corresponding reference population. So if the hedger's underlying lives are healthier than the general population, they will assign experience ratios of less than $100 \%$ to "scale down" the mortality rate applied in the payout (see Table 5 for an example).

5.5.4. A risk exposure period of 55 years - as shown in Tables 4 and 5 - is unattractive to capital markets investors for a number of reasons. Liquidity in this market is still low and would be completely absent at these horizons. The maximum effective investment horizon is no more than 15 years. Just as important, the risks are too great. The likely advances in medical science suggest that the range of outcomes for longevity experience will be very wide for an investment horizon of more than half a century.

5.5.5. To accommodate both an "exposure period" of 55 years or more and a "risk period" (or transaction length) of 15 years, the hedge programme uses a "commutation function" to "compress" the risk period. As explained in Michaelson \& Mulholland (2014, pp. 32-33):

This is accomplished by basing the final index calculations on the combination of two elements: (i) the actual mortality experience, as published by the national statistical reporting agency, applied to the exposure defined for the risk period; and (ii) the present value of the remaining exposure at the end of the risk period calculated using a "re-parameterised" longevity model that takes into account the realised mortality experience over the life of the transaction. This re-parameterisation process involves:

- Selecting an appropriate longevity risk model and establishing the initial parameterisation of the model using publicly available historical mortality data that exist as of the trade date. For a basic longevity model, the parameters that may be established, on a cohort-by-cohort basis, are (i) the current rate of mortality; (ii) the expected path of mortality improvement; and (iii) the variability in the expected path of mortality improvement.

- "Freezing" the longevity risk model, with regard to the related structure; but also defining, in advance, an objective process for updating the model's parameters based on the additional mortality experience that will be reported over the risk period. A determination needs to be made 


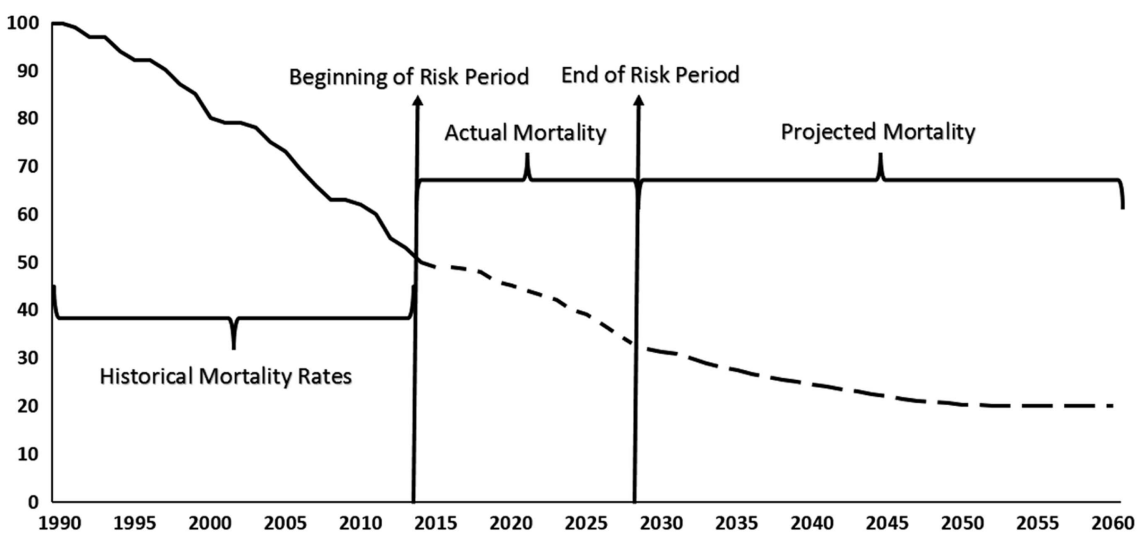

Figure 5. Mortality rates before, during and after the risk period

Note: Projected mortality rates are calculated using experience data available at end of the risk period. Source: Michaelson \& Mulholland (2014, Exhibit 3).

as to which parameters are subject to updating, as well as the relative importance that will be placed on the historical data versus the data received during the risk period.

- Re-parameterising the longevity model by incorporating the additional mortality data reported over the life of the trade. This occurs at the end of the transaction risk period, once the mortality data for the final year in the risk period have been received.

- Calculating the present value of the remaining exposure using the re-parameterised version of the initial longevity model. This is done by projecting future mortality rates, either stochastically or deterministically, and then discounting the cash flows using forward rates determined at the inception of the transaction.

5.5.6. The benefit of this approach to the hedger is that "roll risk" 44 is reduced, since, by taking account of actual mortality rates over the risk period, there will be a much more reliable estimate at the end of the risk period of the expected net present value of the remaining exposure than if only historical mortality rates prior to the risk period were used. The benefit to the investor is that the longevity model is known and not subject to change, so the only source of cash flow uncertainty in the hedge is the realisation of national population mortality rates over the risk period - see Figure 5 .

5.5.7. The hedge itself is structured using a long out-of-the money call option bull spread on future mortality outcomes. The spread has two strike prices or, using insurance terminology, an attachment point and an exhaustion point. ${ }^{45}$ These strikes are defined relative to the distribution of "final index values" calculated using the agreed longevity model. The final index value will be a combination of:

- The "actual" mortality experience of the hedger throughout the risk period which is calculated by applying the reported national population mortality rates to the predefined "exposure vector" and "experience ratio matrix" for each cohort in each year of the risk period, and accumulating with interest, using forward interest rates defined on the trade date.

44 This is the risk that arises when a hedger is not able for some reason to put on a single hedge that covers the full term of its risk exposure and is forced to use a sequence of shorter term hedges which are rolled over when each hedge matures, with the risk that the next hedge in the sequence is set up on less favourable terms than the previous one.

45 The spread is constructed using a long call at the lower strike price and a short call at the upper strike price. 


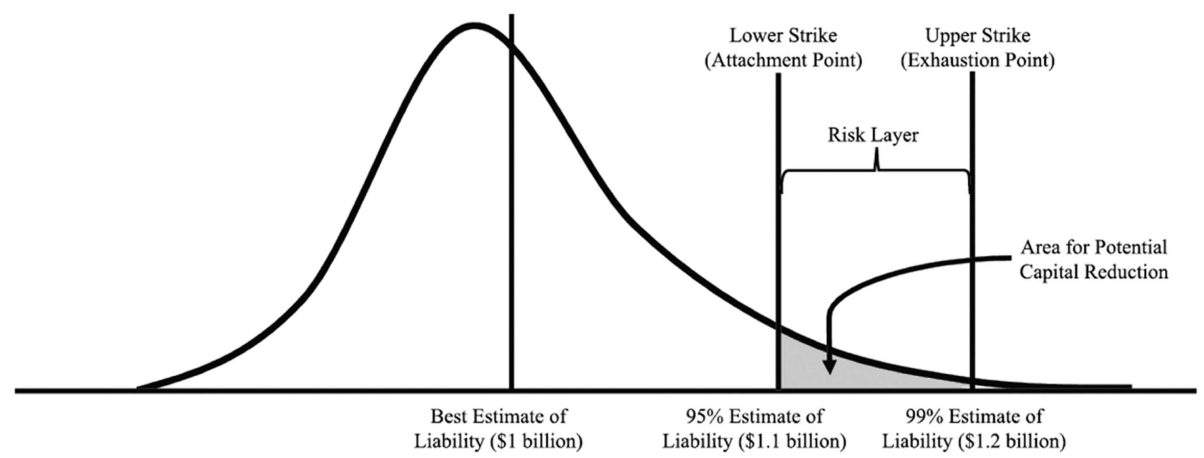

Figure 6. Distribution of the final index value and the potential for capital reduction Source: Michaelson \& Mulholland (2014, Exhibit 4) - not drawn to scale.

- The "commutation calculation" that estimates the expected net present value of the remaining exposure at the end of the risk period, calculated using the re-parameterised version of the initial longevity model.

5.5.8. Given the distribution of the final index, the attachment and exhaustion points are selected to maximise the hedger's capital relief, taking into account the investors' (i.e. risk takers') wish to maximise the premium for the risk level assumed. Investors might also demand a "minimum premium" to engage in the transaction. The intermediary - e.g. the investment bank - therefore needs to carefully work out the optimal amount of risk transfer, given both the hedger's strategic objectives and investor preferences.

5.5.9. The hedger then needs to calculate the level of capital required to cover possible longevity outcomes with a specified degree of confidence. For example, if the "best estimate" of the longevity liability is $\$ 1 \mathrm{bn}$, the (re)insurer may actually be required to issue $\$ 1.2 \mathrm{bn}, \$ 200 \mathrm{~m}$ of which is reserve capital to cover the potential increase in liability due to unanticipated longevity improvement with $99 \%$ confidence.

5.5.10. The (re)insurer may then decide to implement a hedge transaction with a maximum payout of $\$ 100 \mathrm{~m}$. This transaction would begin making a payment to the hedger in the event the attachment point is breached, and then paying linearly up to $\$ 100 \mathrm{~m}$ if the longevity outcome meets or exceeds the exhaustion point. This hedge provides a form of "contingent capital" from investors (up to $\$ 100 \mathrm{~m}$ of the $\$ 200 \mathrm{~m}$ required), enabling the hedger to reduce the amount of regulatory capital it must issue - see Figure 6.

5.5.11. Tail risk protection was actually discussed in Living with Mortality in section 6.4 entitled "Geared Longevity Bonds and Longevity Spreads," which we reproduce here. The geared longevity bond enables holders to increase hedging impact for any given capital outlay.

5.5.12. One way to construct such a bond would be as follows. Looking ahead from time 0 , the payment on each date $t$ can in theory range from 0 to 1 (times the initial coupon). However, again looking ahead from time 0 , we can also suppose that the payment at time $t$ (the survivor index, $S(t, x)$; see paragraph 5.4.10 above) is likely to fall within a much narrower band, say $S(t, x) \in\left[S_{l}(t), S_{u}(t)\right]$. For example, if we are using a stochastic mortality model we could let $S_{l}(t)$ and $S_{u}(t)$ be the $2.5 \%$ and 
$97.5 \%$ percentiles of the simulated distribution of $S(t, x)$. These simulated confidence limits become part of the contract specification at time 0 .

5.5.13. We now set up a special purpose vehicle (SPV) at time 0 that holds $S_{u}(t)-S_{l}(t)$ units of the fixed interest zero-coupon bond that matures at time $t$ for each $t=1, \ldots, T$ (or its equivalent using floating-rate debt and an interest-rate swap). Suppose the SPV is financed by two investors $A$ and $B$. At time $t$, the SPV pays: (i) $S(t, x)-S_{l}(t)$ to $A$ with a minimum of 0 and a maximum of $S_{u}(t)-S_{l}(t)$; and (ii) $S_{u}(t)-S(t, x)$ to $B$ with a minimum of 0 and a maximum of $S_{u}(t)-S_{l}(t)$.

5.5.14. The minimum and maximum payouts at each time to $A$ and $B$ ensure that the payments are always non-negative and can be financed entirely from the proceeds of the fixed-interest zero-coupon bond holdings of the SPV.

5.5.15. The payoff at $t$ to $A$ can equivalently be written as

$$
\left(S(t, x)-S_{l}(t)\right)+\max \left\{S_{l}(t)-S(t, x), 0\right\}-\max \left\{S(t, x)-S_{u}(t), 0\right\}
$$

that is, a combination of a long forward contract, a long put option on $S(t, x)$ (or a "floorlet," with a strike price that is lower than the at-the-money forward rate), and a short call on $S(t, x)$ (or a "caplet" with a strike price that is higher than the at-the-money forward rate). The bond as a whole, therefore, is a combination of forwards, floorlets and caplets. Continuing with the option terminology, we can also observe that the payoff to investor $A$ is often referred to as a long "bull call spread," and for this reason we refer to the payoff in the current context as a long "longevity bull call spread."

5.5.16. Let us suppose that, for each $t, S_{l}(t)$ and $S_{u}(t)$ have been chosen so that the value of the floorlet and the caplet are equal. In this case, the price payable at time 0 by investor $A$ is equal to the sum of the prices of the $T$ forward contracts paying $S(t, x)-S_{l}(t)$ at times $t=1, \ldots, T$. This is equal to (i) the price for the longevity bond paying $S(t, x)$ at times $t=1, \ldots, T$, minus (ii) the price for the fixed-interest bond paying $S_{l}(t)$ at times $t=1, \ldots, T$. This structure therefore gives investors a similar exposure to the risks in $S(t, x)$ for a lower initial price. For this reason, we describe the collection of longevity bull spreads as a geared longevity bond.

5.5.17. As an alternative, $S_{u}(t)$ might be set to 1 , meaning that the caplet has zero value $(S(t, x)$ cannot be bigger than 1). With this structure, investor $A$ has full protection against unanticipated improvements in longevity, but gives away any benefits from poorer longevity than anticipated.

5.5.18. It is important to note in the above construction that there is a smooth progression in the division of the coupon payments between the counterparties over the range of $S(t, x)$. This is preferable to a contract that has a jump in the amount of the payment as $S(t, x)$ crosses some threshold: as often happens with such contracts as barrier options, arguments can often arise as to whether the particular threshold was crossed or not. Such difficulties are avoided with the smooth progression.

5.5.19. The bond described here is a variation on the Société Générale structure where the payoff at $T$ depends only on the single survivor index $S(T, x)$. In the more general case, the payoff depends on the values of $S(1, x), \ldots, S(T, x)$ and the forecast values at $T$ of $S(T+1, x), S(T+2, x), \ldots$ 
Table 6. Standardised Index Hedges Versus Customised Hedges

\begin{tabular}{|c|c|c|}
\hline & Advantages & Disadvantages \\
\hline $\begin{array}{l}\text { Standardised } \\
\text { index hedge }\end{array}$ & $\begin{array}{l}\text { - Cheaper than customised hedges } \\
\text { - Lower set-up/operational costs } \\
\text { - Shorter maturity, so lower counterparty } \\
\text { credit exposure }\end{array}$ & $\begin{array}{l}\text { - Not a perfect hedge: } \\
{ }^{\circ} \text { Basis risk } \\
{ }^{\circ} \text { Roll risk } \\
{ }^{\circ} \text { Base table estimation risk }\end{array}$ \\
\hline Customised hedge & $\begin{array}{l}\text { - Exact hedge, so no residual basis risk } \\
\text { - Set-and-forget hedge, requires minimal } \\
\text { monitoring }\end{array}$ & $\begin{array}{l}\text { - More expensive than standardised hedge } \\
\text { - High set-up and operational costs } \\
\text { - Poor liquidity } \\
\text { - Credit risk: Longer maturity, so larger } \\
\text { counterparty credit exposure } \\
\text { - Less attractive to investors }\end{array}$ \\
\hline
\end{tabular}

Source: Coughlan (2007a).

\section{Index Versus Customised Hedges, and Basis Risk}

\subsection{Overview}

Lucida and Canada Life implemented two very different kinds of capital markets longevity hedges in 2008. Lucida executed a standardised hedge linked to a population mortality index, whereas Canada Life executed a customised hedge linked to the actual mortality experience of a population of annuitants. Aegon's hedges with Deutsche Bank in 2012 and with Société Générale in 2013 were also index hedges, but they were designed to minimise the basis risk involved. ${ }^{46}$ It is important to understand the differences between index and customised hedges. It is also important to understand, measure and manage the basis risk in index hedges. This, in turn, will have implications for regulatory capital relief.

\subsection{Index Versus Customised Hedges}

6.2.1. Standardised index-based longevity hedges have some advantages over the customised hedges that are currently more familiar to pension funds and annuity providers. In particular, they have the advantages of simplicity, cost and greater potential for liquidity. But they also have obvious disadvantages, principally the fact that they are not perfect hedges and leave a residual basis risk (see Table 6) that requires the index hedge to be carefully calibrated.

6.2.2. Coughlan et al. (2007b) show that a liquid, hedge-effective market could be built around just eight standardised $q$-forward contracts with:

- a specific maturity (e.g. 10 years);

- two genders (male, female);

- four age buckets $(50-59,60-69,70-79,80-89)$.

6.2.3. Figure 7 presents the mortality improvement correlations within the male $70-79$ age bucket which is centred on age 75 (Coughlan et al., 2007c). These figures show that the correlations (based on graduated mortality rates) are very high. Consequently, a tailored hedge using, say, $10 q$-forwards

${ }^{46}$ Aegon had a history of buying up smaller insurance companies all over Holland, so had a well-diversified mortality base that was similar to that of (and therefore highly correlated with) the national population, so the population basis risk in the hedge was minimal. 


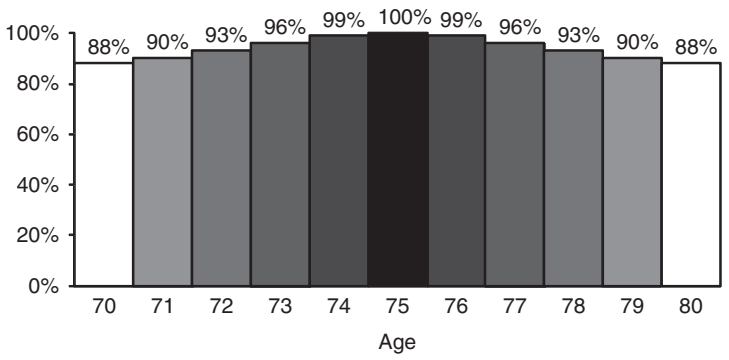

Figure 7. Five-year mortality improvement correlations with England \& Wales males aged 75 Source: Coughlan et al. (2007c, Figure 9.6).

on ages 70-79 will be only marginally more effective than a single $q$-forward using a standard 70-79 age bucket. Coughlan (2007a) estimates that the hedge effectiveness (of a value hedge) is around $86 \%$ (i.e. the standard deviation of the liabilities is reduced by $86 \%$, leaving a residual risk of $14 \%$ ) for a large and well-diversified pension plan or annuity portfolio: see Figure $8 .^{47}$

6.2.4. In order to keep the number of contracts to a manageable level, individual contracts use the average (or "bucketed") mortality across 10 ages rather than single ages. This averaging has positive and negative effects. On the one hand, the averaging reduces the basis risk that arises from the nonsystematic mortality risk that is present in crude mortality rates, even at the population level. ${ }^{48}$ On the other hand, it introduces some basis risk depending on the specific age-structure of the population being hedged. This we now discuss in more detail.

\subsection{Basis Risk}

6.3.1. Basis risk is the residual risk associated with imperfect hedging where the movements in the underlying exposure are not perfectly correlated with movements in the hedging instrument. Basis risk and its quantification have recently attracted the attention of both academics and practitioners (e.g. Li \& Hardy, 2011; Cairns et al., 2014; Longevity Basis Risk Working Group, 2014; Villegas et al., 2017; Li et al., 2017; Cairns \& El Boukfaoui, 2018).

6.3.2. Within the context of longevity risk hedging, a number of sources of basis risk arise: population basis risk; base-table risk; structural risk; restatement risk; and idiosyncratic risk.

6.3.3. Population basis risk is, perhaps, the form of basis risk that most readily comes to mind when considering an index based longevity hedge. Specifically, a hedger might choose to use a hedging

47 A subsequent study by Coughlan et al. (2011) reconfirmed the high degree of effectiveness available with longevity hedges based on national population indices for large pension plans. This study considered a pension fund with a membership whose mortality experience was the same as the UK CMI (Continuous Mortality Investigation) assured lives population; with a hedge based on the England \& Wales LifeMetrics Index, hedge effectiveness of $82.4 \%$ could be achieved. The same study also considered a pension fund with a membership whose mortality experience was the same at the population of California. With a hedge based on the US LifeMetrics Index, hedge effectiveness of $86.5 \%$ could be achieved.

48 For example, for England \& Wales males, variation in the bucketed $q$-forward payoff that is solely due to non-systematic mortality risk (i.e. sampling variation in the death counts) will have a standard deviation of around $0.3 \%$ of the value of the $q$-forward fixed leg. Relative to the uncertainty in the true mortality rate underpinning the $q$-forward payoff with a 10 -year horizon, this sampling variation is negligible. 


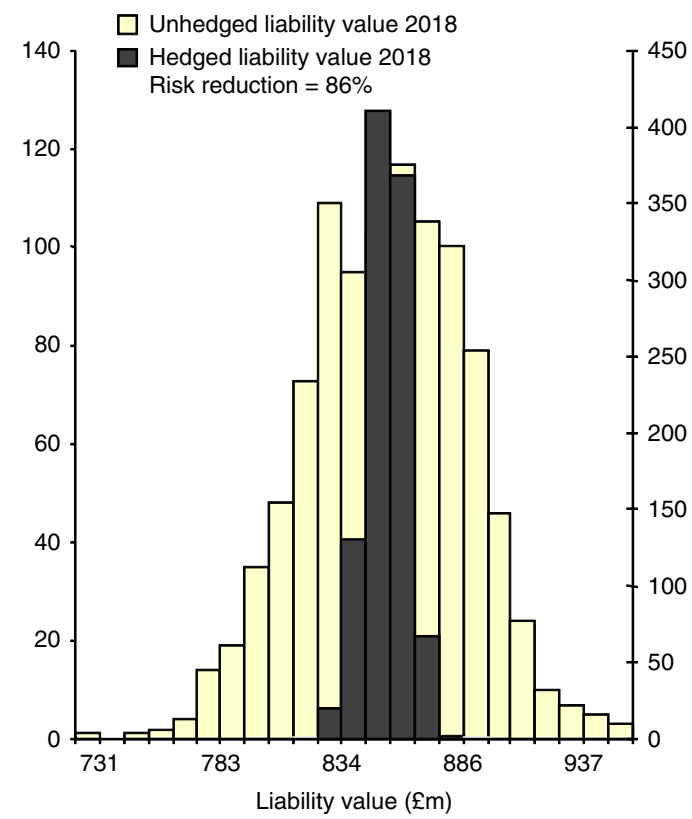

Figure 8. The hedge effectiveness of $q$-forwards Source: Coughlan (2007a).

instrument that is linked to a different population from its own population that it wishes to hedge. This is most common where the hedging instrument is linked to an index based on national mortality rates, while the hedger's own population is a distinctive sub-population with different characteristics from the national average. As a consequence, underlying mortality rates might not just be at a different level from that of the national population, but rates of improvement in both the short and long term might not be perfectly correlated. Modelling and understanding the differences between two populations is an active and rapidly developing subject of research. ${ }^{49}$

6.3.4. Base-table risk concerns how accurately hedgers and also receivers of longevity risk are able to assess the mortality base table for both the hedger's own population and the national population. Whether or not base-table risk contributes to residual risk for the hedger then depends on the nature of the longevity hedge. At one end of the spectrum, from the perspective of the hedger, a customised longevity swap leaves the hedger with no base-table risk, while the receiver is exposed and should charge a higher price to reflect this extra risk. In contrast, for an index-based hedge, base-table risk will be relevant. Base-table risk will then make a more significant contribution to total basis risk if the hedger's own population is small or the time horizon of the hedge is short.

6.3.5. Structural risk relates to the design of the hedging instrument, and it can arise even if there is no population basis risk or base-table risk:

- The hedging instrument might have a non-linear payoff as a function of the underlying risk. This includes contracts with an option-type payoff structure such as the bull call spread in

49 Modelling population basis risk is also a key ongoing element of the Institute and Faculty of Actuaries' ARC research programme on 'Modelling Measurement and Management of Longevity and Morbidity Risk' (www.actuaries.org.uk/arc). 
Michaelson \& Mulholland (2014) and Cairns \& El Boukfaoui (2018), leaving residual risk both below and above the attachment and exhaustion points. It also includes $q$-forwards: these do not include any optionality, but liability cashflows are typically non-linear combinations of the underlying mortality rates.

- The hedging instrument might have a finite maturity, meaning that the longevity risk that emerges after the maturity date is a residual risk that cannot be hedged.

- The reference ages embedded in the hedging instruments might not allow exact matching of the ages in the hedger's population.

- The number of units of the hedging instrument (i.e. the hedge ratio) might not be optimal (i.e. might not minimise residual risk). This might be either unavoidable or unintentional (e.g. through the use of a poorly calibrated model).

- Hedging instruments might not incorporate an inflation linkage and so might not match well with realised pension plan or annuity benefit increases.

In general, structural risk can be adjusted, for example, through the choice of: attachment and exhaustion points; the maturity date; the reference ages; the number of $q$ - or $S$-forwards; and careful calibration and optimisation using the chosen stochastic mortality model.

6.3.6. Restatement risk concerns the possibility that official estimates of the national population or death counts might be revised up or down, with potential impacts on index-based hedge payoffs (Cairns et al., 2016). Restatements will often impact on previously stated mortality rates (especially following a decennial census). Index-based longevity hedges will probably link contractually to the first announcement of a mortality rate, meaning that the restatement of past mortality rates will not alter past payments and hence introduce an additional risk. However, restatements will also have an impact on future estimated population numbers and consequent mortality rates. The future risks and impacts of such restatements can be assessed through use of the same methodology for identifying phantoms proposed in Cairns et al. (2016).

6.3.7. Idiosyncratic risk ${ }^{50}$ is primarily linked to sampling variation and its financial impact within the hedger's population. As with some other examples of basis risk, the impact of idiosyncratic risk will depend on the nature of the hedge (indemnity versus other forms). Given the evolution of the systematic risk in the underlying mortality rates, individuals will either die or survive independently of each other. Proportionately, this risk is larger for smaller pension funds. The level of idiosyncratic risk is also dependent on the heterogeneity in pension amounts (leading to concentration risk): for example, a 1,000-member pension plan in which $10 \%$ of the members are directors (or "big cheeses") who generate $90 \%$ of the liabilities will be more risky than a 1,000-member plan with equal pensions.

6.3.8. Finally, as remarked in Cairns (2014), accurate assessment of basis risk is one part of the process of choosing the best hedge. First, one needs to identify the different options for hedging. ${ }^{51}$ Second, the risk appetite of the hedger needs to be properly assessed. Third, there needs to be an accurate assessment of the basis risk under each hedge. Fourth, prices need to be established for each

50 That is, randomness in individual lifetimes and financial concentrations associated with a small group of individuals.

51 Good enterprise risk management means consideration of all of the available options. Although challenging, the administrative costs of carrying out such an exercise is small compared to the potential economic impact of making the right or wrong choice. 
hedge. Fifth, the combination of price, basis risk and risk appetite then point to a best choice out of all of the options available to the hedger. ${ }^{52}$ Cairns (2014) also highlights that no single hedging option is best for all pension plans. Everything else being equal, customised hedges are more likely to be preferred to index hedges by: smaller pension plans rather than larger (due to the greater idiosyncratic risk); and pension plan sponsors that are more risk averse. Also, certain hedging options (e.g. longevity swaps) are currently only available to pension plans with sufficiently large liabilities.

\subsection{Other Types of Basis Risk}

Other forms of basis risk might arise if a pension plan seeks to hedge the longevity risk associated with a group of active or deferred members, rather than retired members. These groups bring additional risks, including member options (such as lump sum commutation, trivial commutation, early/late retirement, increasing a partner's benefits at the expense of the member's benefits, and pension increase exchanges), partner status at retirement or member death and salary risk. The plan's quantum of exposure to longevity risk depends on how these risks turn out, a risk that itself is not hedgeable.

\section{Credit Risk, Regulatory Capital and Collateral}

\subsection{Overview}

Another risk in Table 6 is counterparty credit risk. This is the risk that one of the counterparties to, say, a longevity swap contract defaults owing money to the other counterparty. When a swap is first initiated, both counterparties might expect a zero excess profit or loss. ${ }^{53}$ But over time, as a result of realised mortality rates deviating from the rates that were forecast at the time the swap started, one counterparty's position will be showing a profit and the other will be showing an equivalent loss. The insurance industry addresses this issue via regulatory capital and the capital markets deal with it via collateral.

\subsection{Regulatory Capital}

7.2.1. The regulatory regime covering insurance companies domiciled in the UK is governed by the Solvency II Directive which came into effect in January 2016 and is used to set regulatory capital requirements.

7.2.2. Regulatory capital is the level of capital or Own Funds required by an insurer's regulatory authority, the PRA in the UK. Solvency II begins with a calculation of the insurer's liabilities, known as technical provisions, which comprises a "best estimate" of the liabilities plus a risk margin - in the case where the liability cannot be reliably measured and/or suitably hedged. The sum of the best

52 Conversely, a hedger's advisers should not let concerns about their own reputational risk influence recommendations: arguably, reputational risk is smaller for indemnity based hedges, and larger for index-based hedges which require higher levels of skill in modelling mortality.

53 This is the case for a transaction involving a pension plan and an insurer, where allowance is made for the insurer's cost of capital and normal profit etc. In a transaction involving an insurer and a reinsurer, it is typical for fees to be added to the 'fixed leg', so commercially there will be a loss to the cedant on day 1 . 
estimate and risk margin can be thought of as the market consistent value or fair value. On top of this, insurers must issue additional risk-based capital to meet first the Minimum Capital Requirement (MCR) and then the Solvency Capital Requirement (SCR).

7.2.3. A major objective of Solvency II is to value all assets and liabilities on a market-consistent basis and to ensure that the regulatory capital that insurance companies issue reflects all the unhedged risks on their balance sheets. The capital should be sufficient to ensure that an insurance company can either (i) survive the next 12 months with a $99.5 \%$ probability or (ii) survive a set of prescribed stress tests. The amount required can be determined using either a stochastic internal model or through the use of the standard stress test, which in the case of longevity risk is a sudden $20 \%$ reduction in mortality rates across all ages. For a 65 -year old UK male, this corresponds approximately to a 1.5 -year increase in life expectancy or a $7 \%$ increase in pension liabilities.

7.2.4. A consequence of any market-consistent approach is that both assets and liabilities are prone to market volatility. Insurance companies invest in long-term illiquid assets, like infrastructure, real estate and equity release mortgages, to reduce asset price volatility, and in corporate bonds to benefit from the credit and illiquidity premia embodied in their higher returns compared with government bonds.

7.2.5. In the case of long-term liabilities, such as annuities and buy-outs, short-term asset price volatility can be partially offset by "matching adjustments" (MAs). MAs are part of Solvency II regulations that depart from a market-consistent approach, by allowing insurers ${ }^{54}$ to estimate the illiquidity premium - inherent in the asset portfolio if it contains such illiquid assets - to be added to the risk-free rate for the purposes of discounting liabilities. To do this, the insurer needs to allocate a specific pool of assets to the liability, where the assets are selected to match the cash-flow characteristics of the liability. The assets need to be matched for the entire term of the liability, in which case the liability can be valued using the higher but less volatile MA-adjusted discount rate. Because both the level and volatility of the liability calculated using this approach are now lower, lower levels of Own Funds and hence SCR are needed. However, because of longevity risk and the dearth of long-maturity longevity-linked assets available to hold in the portfolio, the asset match can never be perfect. The higher MA-adjusted discount rate is reduced somewhat to allow for this and the level of Own Funds correspondingly raised. A particular example is non-pensioner members of pension plans who have both greater longevity risk and more optionality than pensioner members. Both these factors lower the MA-adjusted discount rate and, by raising the level of Own Funds, increase the cost of providing deferred annuities to the pension plan or buying out this segment of the pension plan. Insurers also make use of reinsurance to reduce the volatility of liabilities and this will again have an effect on Own Funds.

7.2.6. One possible implication of Solvency II is that insurers might migrate away from the current cash-flow hedging paradigm towards the value-hedging paradigm. Specifically, insurers might aim to hedge their liability in one year's time as a way to reduce their SCR under Solvency II. This requires comparison of liability and hedge instrument values one year ahead.

7.2.7. Despite Solvency II, some pension plans considering de-risking remain concerned about the financial strength of some insurers, which is why consultants, such as Barnett Waddingham, have launched an insurer financial strength review service, providing information on an insurer's structure, solvency position, credit rating and key risks in their business model.

${ }^{54}$ And reinsurers. 
7.2.8. Regulatory capital deals principally with the credit risk of the insurer. ${ }^{55}$ Conversely, the insurer faces credit risk from the pension plan in the case of, say, a longevity swap, and collateral would need to be posted to deal with this.

\subsection{Collateral}

7.3.1. The role of collateral is to reduce if not entirely eliminate counterparty credit risk in both capital market transactions and insurance contracts.

7.3.2. Collateral in the form of high-quality securities needs to be posted by the loss-making counterparty to cover such losses. However, the collateral needs to be funded and the funding costs will depend on the level of interest rates. Further, the quality of the collateral and the conditions under which a counterparty can substitute one form of collateral for another need to be agreed. This is done in the credit support annex (CSA) to the ISDA ${ }^{56}$ Master Agreement that establishes the swap. The CSA also specifies how different types of collateral will be priced.

7.3.3. All these factors are important for determining the value of the swap at different stages in its life. Biffis et al. (2016) use a theoretical model to show that the overall cost of collateralisation in mortality or longevity swaps is similar to or lower than those found in the interest-rate swaps market on account of the diversifying effects of interest rate and longevity risks - which are to a first order uncorrelated risks. In practice, agreeing the value of the collateral involves an iterative process. Valuing the fixed leg is generally straightforward, but there can be differences of opinion in valuing the floating leg. It is typical in reinsurance contract negotiations for both sides to recommend a basis. If the difference is too far apart, both sides agree to bring in either one or two external experts. If only one is used, both sides are bound by their assessment. If two are used and they are close, both sides agree to split the difference: if they are still too far apart, both sides will allow the experts to appoint an agreed third expert.

\section{Liquidity}

8.1. Liquidity is another important issue raised in Table 6. The key problem with customised solutions for some participants ${ }^{57}$ is that they are not liquid and cannot easily be reversed. By contrast, liquidity is a key advantage of deep and well-developed capital market solutions.

8.2. To ensure long-term viability, it is critical that a traded capital market instrument meets the needs of both hedgers and speculators (or traders). The former require hedge effectiveness, while the latter supply liquidity. However, liquidity requires standardised contracts. The fewer the number of standardised contracts traded, the greater the potential liquidity in each contract, but the lower the potential hedge effectiveness. There is therefore an important tradeoff to be made, such that the number of standardised contracts traded provides both adequate hedge effectiveness and adequate liquidity.

\footnotetext{
55 It also covers the insurer's underwriting, market and operational risks.

56 International Swaps and Derivatives Association.

57 It is not an issue for a pension plan if it is doing a longevity swap as a step to buy-out.
} 
8.3. If they are ever to achieve adequate liquidity, it is likely that capital-markets-based solutions will have to adopt mortality indices based on the national population as the primary means of transferring longevity risk or sub-population indices that are transparent, trustworthy, reliable and durable. However, potential hedgers, such as life assurers and pension funds, face a longevity risk exposure that is specific to their own policyholders and plan members: for example, it might be concentrated in specific socio-economic groups or in specific individuals such as the sponsoring company's directors. Hedging using population mortality indices means that life assurers and pension funds will face basis risk if their longevity exposure differs from that of the national population. Herein lies the tension between index-based hedges and customised hedges of longevity risk, and, in turn, the unavoidable trade-off between basis risk and liquidity.

8.4. The involvement of the capital markets would help to reduce the cost of managing longevity risk. This is because it should lead to an increase in capacity, together with greater pricing transparency (as a result of the activities of arbitrageurs ${ }^{58}$ ) and greater liquidity (as a result of the activities of speculators). These conditions should attract the interest of ILS investors, hedge funds, private equity investors, sovereign wealth funds, endowments, family offices and other investors seeking asset classes that have low correlation with existing financial assets. Longevity-linked assets naturally fit this bill.

8.5. Currently, there is still insufficient interest from these classes of investor. However, Figure 1 shows how the market might eventually come into balance, with increasing numbers of potential sellers of longevity risk protection attracted by a suitable risk premium to enter the market to meet the huge demands of potential buyers.

\section{Mortality Models}

\subsection{Overview}

It is clear from the solutions we have described above that mortality models play a critical role in their design and pricing (see, e.g. Figures 3 and 6). There are three classes of stochastic mortality model in use (with some models straddling more than one class):

- extrapolative or time series models;

- process-based models - which examine the biomedical processes that lead to death;

- explanatory or causal models - which use information on factors which are believed to influence mortality rates such as cohort (i.e. year of birth), socio-economic status, lifestyle, geographical location, housing, education, medical advances and infectious diseases.

Most of the models currently in use are in the first of these classes and we will concentrate on these in this section.

\subsection{Extrapolative or Time Series Models - Single Population Variants}

9.2.1. There are four classes of time-series-based mortality model in use. First is the Lee-Carter class of models (Lee \& Carter, 1992), which makes no assumption about the degree of smoothness in

58 However, to be effective, arbitrageurs need well-defined pricing relationships between related securities and we are still at the very early days in the development of this market. 


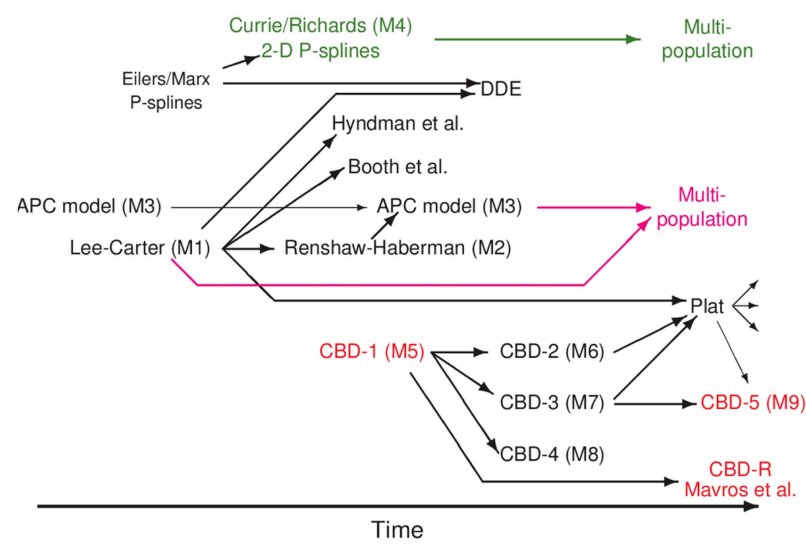

Figure 9. A genealogy of stochastic mortality models Source: Adapted from Cairns (2014)

mortality rates across adjacent ages or years. Second is the Cairns-Blake-Dowd (CBD) class of models (Cairns, Blake \& Dowd, 2006), which builds in an assumption of smoothness in mortality rates across adjacent ages in the same year (but not between years). ${ }^{59}$ Third is the P-splines model (Currie et al., 2004) which assumes smoothness across both years and ages. ${ }^{60}$ Finally, there is the Age-Period-Cohort (APC) model which has its origins in medical statistics (Osmond, 1985; Jacobsen et al., 2002), and was first introduced in an actuarial context by Renshaw \& Haberman (2006). Other features have also jumped from one class to another with the resulting genealogy mapped out in Figure 9. The first two classes of models have also been extended to allow for a cohort effect. ${ }^{61}$ All these models were subjected to a rigorous analysis in Cairns et al. $(2009,2011 \mathrm{a})$ and Dowd et al. (2010b, 2010c). The models were assessed for their goodness of fit to historical data and for both their ex-ante and ex-post forecasting properties.

9.2.2. Cairns et al. (2009) used a set of quantitative and qualitative criteria to assess each model's ability to explain historical patterns of mortality: quality of fit, as measured by the Bayes Information Criterion (BIC); ease of implementation; parsimony; transparency; incorporation of cohort effects; ability to produce a non-trivial correlation structure between ages; and robustness of parameter estimates relative to the period of data employed. The study concluded that a version of the CBD

59 The CBD model was specifically designed for modelling higher age $(55+)$ mortality rates. It has recently been generalised to account for the different structure of mortality rates at lower ages by, e.g. Plat (2009) and Hunt \& Blake (2014).

${ }^{60}$ Other academic studies of mortality models include Hobcraft et al. (1982), Booth et al. (2002a, 2002b), Brouhns et al. (2002a, 2001b, 2005), Renshaw and Haberman (2003a, 2003b, 2006, 2008), Darkiewicz \& Hoedemakers (2004), Biffis (2005), Czado et al. (2005), Delwarde et al. (2007), Koissi et al. (2006), Pedroza (2006), Bauer et al. (2008, 2010), Gourieroux and Monfort (2008), Hari et al. (2008), Kuang et al. (2008), Haberman \& Renshaw (2009, 2011, 2012, 2013), Hatzopoulos and Haberman (2009, 2011), Li et al. (2009, 2015a), Wang and Preston (2009), Biffis et al. (2010), Debonneuil (2010), Lin and Tzeng (2010), Murphy (2010), Yang et al. (2010), Coelho and Nunes (2011), D'Amato et al. (2011, 2012a, 2012b, 2014), Gaille and Sherris (2011), Li and Chan (2011), Milidonis et al. (2011), Russo et al. (2011), Russolillo et al. (2011), Sweeting (2011), Wang et al. (2011), Alai \& Sherris (2014b), Aleksic and Börger (2012), Hainaut (2012), Hyndman et al. (2013), Mitchell et al. (2013), Nielsen and Nielsen (2014), Mayhew and Smith (2014), Danesi et al. (2015), O'Hare and Li (2015), Berkum et al. (2016), Currie (2016) and Richards et al. (2017).

61 See, e.g. Cairns et al. (2009). 
model allowing for a cohort effect was found to have the most robust and stable parameter estimates over time using mortality data from both England \& Wales and the US. This model (usually referred to as "M7") is now the keystone of one of the two approaches recommended by the Life and Longevity Markets Association (LLMA) ${ }^{62}$ (Longevity Basis Risk Working Group, 2014, Villegas et al., 2017, and Li et al., 2017).

9.2.3. Cairns et al. (2011a) focused on the qualitative forecasting properties of the models ${ }^{63}$ by evaluating the ex-ante plausibility of their probability density forecasts in terms of the following qualitative criteria: biological reasonableness; ${ }^{64}$ the plausibility of predicted levels of uncertainty in forecasts at different ages; and the robustness of the forecasts relative to the sample period used to fit the models. The study found that while a good fit to historical data, as measured by the BIC, is a promising starting point, it does not guarantee sensible forecasts. For example, one version of the CBD model allowing for a cohort effect produced such implausible forecasts of US male mortality rates that it could be dismissed as a suitable forecasting model. This study also found that the LeeCarter model produced forecasts at higher ages that were "too precise," in the sense of having too little uncertainty relative to historical volatility. The problems with these particular models were not evident from simply estimating their parameters: they only became apparent when the models were used for forecasting. The other models (including the APC model) performed well, producing robust and biologically plausible forecasts.

9.2.4. It is also important to examine the ex post forecasting performance of the models. This involves conducting both backtesting and goodness-of-fit analyses. Dowd et al. (2010b), undertook the first of these analyses. Backtesting is based on the idea that forecast distributions should be compared against subsequently realised mortality outcomes and if the realised outcomes are compatible with their forecasted distributions, then this would suggest that the models that generated them are good ones, and vice versa. The study examined four different classes of backtest: those based on the convergence of forecasts through time towards the mortality rate(s) in a given year; those based on the accuracy of forecasts over multiple horizons; those based on the accuracy of forecasts over rolling fixed-length horizons; and those based on formal hypothesis tests that involve comparisons of realised outcomes against forecasts of the relevant densities over specified horizons. The study found that the Lee-Carter model, the APC model and the CBD model (both with and without a cohort effect) performed well most of the time and there was relatively little to choose between them. However, another version of the Lee-Carter model allowing for a cohort effect repeatedly showed evidence of instability. ${ }^{65}$

9.2.5. Dowd et al. (2010c) set out a framework for evaluating the goodness of fit of stochastic mortality models and applied it to the same models considered by Dowd et al. (2010b). The methodology used exploited the structure of each model to obtain various residual series that are predicted to be independently and identically distributed (iid) standard normal under the null hypothesis of model adequacy. Goodness of fit can then be assessed using conventional tests of the

62 www.llma.org

63 The P-splines model was excluded from the analysis because of its inability to produce fully stochastic projections of future mortality rates.

64 A method of reasoning used to establish a causal association (or relationship) between two factors that is consistent with existing medical knowledge.

65 See Renshaw \& Haberman (2006). This was later explained in terms of a missing identification condition in the model (Hunt \& Villegas, 2015). 


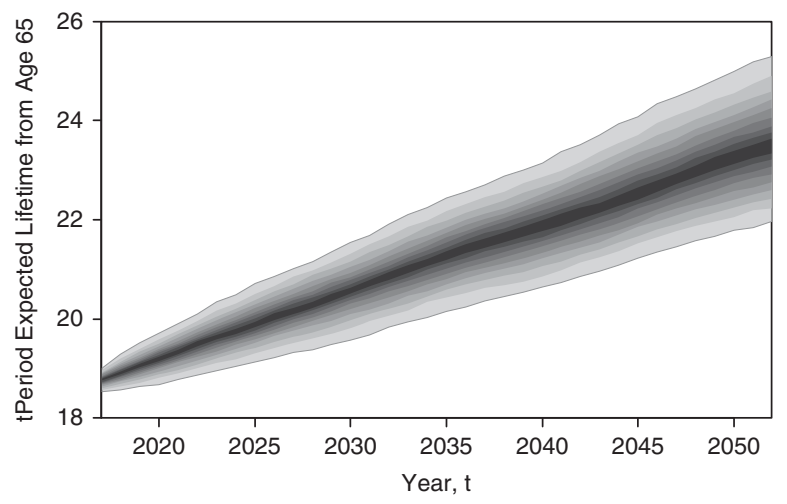

Figure 10. Longevity fan chart for 65-year-old English \& Welsh males Source: Own calculations.

predictions of iid standard normality. For the data set considered (English \& Welsh male mortality data over ages 64-89 and years 1961-2007), there are some notable differences amongst the various models, but none of the models performed well in all tests and no model clearly dominates the others. In particular, all the models failed to capture long-term changes in the trend in mortality rates. Further development work on these models is therefore needed. It might be the case that there is no single best model and that some models work well in some countries, while others work well in other countries.

9.2.6. The CBD model appears to work well in England \& Wales for higher ages, and Figures 10-12 present three applications of the model using ONS data for England \& Wales.

9.2.7. The first (Figure 10) is a longevity fan chart (Dowd et al, 2010a), which shows the increasing funnel of uncertainty concerning future life expectancies out to 2052 of 65 -year-old males from England \& Wales. ${ }^{66}$ By 2047, life expectancy from age 65 is centred around 23 years, shown by the dark central band: an increase of 4 years on the expectation for the year 2017. The different bands within the fan correspond to $5 \%$ bands of probability with the lower and upper boundaries at the $5 \%$ and $95 \%$ quantiles. Adding these together, the whole fan chart shows the $90 \%$ confidence interval for the forecast range of outcomes. We can be $90 \%$ confident that by 2047 , the life expectancy of a 65 -year-old English \& Welsh male will lie between 21.3 and 24.3. This represents a huge range of uncertainty. Since every additional year of life expectancy at age 65 adds around $4-5 \%{ }^{67}$ to the present value of pension liabilities, the cost of providing pensions in 2060 could be 7-8\% higher than the best estimate for 2047 made in 2017.

9.2.8. The second is a survivor fan chart (Blake et al., 2008), which shows the $90 \%$ confidence interval for the survival rates of English \& Welsh males who reached 65 at the end of 2016. Figure 11 shows that there is relatively little survivorship risk before age 75 : a fairly reliable estimate

66 Note projections run from 2017 based on a variant of the CBD model estimated using data for ages 50-89 and years 1977-2016.

67 See paragraph 2.2 . 


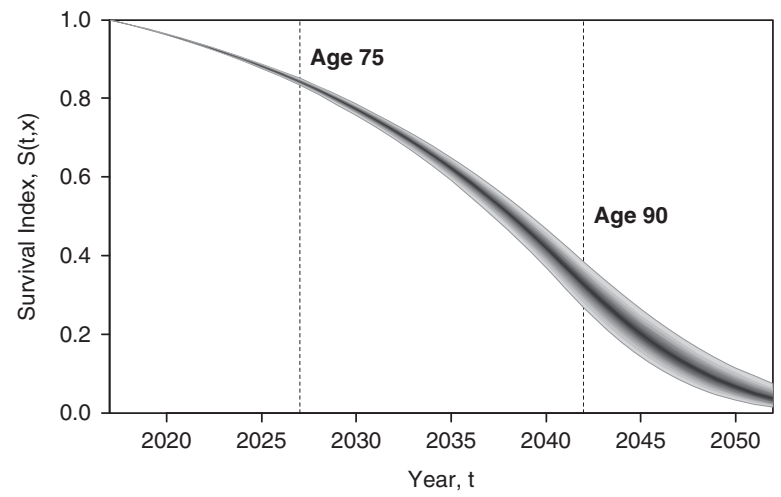

Figure 11. Cohort survivor fan chart for 65-year-old English \& Welsh males Source: Own calculations.

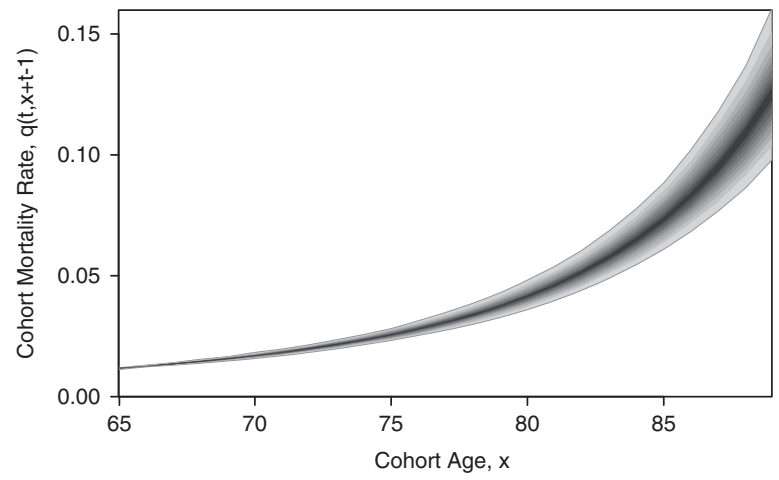

Figure 12. Cohort mortality fan chart for 65-year-old English \& Welsh males Source: Own calculations.

is that $20 \%$ of this group will have died by age $75 .^{68}$ The uncertainty increases rapidly after 75 and reaches a maximum just after age 90 , when anywhere between $27 \%$ and $38 \%$ of the original cohort will still be alive. We then have the long "tail" where the remainder of this cohort dies out some time between 2042 and 2062.

9.2.9. The third is a mortality fan chart which shows the $90 \%$ confidence interval for 65 -year old English \& Welsh males who reached 65 at the end of 2016. Figure 12 shows that there is an increasingly low probability of surviving year to year at very high ages, even with predicted mortality improvements.

9.2.10. By building off a good mortality forecasting model estimated using data from an objective, transparent and relevant set of mortality indices, fan charts provide a very useful tool for both quantifying and visually understanding longevity, survivor and mortality risks.

68 This is one of the reasons why the EIB/BNP Paribas bond discussed in paragraph 1.1.1 was considered expensive: the first 10 years of cash flows are, in present value terms, the most costly cash flows of a bond, and, in the case of the EIB bond, incorporate a longevity hedge that is not really needed. 
Table 7. UK Life Expectancy at Age 65

\begin{tabular}{llc}
\hline \hline Version of the CMI Model & Male (years) & Female(years) \\
\hline CMI_2013 & 22.8 & 25.1 \\
CMI_2014 & 22.8 & 24.9 \\
CMI_2015 & 22.5 & 24.6 \\
CMI_2016 & 22.2 & 24.1 \\
\hline \hline
\end{tabular}

Source: Continuous Mortality Investigation.

9.2.11. One key problem that extrapolative models have is their difficulty in differentiating between a genuine change in the trend of mortality rates and a temporary blip in mortality rates until some time after the change has occurred. In 2016, the UK Office for National Statistics reported that longevity improvements rates at very high ages have slowed down since 2011; but it is not yet clear whether this is a genuine change in the long-term trend, a short-term austerity-driven adjustment, or just the result of a purely random deviation from the previous trend. ${ }^{69}$ Nevertheless, it prompted a debate in the UK in 2016 about the reliability of life expectancy projections. Mortality improvements in UK males averaged $0.6 \%$ p.a. over the preceding four years, compared with $3.2 \%$ p.a. in the decade before and $1.5-2 \%$ between 1995 and $2000 .^{70}$ In response to a possible trend change, the UK Continuous Mortality Investigation (CMI) has lowered its estimate of both male and female life expectancy at age 65 over 4 consecutive years, as Table 7 shows.

9.2.12. In October 2016, Tim Gordon, head of longevity at Aon Hewitt, said: "This is the most extreme reversal in mortality improvement trends seen in the past 40 years. What was initially assumed by many actuaries to be a blip is increasingly looking more like an earlier-than-expected fall-off in mortality improvements. The industry is currently trying to digest all the implications of this emerging information and - inevitably - it is taking time to feed through into insurance and reinsurance pricing." Others say that this could just be "noise." Matt Wilmington, director of pension risk transfer at Legal \& General (L\&G), points out that: "Two years doesn't make a trend it's very volatile from year to year. If we had another five years where we saw far fewer deaths than expected, then we might start to see fairly significant changes, but where we are now, there's not enough to persuade us - or many of the pension plans we work with - that there's a vast reversal in trend in terms of life expectancy just yet." Despite this, Aon Hewitt said that there was sufficient dislocation in the pricing of longevity swaps that pension plans should consider delaying transactions until the market corrects. By the middle of 2017, Aon Hewitt reported that the longevity market was back in sync. ${ }^{71}$ However, Tim Gordon also warned against attempts to time the market: "Timing the longevity market in the same way you would time an equity market is extremely difficult, and plans could be in danger of missing opportunities now if they did that." The difference in mortality improvement rates before and after 2011 is equivalent to a difference in liabilities of $1 \%$ or 4 months

69 Anthony Hilton (2016) Life line, Pensions World, May. See also www.bbc.com/news/health-4060825

${ }^{70}$ Own calculations: ages 60-89 covering the periods 2001-2011 (3.2\% p.a. improvements) and 2011-2015 $(0.6 \%)$. Females $2.6 \%$ falling to $0.2 \%$.

71 All quotes taken from Jenna Gadhavi (2017) Does the bell toll for longevity swaps?, Engaged Investor, 13 January; http://aon.mediaroom.com/news-releases?item=137499; and http://aon.mediaroom.com/news-releases? item $=137590$ 
of pension payments for every retiree: UK pension liabilities would be $£ 25$ bn lower if the future mortality improvement rate were $1 \%$ rather than $3 \% .^{72}$

9.2.13. Consultant Barnett Waddingham has put forward the suggestion that higher health and social care spending between 2000 and 2010 (which grew at an average annual real rate of 4\%) may have caused a blip in longevity estimates by accelerating improvements. Since 2009, health spending has grown at just $1 \%$ per annum in real terms, social care spending has fallen in real terms, and there have been lower mortality improvements - although this correlation does not imply causation. ${ }^{73}$

\subsection{Extrapolative or Time Series Models - Multi-Population Variants}

9.3.1. There are a number of reasons why it might be appropriate or desirable to model two or more populations simultaneously. First, a pension plan might often be relatively small in relation to the national population; it might have a relatively short run of data (e.g. relatively limited coverage of ages, or only a few calendar years of observations) or simply have a lot of sampling variation. In contrast, many national populations have a much longer run of data. By modelling the two populations in tandem and exploiting the correlations between the two, it might be possible to achieve better quality forecasts for the pension plan. Second, the use of multiple population mortality models enables more accurate modelling of the relationships between two or more groups that are directly of interest (e.g. males and females; assured lives and annuitants in a life insurer's book of business; life insurance portfolios in different countries, etc.). This will lead to better consistency in forecasts as well as, for example, an assessment of the diversification benefits of having less-than-perfectly correlated groups of lives. Third, multi-population modelling is essential for any institution seeking to hedge its exposure to longevity risk using index-based hedging instruments: the model is required to assess the level of basis risk in the transaction.

9.3.2. The development of multi-population mortality models has lagged single population modelling quite considerably partly due to a lack of good quality sub-population datasets (the CMI assured lives dataset being a notable exception). The Human Mortality Database (HMD) has data for many countries and offers a useful starting point, but sub-population data present particular challenges that are often not present in international data (e.g. shorter runs of data, smaller population sizes, etc.). In the demography literature, Li and Lee (2005) laid out some key foundations: in particular, the principle of coherence. The ratio of mortality rates in two populations can and will vary over time. However, the principle of coherence requires that this ratio should not diverge over time towards zero or infinity. ${ }^{74}$ In the actuarial literature, key early contributions have been made by Cairns et al. (2011b), Dowd et al. (2011), Li and Hardy (2011) and Börger et al. (2013). ${ }^{75}$ More recently, Villegas et al. (2017) carried out an extensive review of both existing and potential new

72 Professional Pensions, 26 January 2017.

73 Professional Pensions, 29 March 2017. According to the Institute for Fiscal Studies: "But looking at all Department of Health spending rather than the NHS only, after adjusting for the ageing of the population, percapita real spending will be lower in 2019-20 than in 2009-10. An additional $£ 1.3$ billion of Department of Health spending would be required in 2019-20 just to maintain 2009-10 levels" (Luchinskaya et al., 2017).

74 As an example, the principle of coherence means that male mortality rates should (mostly) remain a bit higher than female mortality in the long run, and not cross over with certainty as can happen if single population models are fitted to each group independently.

75 See also Jarner and Kryger (2011), Njenga and Sherris (2011), Börger and Ruß (2012), Zhou et al. (2014), Chen et al. (2015), Kleinow (2015), Li et al. (2015b) and Enchev et al. (2017). 
multi-population models. Despite the general popularity of the Li \& Lee (2005) model, their model has been found to be quite unsuitable for some actuarial applications by both Villegas et al. (2017) and Enchev et al. (2017). Specifically, applications that require a stochastic assessment of longevity risk (e.g. measurement of basis risk or diversification benefits) require models that have a plausible correlation term structure: the $\mathrm{Li}$ and Lee model fails on this criterion. ${ }^{76}$

9.3.3. To satisfy the principle of coherence, Cairns et al. (2011b) make use of a mean-reverting stochastic spread that allows for different trends in mortality improvement rates in the short-run, but parallel improvements in the long run. This study uses a Bayesian framework that allows the estimation of the unobservable state variables that determine mortality and of the parameters of the stochastic processes that drive those state variables to be combined into a single step. The key benefits of this include a dampening of the impact of Poisson variation in death counts, ${ }^{77}$ full allowance for parameter uncertainty, and the flexibility to deal with missing data.

9.3.4. Dowd et al. (2011) employ a "gravity" model to achieve coherence using an iterative estimation procedure. ${ }^{78}$ The larger population is modelled independently (similar to the approach recommended by Villegas et al., 2017), but the smaller population is modelled in terms of spreads (or deviations) relative to the evolution of the larger population. To satisfy the principle of coherence, the spreads in the period and cohort effects between the larger and smaller populations depend on gravity or spread reversion parameters for the two effects. The larger the two gravity parameters, the more strongly the smaller population's mortality rates move in line with those of the larger population in the long run.

9.3.5. In their comprehensive comparison of two-population models, Villegas et al. (2017) find that two models satisfy best their criteria for a good two-population model: the common age effect model (Kleinow, 2015) with a cohort effect added; and a variant of the CBD family labelled as M7-M5. ${ }^{79}$ Additionally, they offer useful guidance on the minimum quality of data for the sub-population: a minimum annual exposure of 20,000-25,000 lives over at least 8-10 years, ${ }^{80}$ although Bayesian methods offer the potential to relax these criteria somewhat (e.g. Chen et al., 2017, Cairns et al., 2011b, 2017a).

\subsection{Process-Based and Causal Models}

9.4.1. Until recently, these classes of models were not widely used, since the relationships between biomedical and causal factors and underlying death rates were not sufficiently well understood and because the underlying data needed to build the models were unreliable. This has begun to change.

76 The Li and Lee model commonly predicts perfect correlation between future (log) death rates in two populations at very different ages. Biologically, this is highly implausible.

77 The study uses the common assumption that individual deaths follow a Poisson distribution. If one of the populations is relatively small, Chen et al. (2017) show that the standard two-stage maximum likelihood (in contrast to the one-stage Bayesian) approach produces highly biased estimates of the period effect volatilities.

78 See Hunt \& Blake (2018) for a superior set of identification conditions for estimating the gravity model.

79 Model M7 is used to model the principal population, while model M5 is used to model the spread between the second population and the principal population.

${ }^{80}$ Referring back to the final sentence in paragraph 9.3.1, while multi-population modelling is essential for index-based hedging, this can only really be done in big plans. It is also the case that it is only such big plans that have access to bespoke products due to their size. 


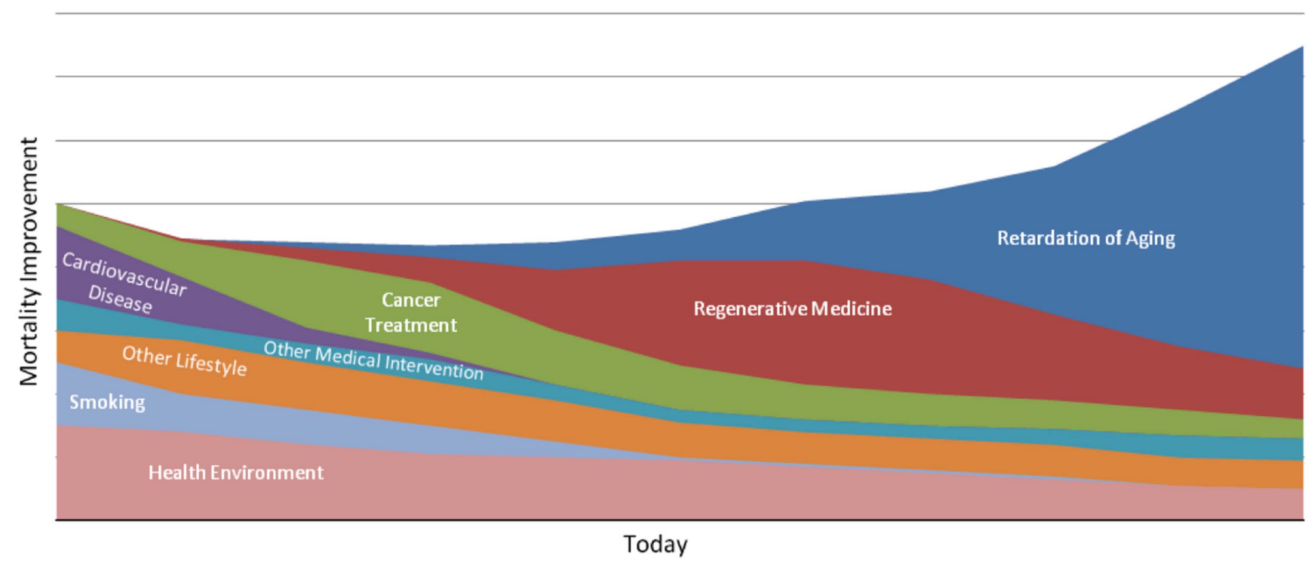

Figure 13. Timeline into the future

Note: Structural modelling of medical-based mortality improvement explores the timing, magnitude and impact of different phases of new medical advances on the horizon.

Source: RMS (2010) "Longevity Risk."

9.4.2. In 2012, RMS launched a series of mortality indices and models via a platform called RMS LifeRisks. The platform allows life insurance companies and pension funds in the UK, the USA, France, Germany, Holland and Canada to model and manage their exposure to longevity and mortality risks, taking into account recent medical research and social change projections. There are two principal models. ${ }^{81}$

9.4.3. The first model is the RMS longevity risk model. This is the base model used to project mortality and variations in mortality during normal conditions when there are no extreme mortality events. The projections depend on a number of so-called "vitagion categories" or individual sources of mortality improvement (see Figure 13). The five categories used by RMS are: lifestyle trends, including smoking prevalence; health environment; medical intervention; regenerative medicine, such as stem cell research, gene therapy and nanomedicine; and the retardation of ageing, including telomere shortening and caloric restriction.

9.4.4. The second model is the RMS infectious diseases model. This is used to estimate the additional mortality arising from the outbreak of certain infectious diseases, e.g. pandemic influenza. Both models were used in pricing the Kortis bond (see section 5.2) and an outbreak of something like influenza would be the most likely reason for the attachment point being reached during the life of the bond.

9.4.5. Academic researchers have recently begun experimenting with the introduction of causal variables in their mortality models (e.g. Hanewald, 2011; Gaille \& Sherris, 2011; Alai et al., 2014a; Villegas \& Haberman, 2014; Gourieroux \& Lu, 2015; Cairns et al., 2017a). Practitioners also started to use post code as a measure of socio-economic class (SEC) in their proprietary mortality models, especially for pricing annuities. An early example is Richards (2008).

${ }^{81}$ It is worth pointing out that, unlike the extrapolative or time series models, the RMS models have never been published or subject to independent peer review. 
9.4.6. In 2008, Club Vita, a UK longevity data and analytics company, was set up with the express purpose of improving the socio-economic modelling of mortality data, allowing the segmentation of projections by SEC. To illustrate, cancer mortality related to smoking (such as larynx, oropharynx, oral cavity and lung) is more commonly associated with the lowest SEC, while cancer mortality related exposure to the sun (malignant melanoma) is more commonly associated with the highest SEC. Segmented longevity trend models have improved in recent years as a result of new insights from medical science and a greater understanding of cause of death for each SEC. The benefits of this to a pension plan have been an improved (and sometimes lower) best estimate of life expectancy (due to a more accurate socio-economic breakdown of the plan's membership) with less uncertainty in the base table. The benefits to an insurer seeking new business have been refined pricing, better assessment of diversification, more effective risk selection, and increased competitiveness (Baxter \& Wooley, 2017). However, there is still an ongoing debate around using trend assumptions by SEC. For example, Jon Palin of Barnett Waddingham argues: "The evidence is less clear on the level of historical mortality improvements in pension schemes and other segments of the population, and to what extent a different assumption should be made for them." 82

9.4.7. The emergence of new multi-population datasets with socio-economic subdivisions is also beginning to offer much greater potential for the development of reliable and robust multipopulation models. For example, Cairns et al. (2017a) make use of Danish population data subdivided using a measure of affluence that combines wealth and income, and utilising this data, they develop a 10-population CBD-type stochastic model over the age range 55-94. With ten subpopulations to analyse, they avoid excessive model complexity by assuming a relatively simple model for correlations between sub-populations. A Bayesian framework is exploited to dampen the effect of sampling variation that is inherent in the ten relatively small sub-populations. It is anticipated that in the near future this and other datasets will become publicly available to allow researchers to develop alternative models, as well as further road-testing existing models.

\section{Applications of the Mortality Models}

\subsection{Overview}

In this section, we introduce some applications of the extrapolative mortality models introduced in the previous section: practical implementation of stochastic mortality models; determination of the longevity risk premium; estimating regulatory capital relief with a hedge in place; and comparison of alternative longevity risk management options. We begin by considering different types of users of these models.

\subsection{Users of Stochastic Mortality Models}

10.2.1. The following are potential users (directly or indirectly) of stochastic mortality models: insurers and reinsurers; regulators (e.g. the PRA); pension plans; specialist and general investors; actuaries and actuarial consultants; and software providers (e.g. Longevitas).

\footnotetext{
${ }^{82}$ http://www.theactuary.com/features/2017/08/mortality-improvements-in-decline/
} 
10.2.2. Insurers and reinsurers have a variety of reasons for using stochastic mortality models. Arguably, the principal reason is that they form part of an overall package of good enterprise risk management alongside stochastic models for other major risks, all augmented by a range of appropriate stress and scenario tests. Insurers can then use stochastic models to assess their economic capital requirements. Closely linked to this, many insurers are moving towards the use of stochastic models to assess regulatory capital requirements. For example, the PRA strongly encourages the use of stochastic mortality models with the standard one-year horizon under Solvency II (Prudential Regulatory Authority, 2015, 2016). Multi-population models also offer the potential for insurers to assess the diversification benefits resulting from exposure to different portfolios of lives (males/ females, smokers/non-smokers, assurances/annuities, multi-country, etc.), with subsequent reductions, for example, in regulatory capital. Lastly, insurers might wish to use stochastic models to compare different options for the management of longevity risk. Depending on in-house capability, insurers might develop their own suite of stochastic mortality models, or use external expertise. This might come in the form of ready-to-use mortality software that is employed in-house by appropriately trained staff, or by contracting external consultants to perform stochastic analyses.

10.2.3. Regulators will not, typically, be direct users of stochastic mortality models. However, they do need to be sufficiently knowledgeable in their use (including awareness of the assumptions and limitations of each model) in order to be able to assess how they are being used by life insurers. Additionally, they need to be able to give periodic guidance on the use of stochastic models, including which models are, or are not, acceptable (see, for example Prudential Regulatory Authority, 2015, 2016).

10.2.4. The acceptance of systematic longevity risk will, in general, form part of the core risk taking activity of an insurer up to a level that is consistent with its overall risk appetite. In contrast, acceptance of longevity risk is not generally part of the core business of the typical sponsor of an occupational pension plan (nor indeed is investment and interest-rate risk). Nevertheless, systematic longevity risk is present and therefore requires careful attention. Large pension plans have the resources to assess their exposure to longevity risk through the use of both stochastic modelling and deterministic scenarios: again as part of a wider programme of integrated risk management. As with insurers, this might be done in-house, but more often this would be a service provided by the plan's actuarial advisers. Smaller pension plans are less likely to have the financial resources to carry out a full stochastic assessment of longevity risk. However, there is the potential for the longevity risk research community to develop a small range of deterministic longevity scenarios (expressed as adjustments to the preferred best estimate forecast) that capture the essence of realistic extreme stochastic scenarios. On the other hand, consultancies now tend to have fairly streamlined processes for running off stochastic projections in order to illustrate the magnitude of each element of the longevity risk; these would typically be based on simplified pension benefits but would additionally reflect the most important aspects of the scheme, such as membership age, gender, and pension amounts. Such scenarios and projections should contrast favourably with the poorly formulated $20 \%$ stress test required under Solvency II (see Cairns \& El Boukfaoui, 2018). Models, therefore, can help plans determine appropriate target funding levels and contribution rates, as well as assess the risks associated with meeting these targets. Finally, as remarked earlier, use of stochastic models is recommended as a way to help choose between alternative longevity risk management options (including retention of the risk).

10.2.5. Pension plans also need to assess the potential future funding levels that might result from future uncertain investment returns, interest rate changes and changes in longevity. Stochastic 
mortality models can be used as part of a larger internal modelling exercise to assess uncertainty in funding levels. Larger plans will have the resources to carry out such an exercise. For smaller plans, stochastic models can again be used by actuarial consultants to generate a small number of deterministic extreme scenarios that can be applied to a range of smaller pension plans.

10.2.6. Specialist and general investors in longevity risk (e.g. ILS investors, hedge funds, private equity investors, sovereign wealth funds, endowments and family offices) and other receivers of longevity risk (e.g. reinsurers) are only likely to invest in this risk if it offers an acceptable risk premium, taking into account the low correlation between longevity risk and financial market risks and hence the potential diversification benefits from including longevity-linked products in an investment portfolio. This will be reflected in the price of the transaction at the outset relative to a best estimate or expected value. A rigorous approach to this requires a set of stochastic models to assess how much risk there is around the expected payoff. ${ }^{83}$ In a competitive market, the size of the risk premium will reflect each potential investor's other exposures: for example, a reinsurer might be satisfied with a lower risk premium for longevity risk if they have offsetting life assurance exposures.

\subsection{Practical Implementation of Stochastic Mortality Models}

10.3.1. It is common practice in the UK to use different methodologies for setting central forecasts and for risk assessment around that central forecast. For example, life insurers might use the CMI_2016 model (formally known as the CMI mortality projection model, calibrated using data up to 2016) to frame their central forecast and calculate best estimate liabilities. They then follow PRA guidelines (Prudential Regulatory Authority, 2015, 2016) and use stochastic mortality models to assess, proportionately, how much risk there is around that best estimate (Cairns et al., 2017b). The use of CMI_2016 allows users some control over future improvement rates and, in key elements, requires the exercise of sound judgement (e.g. in setting the long-term rate of improvement). This contrasts with the more objective statistical approach prevalent in stochastic mortality modelling. Under the stochastic approach, the central forecast is determined by: the choice of model; the choice of time series model (or equivalent) for forecasting period and cohort effects; and the historical calibration period. These elements are ones that can be chosen objectively using standard statistical methods (see, for example Cairns et al., 2009; Richards et al., 2017). No further judgement is required once these selections have been made.

10.3.2. Current research is attempting to close the gap between the two approaches. For example, Richards et al. (2017) focus on the Age Period Cohort Improvements (APCI) model that underpins the historical calibration of the CMI_2016 model, and propose a coherent stochastic approach for forecasting. On the other hand, Cairns et al. (2017b) discuss an approach that closes the gap between the CMI central forecast and the mean trajectory under the objective statistical approach. This involves giving the user some control over setting the short and long term central trends in the period and cohort effects in a stochastic model. With some minor constraints applied to the historical calibration of the CMI model, the adapted stochastic model and the CMI_2016 projections can produce consistent central forecasts, allowing users to place greater reliance on the outputs of the stochastic model.

${ }^{83}$ In order to deal with model risk. 


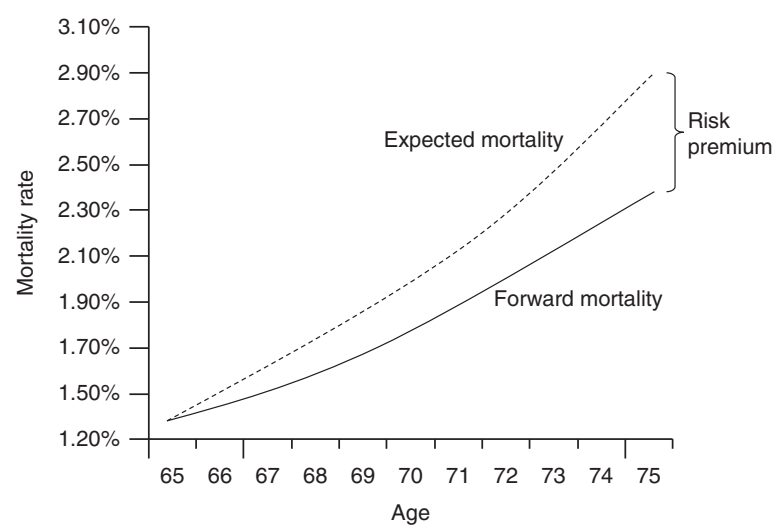

Figure 14. Cohort expected and forward mortality rate curves for a cohort currently aged 65 and $q$-forward maturity at age 75

Note: Lines are illustrative only.

Source: Adapted from Loeys et al. (2007, Chart 9).

\subsection{Determining the Longevity Risk Premium}

10.4.1. As just discussed, the provider of any longevity hedge requires a premium to assume longevity risk. This means that the forward rate agreed at the start of any $q$-forward contract will be below the anticipated (expected) mortality rate on the maturity date of the contract. Similarly, the implied forward life expectancy in any longevity swap will be higher than the anticipated (expected) life expectancy. Figure 14 shows a typical relationship between the expected and forward mortality rate curves and the risk premium for a particular cohort currently aged $65 .{ }^{84}$ Figure 15 shows the same for a particular age (in this case 65-year-old English \& Welsh males) for years 2005-2025: the further into the future, the more uncertainty there is in the mortality rate and the bigger the risk premium.

10.4.2. As remarked above, a stochastic model can be used to assess how much uncertainty there is in the underlying hedge instrument, and then this information can be used to determine an appropriate risk premium. There are different approaches to setting the price, for example: discounting the expected payoff at an appropriate risk-adjusted discount rate that reflects the assessed level of risk; or calculating a risk-adjusted expected payoff prior to discounting at the risk-free rate. When applied to the pricing of multiple contracts, not all frameworks will produce consistent prices over a range of contracts and maturities. However, the method of risk adjustment proposed by Cairns et al. (2006) using an explicit market price of risk for each period effect and for each year is one that does guarantee pricing consistency. This can be used to determine what might be thought of as midmarket prices, around which participants in the market can set buying and selling prices that reflect the degree of market illiquidity.

${ }^{84}$ Loeys et al. (2007) relate the forward mortality rate to the expected mortality rate through the formula $q^{f}=(1-T \cdot \gamma \cdot \sigma) q^{e}$, where $q^{f}$ is the forward mortality rate, $q^{e}$ is the expected mortality rate, $T$ is the time to maturity, $\sigma$ is the volatility (annualised standard deviation) of changes in the mortality rate, and $\gamma$ is the annualised Sharpe ratio required by the counterparty (sometimes also referred to as the market price of risk). 


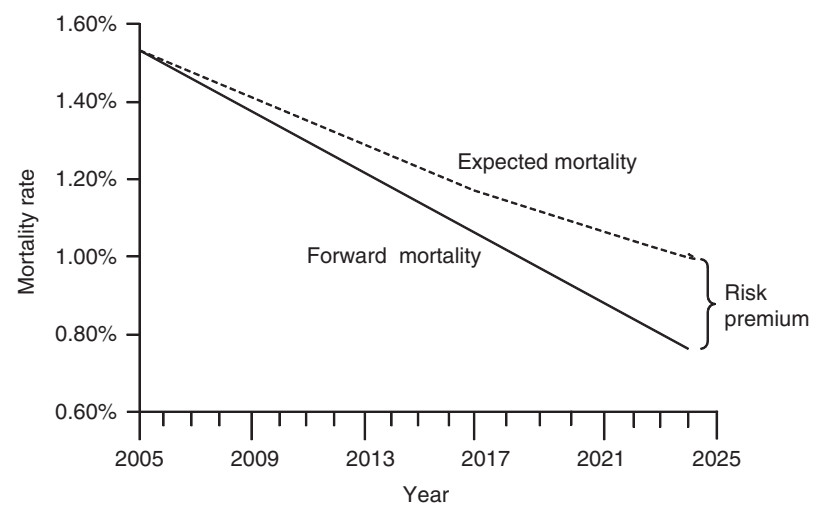

Figure 15. Expected and forward mortality rate curves for 65-year-old English \& Welsh males, 2005-2025

Note: Lines are illustrative only.

Source: Adapted from Coughlan (2007a).

\subsection{Estimating Regulatory Capital Relief}

10.5.1. In section 7.2 above, we discussed regulatory capital. Under Solvency II, an insurer's regulatory capital can be reduced if its liabilities are appropriately hedged.

10.5.2. This necessitates bringing the relevant regulatory authority on board sooner rather than later, as experience in the Netherlands shows. The Dutch financial regulator, the Dutch National Bank (DNB), assesses longevity hedges on a case-by-case basis. A particular case is insurance, pensions and investments firm Delta Lloyd's two index-based longevity hedges. ${ }^{85}$ Delta Lloyd had its Solvency II capital ratio reduced by 14 percentage points at the end of 2015 following "intense discussions." This was due to a disagreement with the DNB about the inclusion of risk margin relief on the two longevity hedges beyond the duration of the hedges. The DNB treats an index-based hedge as a financial instrument, whereas it treats a customised hedge as a reinsurance contract. It wanted the index-based hedges to be restructured to "ensure reinsurance treatment," otherwise Delta Lloyd faced a further 7 percentage points deduction from its Solvency II ratio.

10.5.3. In June 2016, the DNB clarified its position. It agreed that for an index-based swap, capital relief will be proportional to the risk transfer. However, it felt that some previous index-based deals had been of too short duration, too out-of-the-money and not a good match for actual liabilities. ${ }^{86}$

10.5.4. A detailed account of how to calculate regulatory capital relief in a longevity hedge can be found in Cairns and El Boukfaoui (2018). ${ }^{87}$ They describe a flexible framework that blends practical

85 See section 11 below.

86 See: Pigott \& Walker (2016); Solvency II Troubleshoot: Longevity Swaps and Risk Margin Relief, InsuranceERM, 17 May 2016; https://www.insuranceerm.com/analysis/solvency-ii-troubleshoot-longevityswaps-and-risk-margin-relief.html

87 With or without regulatory capital requirements, their methodology can be applied equally well (and, arguably, more cleanly) to economic capital relief using an insurer's own economic capital framework and risk appetite. 
issues with current academic modelling work. Key elements include careful assessment of basis risk, subdivided into population basis risk and other sources. They then consider a specific longevity hedge with a call option spread payoff structure and analyse the impact on regulatory capital. A key conclusion is that the balance between population basis risk and other sources of basis risk (especially structural basis risk) is highly dependent on the exhaustion point of the underlying option. For example, in a Solvency II setting, if the exhaustion point is close to the $99.5 \%$ quantile of the underlying risk, the recognition of population basis risk can have a significant effect on the regulatory capital required. In contrast, if the exhaustion point is somewhat below the $99.5 \%$ quantile (e.g. 95\%), then population basis risk has a negligible impact on the amount of regulatory capital relief. ${ }^{88}$ In the latter case, therefore, the index-based hedge acts in a very similar way to a reinsurance arrangement with similar attachment and exhaustion points in terms of its impact on regulatory capital. The authors conclude that hedgers need to consider carefully the terms of an index-based hedge (in the case considered, the attachment and exhaustion points and the maturity date), to ensure the best outcome. Further, in light of the evidence in the previous two paragraphs, insurers should discuss their plans with their local regulator before proceeding with a hedge. Bearing this in mind, Cairns \& El Boukfaoui (2018) outline a clear set of steps that can be used to document regulatory capital relief calculations with the recommendation that these steps be followed as a way to facilitate discussions with local regulators. This includes a requirement to document clearly the structure of the two-population stochastic mortality model, how this is calibrated, how death rates get extrapolated to high ages, and how central forecasts will be determined at future valuation dates incorporating new information up to that valuation date.

\subsection{Comparison of Risk Management Options}

Good risk management practice includes consideration of a variety of viable options for reducing exposure to longevity risk, and stochastic models have a key quantitative role, alongside qualitative criteria, in the process that leads to choosing one option over another. Cairns (2014) outlines some of the issues. The stochastic model can be used in a consistent way to evaluate a hedger's longevity risk profile with and without each of the hedging options in place. The range of options itself might be constrained by the size of the liability to be hedged (for example customised longevity swaps have typically been restricted to larger pension plans) but should, in the first instance, include both customised and index-based hedges. Any analysis should also take into account a hedger's exposure to idiosyncratic risk. Once residual risk has been evaluated, the hedger is then in a position to compare the different options. This should take into account the hedger's general risk appetite as well as the underlying premium for a hedge (section 10.4) and future requirements for adjustments to the hedge (e.g. a buy-in used prior to a full buy-out). Cairns (2014) discusses, in a stylised fashion, how these multiple inputs can result in different final decisions: one size does not fit all. ${ }^{89}$

${ }^{88}$ For the examples in Cairns \& El Boukfaoui (2018) if the exhaustion point is at the 99.5\% quantile, the inclusion of population basis risk can reduce regulatory capital relief by around $15 \%$ to $20 \%$. In contrast, if the exhaustion point is at the $95 \%$ quantile, the impact on regulatory capital relief of population basis risk is effectively zero as the hedge always pays off in full in the most extreme $0.5 \%$ of scenarios.

89 For example, a highly risk averse hedger will normally opt for a customised hedge, whereas a hedger with a greater appetite for risk might favour an index-based hedge if the price is right. 


\section{Developments in the Longevity Risk Transfer Market Since 2006}

11.1. As mentioned at the beginning of this article, the global longevity de-risking market began in the UK in 2006. Prior to this time, the UK market was dominated by two life assurers, Prudential ${ }^{90}$ and L\&G, which did business of approximately $£ 2$ bn a year across a large number of small transactions. The total potential size of the UK market alone is around $£ 2.7 \operatorname{trn}$ (on a buy-out basis) and this encouraged a raft of new players, in particular mono-line insurers, to enter the market. ${ }^{91}$ The first of these was Paternoster, but others quickly followed including Pension Insurance Corporation (PIC), Synesis ${ }^{92}$ and Lucida, ${ }^{93}$ all of which were backed by investment banks and private equity investors. In 2007, Goldman Sachs established its own pension insurer, Rothesay Life. Paternoster ${ }^{94}$ executed the first buy-out in November 2006 of the Cuthbert Heath Family Plan, a small UK plan with just 33 members. It also executed the first pensioner buy-in with Hunting PLC in January 2007.95

11.2. The world's first publicly announced longevity swap between Swiss Re and the UK life office Friends' Provident in April 2007 (although this was structured as an insurance or indemnification contract rather than a capital market transaction). 2007 also saw the release of the LifeMetrics Indices covering England \& Wales, the US, Holland and Germany by J. P. Morgan, the Pensions Institute and Willis Towers Watson (WTW) (then Towers Watson). ${ }^{96}$ Xpect Age and Cohort Indices were launched in March 2008 by Deutsche Börse. ${ }^{97}$ These indices cover, respectively, life expectancy at different ages and survival rates for given cohorts of lives in England \& Wales, the USA, Holland and Germany and its regions. The purpose of these indices is to provide a benchmark for the trading of longevity-linked instruments. In 2009, longevity swaps began to be offered to the market based on Deutsche Börse's Xpect Cohort Indices.

11.3. The world's first capital market derivative transaction, a $q$-forward (or mortality forward) contract, ${ }^{98}$ between J. P. Morgan and the UK pension fund buy-out company Lucida, took place in January 2008. The world's first capital market longevity swap was executed in July 2008: Canada Life hedged $£ 500 \mathrm{~m}$ of its UK-based annuity book (purchased from the defunct UK life insurer Equitable Life). This was a 40-year swap customised to the insurer's longevity exposure to 125,000 annuitants. The longevity risk was fully transferred to investors, which included hedge funds and ILS funds. J. P. Morgan acted as the intermediary and assumes counter-party credit risk. In August 2011, ITV, the UK's largest commercial TV producer, completed a $£ 1.7 \mathrm{bn}$ bespoke longevity swap with Credit Suisse for its $£ 2.2 \mathrm{bn}$ pension plan: the cost of the swap is reported as $£ 50 \mathrm{~m}(3 \%$ of the notional swap value). ${ }^{99}$ In February 2010, Mercer launched a pension buy-out index for the UK to

90 We will use Prudential to refer to the UK-based insurer.

91 The timing was motivated by a number of external factors, such as a strengthened funding standard, increased accounting transparency of pension liabilities on corporate balance sheets, the establishment of the PPF with risk-based levies that depended on the size of plan deficits, and the beginning of the closure of defined benefit pension plans.

92 Acquired by PIC in 2008.

93 Acquired by L\&G in 2013.

94 Acquired by Rothesay Life in 2011.

95 See Appendix A for a list of publicly announced UK buy-ins above $£ 100 \mathrm{~m}$ between 2007 and 2016 .

96 Coughlan et al. $(2007 \mathrm{c})$.

97 www.deutsche-boerse.com/xpect_e

98 Coughlan et al. (2007b).

99 https://www.professionalpensions.com/professional-pensions/news/2104113/gbp17bn-itv-deal-predictedspark-longevity-swaps-surge 
track the cost charged by insurance companies to buy out corporate pension liabilities: at the time of launch, the cost was some $44 \%$ higher than the accounting value of the liabilities, ${ }^{100}$ which highlights the attraction of using cheaper alternatives, such as longevity swaps, to transfer longevity. ${ }^{101}$

11.4. On 1 February 2010, the Life and Longevity Markets Association (LLMA) was established in London. Its current members are Aviva, AXA, Deutsche Bank, J. P. Morgan, Morgan Stanley, Prudential, and Swiss Re. LLMA was formed to promote the development of a liquid market in longevity- and mortality-related risks.

11.5. This market is related to the ILS market and is also similar to other markets with trend risks, e.g. the market in inflation-linked securities and derivatives. LLMA aims to support the development of consistent standards, methodologies and benchmarks to help build a liquid trading market needed to support the future demand for longevity protection by insurers and pension funds. In April 2011, the LifeMetrics indices were transferred to LLMA with the aim of establishing a global benchmark for trading longevity and mortality risk.

11.6. In December 2010, building on its successful mortality catastrophe Vita bonds and taking into account the lessons learned from the failed EIB/BNP longevity bond, Swiss Re launched an 8-year longevity-spread bond valued at $\$ 50 \mathrm{~m}$. To do this, it used a special purpose vehicle, Kortis Capital, based in the Cayman Islands. As with the mortality bonds, the longevity-spread bonds are designed to hedge Swiss Re's own exposure to mortality and longevity risk. In particular, holders of the bonds face a reduction in principal if there is an increase in the spread between mortality improvements in 75-85-year-old English \& Welsh males and 55-65-year-old US males, indicating that Swiss Re has life insurance (mortality risk) exposure in the USA and pension (longevity risk) exposure in the UK. ${ }^{102}$

11.7. The world's first longevity swap for non-pensioners (i.e. for active and deferred members of a

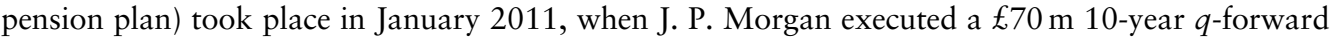
contract with the Pall (UK) pension fund. This was a value swap designed to hedge the longevity risk in the value of Pall's pension liabilities, rather than the longevity risk in its pension payments as in the case of cash flow swaps - which have been the majority of the swaps that have so far taken place. Longevity risk prior to retirement is all valuation risk: there is no cash flow risk and most of the risk lies in the forecasts of mortality improvements at specific future valuation dates. Further, the longevity exposure of deferreds is not well defined as a result of the options that plan members have.

11.8. In 2011, WTW introduced the pension captive structure. A plan executes a pensioner buy-in with a standard insurer, ${ }^{103}$ but then the insurer reinsures the buy-in with a captive insurer owned by

100 https:/www.uk.mercer.com/newsroom/global-buyout-index.html. In October 2017, the cost was 39\% higher (Mercer Global Pension Buyout Index December 2017, https://www.mercer.com/content/dam/mercer/ attachments/global/Retirement/monthly-report/gl-2017-mercer-global-pension-buyout-index-december.pdf)

101 The buy-out offloads all risks (i.e. including investment, inflation, interest rate and longevity risks) which explains, in part, the higher costs. A closer comparison to a longevity swap is a buy-in, since both just offload longevity risk. In October 2017, the cost of a buy-in was $13 \%$ higher than the accounting value of the liability and $7 \%$ higher than the funding value of the liability, reflecting the way that funding assumptions are generally closer to best-estimate than accounting assumptions (Mercer Global Pension Buyout Index December 2017).

102 The Kortis bond was analysed in section 5.2 above and in more detail in Hunt \& Blake (2015).

103 The standard insurer needs to be UK regulated, the captive is off-shore; the standard insurer will have the modelling skills etc, while the captive is effectively an empty shell. 
the sponsor. Captives can provide a cost-effective solution compared with either a traditional buy-in or directly running the plan over the longer term. This is because there can be a more efficient blending of investment management services with insurance, combined with a more effective disaggregation of risks and hence a more capital-efficient management of those risks. The first plan to use this structure was Coca Cola in 2011 (Willis Towers Watson, 2017).

11.9. In December 2011, Long Acre Life entered the market to offer cheaper pension insurance solutions to larger plans with liabilities above $£ 500 \mathrm{~m}$. Under these solutions, companies offload their pension plans to an insurance vehicle in which they also invest and so share the profits along with external investors: the target return is $15 \%$ p.a. ${ }^{104}$ In January 2012, L\&G began offering longevity insurance (in the form of deferred buy-ins) for the 1,000 or so smaller plans with liabilities in the range $£ 50-£ 250 \mathrm{~m}$. In February 2012, UK pension consultant Punter Southall adopted PensionsFirst's pension liability and risk management software (PFaroe) to automate the production of actuarial valuations and hence cut costs for pension plans, particularly small ones. In the same month, another UK consultant Hymans Robertson, launched a pension de-risking monitoring service which compares the costs of a full buy-out with the costs of a buy-in covering only pensioner members and the costs of a longevity swap.

11.10. The first pension risk transfers deals outside the UK took place in 2009-11. The first buy-in deal outside the UK was in 2009 in Canada; it was arranged by Sun Life Financial and valued at C\$50 m. The first buy-in deal in Europe was in December 2010 between the Dutch food manufacturer Hero and the Dutch insurer Aegon (€44 m). The first buy-in deal in the USA (valued at $\$ 75 \mathrm{~m}$ ) took place in May 2011 between Hickory Springs Manufacturing Company and the Prudential Insurance Co of America (PICA). ${ }^{105}$ The first buy-out deal outside the UK was announced in May 2011 and involved the C\$2.5bn Nortel pension plan in Canada. In September 2011, CAMRADATA Analytical Services launched a new pension risk transfer (PRT) database for US pension plans. The database provides insurance company organisational information, pension buy-in and buy-out product fact sheets and screening tools, pricing data, up-to-date information on each PRT provider's financial strength and relevant industry research. Users can request pension buy-in and buy-out quotes directly from providers, including American General Life Companies, MetLife, Pacific Life, Principal Financial Group, PICA, Transamerica and United of Omaha.

11.11. The first international longevity reinsurance transaction took place in June 2011 between Rothesay Life (UK) and PICA (US) and was valued at $£ 100 \mathrm{~m}$. The first life book reinsurance swap since the Global Financial Crisis of 2007-2008 also took place in June 2011 between Atlanticlux and institutional investors and was valued at $€ 60 \mathrm{~m}$.

11.12. In February 2012, Deutsche Bank (through its insurance subsidiary Abbey Life) executed a huge $€ 12$ bn index-based longevity swap for insurer Aegon in the Netherlands. This solution was based on Dutch national population data and enabled Aegon to hedge the liabilities associated with a portion of its annuity book (of €30bn). Deutsche Bank pays floating payments associated with the realised mortality rates of the reference index, but these payments are capped and floored. Aegon pays fixed premiums. The maturity of the swap is 20 years. A commutation mechanism determines

104 This proposition failed to attract sufficient commercial interest and the company was dissolved in January 2016.

105 We will use PICA to refer to the US-based insurer, which is a Prudential Financial, Inc. company, as well as Prudential Retirement and Prudential Retirement Insurance and Annuity Company (PRIAC). 
the payment at maturity - the mechanism is designed to provide longevity protection for liability cashflows occurring beyond the 20 -year maturity point. The swap has the structure of a series of call option spreads each with a long out-of-the money call at a strike price (or floor) and a short out-ofthe money call at a higher strike price (or cap). Because the swap began deep out of the money (i.e. the floor is considerably higher than initial mortality rates), the amount of longevity risk actually transferred is far less than that suggested by the $€ 12$ bn notional amount. Nonetheless, the key driver for this transaction from Aegon's point of view was the reduction in regulatory capital it achieved. Most of the longevity risk has been passed to investors in the form of private bonds and swaps. ${ }^{106}$

11.13. In June 2012, General Motors Co. (GM) announced a massive deal to transfer up to $\$ 26 \mathrm{bn}$ of pension obligations to PICA. This is by far the largest ever pension and longevity risk transfer deal globally. The transaction is effectively a partial pension buy-out involving the purchase of a group annuity contract for GM's salaried retirees who retired before 1 December 2011 and refused a lump sum offer in 2012. To the extent retirees accepted a lump sum payment in lieu of future pension payments, the longevity risk was transferred directly to the retiree. ${ }^{107}$ The deal was classified as a partial buy-out rather than a buy-in because it involved the settlement of the obligation. In other words, the portion of the liabilities associated with the annuity contract will no longer be GM's obligation. Moreover, in contrast to a buy-in, the annuity contract will not be an asset of the pension plan, but instead an asset of the retirees. In October 2012, Verizon Communications executed a $\$ 7.5$ bn bulk annuity buy-in with PICA. The total buy-out deals market in the USA in 2012 amounted to $\$ 36 \mathrm{bn}$.

11.14. The UK buy-outs for private sector pension plans had all involved plans that were closed to future accrual. However, in March 2012, PIC executed the first buy-out of a plan open to future accrual: the sponsoring employer, the high-tech manufacturer Denso, will pay PIC an annual premium based on the number of active members and their salaries, but PIC will assume all the liabilities. PIC had previously conducted an innovative buy-in in May 2011 with the London Stock Exchange's DB pension plan which not only insured current pensioner members, but will also automatically insure active and deferred members when they reach retirement.

11.15. In June 2012, the OECD released the first edition of Pensions Outlook. This called on governments to kick-start the creation of a functioning longevity risk market and consider issuing longevity bonds, without which the annuity market is unlikely to work well. In September 2012, Swiss Re Europe released a report entitled A mature market: building a capital market for longevity risk. The report called for the development of a capital market for longevity risk. It said that "Society's longevity risk could be tackled to a greater extent if reinsurers were able to expand their capacity, and this could be done by encouraging capital market investors to invest in longevity instruments. ... The main challenges include achieving transparency in measuring the risk and potential liability, building a secondary market, increasing investor education, providing the right level of return and regulation."108

11.16. In December 2012, the enhanced buy-in market opened for business in the UK for DB pension plans. An enhanced buy-in is where a plan's trustees buy a group annuity as an investment of the plan, where some or all of the members covered by the policy are medically underwritten. Medical

\footnotetext{
106 https://www.cass.city.ac.uk/_data/assets/pdf_file/0008/141587/Sagoo_Douglas_presentation.pdf

107 In fact, the lump sum was only offered to limited cohorts of plan members.

108 http://www.swissre.com/media/news_releases/nr_20120924_capital_market_longevity.html
} 
underwriting, which is now commonplace in the individual annuity market (i.e. in relation to DC pensions), has the potential to reduce the cost to the plan of the longevity hedge compared with standard annuities, on the grounds that certain members might have lower than average life expectancy as a result of their lifestyle or some serious life-shortening illness. The market was introduced by two specialist insurers, Partnership and Just Retirement, but other larger insurers followed, e.g. L\&G which offers a Large Individual Defined Benefit Annuity (LIBDA) service.

11.17. In February 2013, the first medically underwritten bulk annuity (MUBA) transaction was executed in the UK by Partnership (Harrison \& Blake, 2013). This involved each member filling in a medical questionnaire in order to get a more accurate assessment of their life expectancy based on their medical history or lifestyle. This was particularly useful in the case of "top slicing," where plan trustees insure the pensioners (who will typically be the company directors) with the largest liabilities and who therefore represent a disproportionate risk concentration for the plan. In December 2014, Partnership executed a $£ 206 \mathrm{~m}$ medically underwritten bulk annuity transaction with a top slicing arrangement for the $£ 2$ bn Taylor Wimpey pension plan. L\&G transacted a $£ 230 \mathrm{~m}$ medically underwritten buy-in in December 2015 with the Kingfisher Pension Scheme, covering 149 high-value members. The process of collecting medical information has been streamlined in recent years using third-party medical data collectors, such as MorganAsh, Age Partnership and Aon's AHEAD platform - the first two of which also perform MUMS (medically underwritten mortality studies). New business more than doubled from $£ 540 \mathrm{~m}$ in 2014 to $£ 1,200 \mathrm{~m}$ in 2015 , i.e. from $5 \%$ to $12.5 \%$ of the market (Hunt \& Blake, 2016). In April 2016, the two largest UK medical underwriters, Partnership and Just Retirement - which both entered the market in 2012 - merged to form Just valued at $£ 16$ bn. In December 2016, Just executed a $£ 110$ m medically underwritten buy-in with the Land Securities Group of Companies’ DB pension fund.

11.18. In April 2013, L\&G reported its first non-UK deal, the buy-out of a $€ 136 \mathrm{~m}$ annuity book from New Ireland Life. In June 2013, the Canadian Wheat Board executed a C $\$ 150 \mathrm{~m}$ pension buyin from Sun Life of Canada, involving inflation-linked annuities, while in March 2014, an unnamed Canadian company purchased $\mathrm{C} \$ 500 \mathrm{~m}$ of annuities from an insurer reported to be Industrial Alliance, making it the largest ever Canadian pension risk transfer deal to date.

11.19. In August 2013, Numerix, a risk management and derivatives valuation company, introduced a new asset class called "life" on its risk modelling platform (in addition to equities, bonds and commodities).

11.20. In September 2013, UK consultant Barnett Waddingham launched an insurer financial strength review service which provides information on an insurer's structure, solvency position, credit rating, and key risks in their business model. This service was introduced in response to concerns about the financial strength of some buy-out insurers.

11.21. In November 2013, SPX Corp. of Charlotte, NC, purchased a buy-out contract with Massachusetts Mutual Life Insurance Co. as part of a deal that moved $\$ 800 \mathrm{~m}$ in pension obligations off SPX's balance sheet.

11.22. Also in November 2013, Deutsche Bank introduced the Longevity Experience Option (LEO). It is structured as an out-of-the-money bull call option spread on 10-year forward survival rates and has a 10-year maturity. The survival rates are based on males and females in five-year age cohorts (between 50 to 79) derived from the England \& Wales and Netherlands LLMA longevity indices. 
LEOs are traded over-the-counter under a standard ISDA contract. They allow longevity risk to be transferred between pension funds, insurance companies and investors. They are intended to provide a cheaper and more liquid alternative to bespoke longevity swaps which are generally costly and time consuming to implement. Purchasers of the option spread, such as a pension fund, will gain if realised survival rates are higher than the forward rates, but the gains will be limited, thereby providing some comfort to the investors providing the longevity hedge. The 10-year maturity is the maximum that Deutsche Bank believed investors will tolerate in the current stage in the development of a market in longevity risk transfers. It was reported that Deutsche Bank executed its first LEO transaction with an ILS fund in January $2014 .{ }^{109}$

11.23. In December 2013, Aegon executed a second longevity risk transfer to capital markets investors and reinsurers, including SCOR. Société Générale was the intermediary in the deal covering liabilities of $€ 1.4 \mathrm{bn}$ and RMS was the modelling agent. The main difference with the Deutsche Bank hedge is that there will be a single payment by Société Générale to Aegon if the swap is in-the-money at maturity (see section 5.5).

11.24. Also in December 2013, the Joint Forum reported on the results of its consultation on the longevity risk transfer market. It concluded that this market is not yet big enough to raise systemic concerns, but "their massive potential size and growing interest from investment banks to mobilise this risk make it important to ensure that these markets are safe, both on a prudential and systemic level” (Joint Forum, 2013, p.2).

11.25. In February 2014, the Mercer Global Pension Buy-out Index was introduced. It shows the benchmark prices of 18 independent third-party insurers in four countries with significant interest in buying out DB liabilities: UK, USA, Canada and Ireland. Costs were highest in the UK where the cost of insuring $£ 100 \mathrm{~m}$ of pension liabilities was $123 \%$ of the accounting value of the liabilities ${ }^{110}$ equivalent to a price of $£ 32$ per $£ 1$ p.a. of pension (Towers Watson, 2015). The comparable costs in Ireland, the USA and Canada were $117 \%, 108.5 \%$ and $105 \%$, respectively. The higher cost in the UK is in part due to the greater degree of inflation uprating of pensions in payment in the UK compared with the other countries. The difference between the USA and Canada is explained by the use of different mortality tables. Rising interest rates (following the unwinding of global quantitative easing programmes) and equity markets will lower funding deficits and hence lead to lower buy-out costs in future, especially in the USA.

11.26. In July 2014, Mercer and Zurich launched Streamlined Longevity Solution, a longevity swap hedge for smaller pension plans with liabilities above $£ 50 \mathrm{~m}$. This is part of a new Mercer SmartDB service which provides bespoke longevity de-risking solutions and involves a panel of reinsurers led by Zurich. It reduces the costs by having standardised processes for quantifying the longevity risk in each pension plan. The first deal, valued at $£ 90 \mathrm{~m}$, was transacted with an unnamed UK pension plan in December 2015. A second deal - this time with the UK pension plan of the Italian tyre company Pirelli - was executed in August 2016 for $£ 600 \mathrm{~m}$.

109 https://www.professionalpensions.com/professional-pensions/news/2305081/deutsche-bank-launcheslongevity-swap-alternative; http://www.artemis.bm/blog/2013/11/04/first-longevity-experience-option-to-betraded-by-deutsche-bank-by-year-end/

110 Note from paragraph 11.3 above that the UK buy-out premium was 44\% in February 2010 and $39 \%$ in October 2017, indicating how volatile the premium can be and the importance of getting the timing of the buyout right to minimise costs. 
11.27. There is evidence of increasing demand from reinsurance companies for exposure to large books of pension annuity business to offset the risk in their books of life insurance. ${ }^{111}$ For example, in July 2014, Warren Buffett's Berkshire Hathaway agreed to a $£ 780 \mathrm{~m}$ quota-reinsurance deal with PIC. Similarly, in August 2014, Delta Lloyd executed a 6-year index-based longevity swap covering $€ 12$ billion of its longevity reserves with RGA Re, ${ }^{112}$ while AXA France executed a $€ 750$ m longevity swap with Hannover Re.

11.28. In March 2014, L\&G announced the biggest single buy-out in the UK to date when it took on $£ 3$ bn of assets and liabilities from ICI's pension plan, a subsidiary of AkzoNobel. The deal uses "umbrella" contracts which enables the plan to add further liabilities onto the original contract. ${ }^{113}$ In December 2014, L\&G announced the largest ever UK buy-in valued at $£ 2.5$ bn with US manufacturer TRW. In fact, in 2014, TRW became the first global corporation to simultaneously complete three de-risking transactions in three different countries: the UK, the USA and Canada. Also in 2014, the Aviva Staff Pension Scheme completed the first limited recourse longevity swap, involving $£ 5$ billion in liabilities and 19,000 participants.

11.29. Around $£ 13$ bn of bulk annuity deals were executed in the UK in 2014 , the largest volume of business since the de-risking market began in 2006 and beating the previous best year of 2008, just before the GFC, when $£ 7.9 \mathrm{bn}$ of deals were completed. The total volume of de-risking deals in the UK in 2014 alone (covering buy-outs, buy-ins and longevity swaps) was $£ 35 \mathrm{bn}$. Included in this sum is the UK's largest transaction to date, namely the longevity swap for the British Telecom (BT) Pension Scheme, covering $£ 16$ bn of pension liabilities, arranged by PICA in July 2014. To complete the transaction, the BT scheme created its own captive insurer located in Guernsey, which insured the longevity risk. The captive insurer then reinsured the risk in a fully collateralised arrangement with PICA. This was the world's first ever pension longevity captive transaction. Captive and limited recourse transactions have dominated the market since.

11.30. In December 2014, WTW launched Longevity Direct, an off-shore longevity swap hedging service that gives medium-sized pension plans with liabilities between $£ 1-3$ bn direct access to the reinsurance market, via its own cell (or captive) insurance company. This allows plans to bypass (or pass through) insurers and investment banks - the traditional de-risking intermediaries - and significantly reduces transactions costs and completion times, while still getting the best possible reinsurance pricing. The first reported transaction on the Longevity Direct platform was the $£ 1.5 \mathrm{bn}$ longevity swap executed by the Merchant Navy Officers Pension Fund (MNOPF) in January 2015 which was insured by MNOPF IC, a newly established cell insurance company based in Guernsey, and then reinsured with Pacific Life Re. In February 2015, PwC launched a similar off-shore longevity swap service for pension plans as small as $£ 250 \mathrm{~m}$. It uses a Guernsey-based incorporated cell company called Iccaria, established by Artex Risk Solutions, to pass longevity risk directly on to reinsurers. The arrangement is fully collateralised and each plan owns a cell within Iccaria which again avoids the costs of dealing with insurer and investment bank intermediaries. WTW also

111 The biggest buyers of longevity risk at the present time are global reinsurers. Nevertheless, according to Hannover Re: "The number of risk-takers is limited and there is not unlimited capacity in the market for taking on longevity risk. The increasing worldwide demand for longevity cover will challenge the capacity for securing longevity risk" (quoted in Punter Southall, 2015).

$112 \mathrm{http} / / /$ www.artemis.bm/blog/2014/08/22/delta-lloyd-in-eur-12-billion-index-based-longevity-swap-withrga-re/

113 By October 2016, the ICI plan had completed 11 such deals - with L\&G, Prudential (UK) and Scottish Widows - with a total value of $£ 8$ bn, saving the parent company over $£ 100 \mathrm{~m}$ in costs. 
introduced the first tracking software system to follow live insurer pricing, sending alerts when a plan closes in on a target price.

11.31. In response to the announcement by the UK finance minister (George Osborne) in his Budget Speech on 19 April 2014, that UK pension plan members no longer needed to buy annuities when they retired (which resulted in an immediate fall in annuity sales of more than $50 \%$ ), a number of traditional annuity providers, such as Scottish Widows, reported that they were considering entering the bulk annuity market.

11.32. In November 2014, the Longevity Basis Risk Working Group (2014) of the Institute \& Faculty of Actuaries (IFoA) and LLMA published Longevity Basis Risk: A Methodology for Assessing Basis Risk. ${ }^{114}$ This study develops a new framework for insurers and pension plans to assess longevity basis risk. This, in turn, will enable simpler, more standardised and easier to execute index-based longevity swaps to be implemented. Index-based longevity swaps allow insurers and pension plans to offset the systemic risk of increased liabilities resulting from members living longer than expected. It had hitherto been difficult to assess how effectively an index-based longevity swap could reduce the longevity risk in a particular insurance book or pension plan. The methodology they developed is applicable to both large plans (which are able to use their own mortality data in their models) and smaller plans (by capturing demographic differences such as socio-economic class and deprivation). In May 2016, a follow-up study - carried out by Macquarie University, Mercer Australia, and the University of Waterloo - was announced. The purpose was to design a "readily applicable methodology" for use with longevity risk indices: "Such indices are often used in pension benefits and annuitant liabilities, as well as in providing actuaries with key data, ... but the problem of the existence of basis risk remains unsolved." This follow-up study was published in December 2017 (Li et al., 2017). The report distinguishes between three types of basis risk (population, sampling and structural basis risk) and takes the proposed models in the 2014 report through to full analysis of hedge effectiveness. The report contains extensive numerical analyses that consider how hedge effectiveness depends on a range of input variables, including different book populations, size of book population, and type of hedge instrument, as well as the sensitivity to the underlying risk measure itself.

11.33. In March 2015, the UK government announced that it would introduce a new competitive corporate tax structure to allow ILSs to be domiciled in the UK. In May 2015, Rothesay Life, the insurance company owned by Goldman Sachs, bought out the liabilities of Lehman Brothers' UK pension plan for $£ 675 \mathrm{~m}$, thereby securing the pensions of former employees of the company associated with the beginning of the GFC.

11.34. In April 2015, Swiss Re Capital Markets led the issuance of $€ 285 \mathrm{~m}$ of excess mortality insurance-linked securities by Benu Capital Limited (Benu) on behalf of AXA Global Life. Swiss Re Capital Markets underwrote the transaction via two classes of principal-at-risk variable rate notes issued by Benu, an Irish private company incorporated with limited liability. The notes have a 5-year risk period starting on 1 January 2015. The proceeds of the notes each collateralise a counterparty contract with AXA Global Life, providing protection against excess mortality in France, Japan and the US via country age and gender weighted population mortality indices. It was the largest excess mortality issuance since $2007 .^{115}$

114 A version of this report was subsequently published as Villegas et al. (2017).

115 http://www.swissre.com/media/news_releases/nr_20150428_large_excess_mortality_issuance.html 
11.35. The largest buy-out to date in the UK was for the Philips Pension Fund which in November 2015 completed a full buy-out of the pension benefits of 26,000 members valued at $£ 2.4$ bn with PIC. An interesting feature of this deal was that a buy-out was combined with a longevity hedge. The longevity risk was simultaneously reinsured with Hannover Re. Another interesting feature was that it covered both retired and deferred members, with the latter's benefits valued at $£ 1 \mathrm{bn}$.

11.36. An important new longevity-linked product that recently took off in the UK was the equity release mortgage. This allows individuals to release equity in their homes to fund their retirement without downsizing. L\&G, for example, set up L\&G Home Finance for this purpose and in its first year completed more than $£ 400 \mathrm{~m}$ equity release mortgage sales. Since equity release contracts typically involve a no negative equity guarantee, ${ }^{116}$ the product provider is exposed to the risk that mortgagors live longer than expected.

11.37. In 2015, L\&G directly entered both the USA and European pension risk transfer markets. It executed a $\$ 450 \mathrm{~m}$ transaction with the US subsidiary of Royal Philips covering 7,000 plan members in October and a $€ 200 \mathrm{~m}$ deal with ASR Nederland NV, a Dutch insurer in December. The pension obligations were transferred to L\&G Re in cooperation with Hannover Re. L\&G said: "The pension risk transfer market has become a global business... The potential market for pension risk transfer in the US, UK and Europe is huge, and will play out over many decades.” Two US insurers were also involved in the Royal Philips deal: PICA acquired $\$ 450 \mathrm{~m}$ of plan liabilities covering another 7,000 members, while American United Life Insurance Company issued annuity contracts to 3,000 deferred plan members, valued at $\$ 200 \mathrm{~m}$.

11.38. In January 2015, the Bell Canada Pension Plan executed a C $\$ 5$ bn longevity swap with Sun Life Financial, ${ }^{117}$ SCOR, and RGA Re; it was SCOR's first transaction in North America. In the process, Canada became the first country apart from the UK to have all three pension risk transfer solutions actively in use. In the same year, it completed its first inflation-linked buy-in annuity transaction, while in 2017 it completed its first buy-in annuity covering active future benefits. ${ }^{118}$ In June 2015, Delta Lloyd did a second $€ 12$ bn longevity swap with RGA Re: the swap was also indexbased, with an 8-year duration and had a notional value of $€ 350 \mathrm{~m} .{ }^{119}$ In July 2015, Aegon did one valued at $€ 6$ bn with Canada Life Re, a new entrant to the de-risking market in 2015. Another new entrant was Scottish Widows.

11.39. In June 2015, the Mercer Pension Risk Exchange was launched. It gives clients in the USA, UK and Canada up to date buy-in and buy-out pricing based on their plan's data. It collects prices provided monthly by insurers in the bulk market, based on plan benefit structures and member data. Mercer said: "Many companies have the appetite to transfer pension risk off their balance sheet, but they face barriers: lack of clear information about the true cost of a buy-in or buy-out, limited transparency, the fluctuation of market rates and plan economics to name but a few. [The exchange will enable] sponsoring employers and trustees to be more strategic and sophisticated in their

116 That is, the amount that the individual or their estate (if the individual dies) needs to repay (i.e., amount borrowed plus accrued interest) cannot exceed the equity in the home.

117 Sun Life Financial uses the RMS Longevity Risk Model, which RMS describes as a 'structural meta-model of geroscience advancement'.

118 Eckler Consultants (2017) Pension Risk Transfer Report, November.

119 http://www.artemis.bm/blog/2015/06/26/delta-lloyd-rga-in-second-e12-billion-longevity-swap-deal/ 
approach and to know that they are executing a buy-in or a buy-out at the best time for them and at a competitive price."

11.40. In April 2016, WTW released PulseModel which uses medical science and the opinions of medical experts to improve longevity predictions. For example, the model predicts that $16 \%$ of 50 year-old men in the UK will develop type- 2 diabetes in the next 20 years, but this rises to $50 \%$ for those who are both obese and heavy smokers. Overall, the model predicts that longevity improvements in the future will be lower than currently predicted, at around $1 \%$ p.a. rather than $1.5 \%$. If this turned out to be correct, then the current price of longevity of risk transfer products would be too high.

11.41. In 2016 , there were a total of $£ 8.6 \mathrm{bn}$ in buy-outs and buy-ins and $£ 1.6 \mathrm{bn}$ in longevity swaps. $^{120}$

11.42. The largest buy-in in 2016 (in December) was Phoenix Life's $£ 1.2$ bn buy-in for the 4,400 pensioners in the PGL Pension Scheme, which is sponsored by the Phoenix Group, Phoenix Life's parent company. This replaced a longevity swap it had set up for the plan in 2014. This is the first example of a transaction which transforms a longevity swap into a bulk annuity. Phoenix Life saw this as an opportunity to bring $£ 1.2 \mathrm{bn}$ of liquid assets (mostly UK government bonds) onto its balance sheet, which could then be swapped into a higher yielding, matching portfolio, structured to maximise the capital benefit under Solvency II. This, in turn, meant that Phoenix Life would be assuming the market risks associated with the PGL scheme pension liabilities in addition to the longevity risks - and already does this on its existing book of individual annuities which are backed by $£ 12$ bn of assets. The timing was also critical. Phoenix wanted to ensure that its internal model under Solvency II had bedded down well and that the capital and balance sheet impacts of the transaction were well understood, and that Phoenix had elicited the full support of the PRA for the transaction, thereby ensuring execution certainty. Phoenix also provided comfort to the plan's trustees by giving them "all-risks" cover from point of buy-in ("all-risks" cover is not usually provided until buy-out) and strong collateral protection. ${ }^{121}$

11.43. 2016 saw the beginning of a trend towards consolidation amongst insurance companies involved in the longevity risk transfer business in the UK. For example, Aegon sold its $£ 9$ bn UK annuity portfolio to Rothesay Life ${ }^{122}$ and L\&G between April and May, as part of a strategy to free up capital from non-core businesses. Part of the reason for this is the additional capital requirements under Solvency II. ${ }^{123}$ Similarly, in September, Deutsche Bank sold its Abbey Life subsidiary to Phoenix Life - a consolidator of closed insurance books - for $£ 935 \mathrm{mn}$, as part of a planned programme of disposals aimed at restoring its capital base. There is an estimated $£ 100 \mathrm{bn}$ of UK individual annuities in back books and further consolidation of these back books is anticipated.

120 Pensionfundsonline, 15 December 2016.

121 Stephanie Baxter (2017) How PGL's longevity swap was converted into a buy-in, Professional Pensions, 10 April.

122 In August 2017, Goldman Sachs sold its remaining stake in Rothesay Life to a consortium comprising US buy-out firm Blackstone, Singapore's sovereign wealth fund GIC, and US life insurer MassMutual in a deal valuing Rothesay Life at around $£ 2$ bn; http:/www.cityam.com/269996/goldman-sachs-sells-final-stake-2bnrothesay-life

123 Solvency II has increased capital requirements and has reduced the attractiveness of annuities as a business line for certain insurers and raised buy-out prices by 5-7\% (Financial News, 28 March-3 April 2016). 


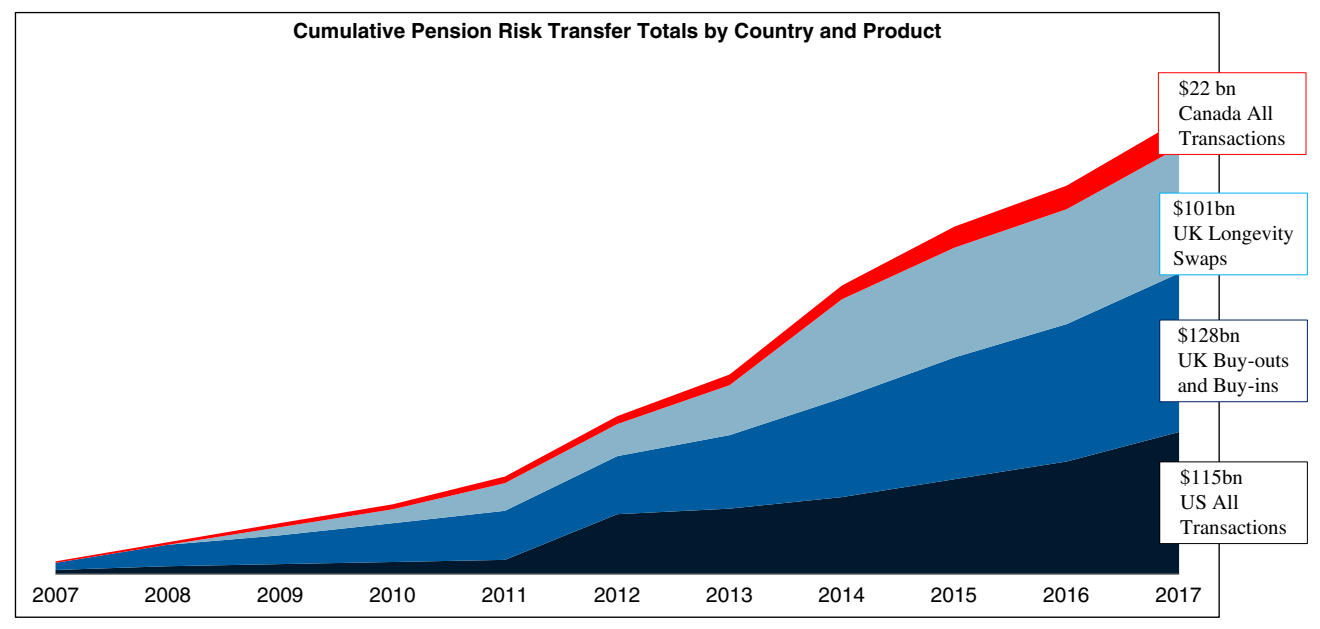

Figure 16. Cumulative pension risk transfers by product and country, 2007-17 Sources: LIMRA, Hymans Robertson, LCP and PFI analysis as of December 31, 2017.

In December 2017, L\&G sold its $£ 33$ bn closed book of traditional insurance-based pensions, savings and investment policies to the ReAssure division of Swiss Re for $£ 650 \mathrm{~m}$.

11.44. Solvency II has also been blamed for some companies pulling out of the bulk annuities market altogether, a key example being Prudential in January 2016. Prudential is reported to be selling a portion of its $£ 45$ bn UK annuity and pension liability businesses due to an inadequate return on capital and to transfer that capital to its growing businesses in Asia. ${ }^{124}$ Reinsurance deals have also increased in response to Solvency II, involving non-EU reinsurers. For example, PIC executed a $£ 1$.6bn longevity reinsurance agreement with PICA in June 2016.

11.45. 2016 also witnessed the increasing streamlining and standardisation of contracts. This is particularly beneficial to small plans below $£ 100 \mathrm{~m}$. Previously, smaller plans have been less attractive to insurers due to the higher costs of arranging such deals relative to the profit earned. To circumvent this, consultants have begun offering services that allow smaller plans to access improved pricing and better commercial terms using a standardised off-the-shelf process incorporating prenegotiated legal contracts. Pricing is more competitive because the insurer's costs are kept low. An example is WTW's Streamlined Bulk Annuity Service. The increasing maturity of the market has meant that some larger plans have also been prepared to use pre-negotiated contracts (Willis Towers Watson, 2017).

11.46. 2016 was also the tenth anniversary of the longevity transfer market. Since its beginning in the UK in $2006, £ 40$ bn of buy-outs and $£ 31$ bn of buy-ins have taken place in the UK, covering 1 million people. ${ }^{125}$ Yet this equates to just $5 \%$ of the $£ 1.5$ trn of UK DB pension assets and $3 \%$ of the $£ 2.7$ trn of DB pension liabilities on a buy-out basis. In addition, 48 longevity swaps are known to have been completed in the UK between 2007 and 2016, valued at $£ 75$ bn and covering 13 insurance companies' annuity and buy-out books, 22 private sector pension funds, and one local authority

124 https://www.ftadviser.com/pensions/2016/12/05/prudential-seeks-buyers-for-45bn-annuity-business/

125 LCP, Professional Pensions (15 December 2016 and 26 January 2017). Since 2007, some 92 buy-ins have been completed - see Table A1. 
pension fund (some of which executed more than one swap). ${ }^{126}$ Figure 16 shows the growth of the global market in longevity risk transfer between 2007 and 2017. A total of $\$ 366$ bn in transactions have been completed during this period.

11.47. At the beginning of 2017 , there were eight UK-domiciled insurers actively participating in the pension risk transfer market in the UK. The largest players are PIC and Legal \& General, with market shares of 37\% and 30\%, respectively. The others are Rothesay Life, Canada Life, Zurich, Scottish Widows, Standard Life, and new entrant Phoenix (since August). Occasionally, the insurers co-operate in a transaction. To illustrate, in August 2017, L\&G executed a longevity swap in respect of $£ 800 \mathrm{~m}$ of the pension liabilities of Scottish and Southern Energy (SSE), while PIC completed a $£ 350 \mathrm{~m}$ buy-in for the company. Consultant LCP estimated that $£ 12$ bn buy-ins and buy-outs took place in 2017 and predicts that $£ 15$ bn will take place in 2018 , with total insurer capacity at $£ 25$ bn: "There remains significant capacity and competition - even if a large back-book comes to market providing attractive opportunities for pension plans to transfer longevity risk through a buy-in or buy-out." 127

11.48. One of the largest deals in 2017 (September) involved a $£ 3.4$ bn longevity swap between the Marsh \& McLennan Companies (MMC) UK Pension Fund and both Canada Life Reinsurance and PICA, using Guernsey-based incorporated cell companies, Fission Alpha IC Limited and Fission Beta IC Limited. MMC subsidiary Mercer led the transaction as adviser to the pension fund trustee and the deal was the first to be completed using the Mercer Marsh longevity captive solution, with no upfront premium. The two reinsurers shared the risk equally and the use of the captive ICC vehicle meant that no insurer intermediary was required, making the deal more cost-effective for the pension fund. ${ }^{128}$ Also in September, the British Airways' Pension Scheme used a similar Guernsey-based captive insurer to set up a $£ 1$.6bn longevity swap. The longevity risk was then reinsured with Partner Re and Canada Life Re. The scheme had previously hedged $£ 2.6 \mathrm{bn}$ of liabilities through two longevity swap transactions executed by Rothesay Life in 2010 and 2011. ${ }^{129}$ In November 2017, PIC executed a $£ 900 \mathrm{~m}$ longevity swap with PICA, while in December 2017, L\&G executed a $£ 600$ m longevity swap with PICA. ${ }^{130}$

11.49. In December 2017, NN Life, part of the Nationale-Nederlanden Group, executed an indexbased longevity hedge with reinsurer Hannover Re, in a deal covering the insurer against the longevity trend risk in $€ 3 \mathrm{bn}$ of its liabilities. The structure is similar to the 2013 Aegon tail-risk deal arranged by Société Générale and builds on subsequent work including Michaelson \& Mulholland (2014) and Cairns \& El Boukfaoui (2018). While the term of the transaction is 20 years, NN Life is protected over a longer time period via a commutation function ${ }^{131}$ that applies at maturity. If

126 www.artemis.bm/library/longevity_swaps_risk_transfers.html; see Table A2 for a full list of UK publicly announced longevity swaps between 2007 and 2016.

127 https://www.lcp.uk.com/media-centre/press-releases/2017/08/buy-in-and-buy-out-volumes-nearly-double; LCP (2018) Pension De-risking 2018.

$128 \mathrm{http}: / / w w w . a r t e m i s . b m / b l o g / 2017 / 09 / 14 / \mathrm{mmc}-$ pension-offloads-huge-3-4bn-of-longevity-risk-to-reinsurers. The counter to this cost-effectiveness is that the hedger takes on additional counterparty risk. If a reinsurer fails then there is no insurer to protect the pension scheme.

129 Nick Reeve (2017) BA scheme uses 'captive insurer' in $£ 1.6$ bn longevity risk hedge, IPE, 13 September.

130 https://www.pensioncorporation.com/media/press-releases/Prudential, PIC Reach \$1.2 Billion Longevity Reinsurance Agreement; L\&G reinsures $£ 600 \mathrm{~m}$ of longevity risk through Prudential, Professional Pensions, 21 December 2017.

131 See paragraph 5.5.5. 
longevity improvements have been much stronger than expected, this will be assumed to continue until the liabilities run-off and NN will receive a payment under the hedge. The transaction helped to reduce the solvency capital requirement of NN's Netherlands life business by $€ 35 \mathrm{~m}$. The index attachment point for the hedge is close to NN's best estimate, which helps maintain the SCR relief and effective risk transfer over time. ${ }^{132,133}$

11.50. In April 2015, the UK government introduced "freedom and choice" pension reforms which gave more flexibility to how individuals could draw down their DC pension pots. In particular, there was no longer a requirement to purchase an annuity. ${ }^{134}$ This immediately led to a fall in annuity sales by more than $50 \%$. The situation was not helped by the fall in gilt yields (which led to a corresponding fall in annuity rates) arising from the government's quantitative easing programme introduced after the GFC. In August 2017, a 65-year old with a $£ 100,000$ pension pot, could get a level income for life of $£ 4,894$ : 2 years before, the amount would have been $£ 5,292 .{ }^{135}$ By 2017 , the following insurers had pulled out of the open market for annuities: Aegon, LV =, Partnership (before it merged with Just Retirement to form Just), Prudential, Standard Life, Friends Life (merged with Aviva), Reliance Mutual, B\&CE, and Retirement Advantage. This leaves just six providers left in what was once the world's largest annuity market: Aviva (offering standard and enhanced annuities), Canada Life (standard and enhanced), Hodge Lifetime (standard only), Just (enhanced only), Legal $\&$ General (standard and enhanced) and Scottish Widows (standard only). ${ }^{136}$

11.51. In order to reduce the costs of de-risking, pension plans are encouraged to perform some liability reduction exercises, the key ones being: ${ }^{137}$

- Enhanced transfer values (ETVs) - allow deferred members to transfer an uplifted value of their benefits to an alternative arrangement. In August 2017, a 64-year old entitled to an index-linked pension starting at $£ 10,000$ from age 65 would be offered a transfer value of $£ 237,000$, according to the Xafinity Tranfer Value Index. ${ }^{138}$

- Flexible retirement options (FROs) - allow deferred members aged 55 and over to retire early, or to take a transfer value and secure benefits in a different format from their plan benefits, or to use funds for drawdown purposes.

- Pension increase exchanges (PIEs) - allow pensioners to exchange non-statutory increases for a higher immediate pension with lower or even zero future increases (e.g. a $£ 10,000$ annual pension with RPI uplifting is replaced by a $£ 12,000$ annual pension with no further increases).

- Trivial commutations (TCs) - allow members with low value benefits to cash these in.

The most common exercises currently in the UK are PIEs and TCs - and these can be conducted either before or at the same time as a bulk purchase annuity broking exercise.

11.52. Innovation is a continuing feature of this market. Some examples include (see, e.g. Legal \& General \& Engaged Investor, 2016):

$132 \mathrm{http}: / / w w w . a r t e m i s . b m / b l o g / 2017 / 12 / 01 / \mathrm{nn}$-life-gets-index-based-longevity-hedge-from-hannover-re/

133 https://www.nn-group.com/Investors/Capital-Markets-Day-2017.htm

134 https://www.pensionsadvisoryservice.org.uk/about-pensions/pension-reform/freedom-and-choice

135 Josephine Cumbo, Pensioners hit as annuity rates drop 10\% in two years, Financial Times, 1 September.

136 Source: Hargreaves Lansdown, August 2017.

137 Professional Pensions (2016) Risk reduction and the extent of trust in pension scheme advisers and providers, June, p.26.

${ }^{138}$ Hannah Godfrey (2017) DB transfer values back on the rise in August, Professional Adviser, 7 September. 
- Buy-ins and buy-outs with deferred premium payments - to spread costs.

- Phased de-risking using a sequence of partial buy-ins with an "umbrella" structure to avoid more than one set of contract negotiations - to spread costs.

- Accelerated buy-ins - the insurer provides a loan to the plan equal to the deficit (sometimes called a winding up lump sum (WULS)), so that a partial buy-in can take place immediately, with this converting to a full buy-in when the loan has been repaid, with the option of a full buy-out at a later date.

- Forward start buy-ins - a standard buy-in with the start date delayed to reflect the level of funding available, with additional options, such as paying deferred members as and when they retire if this is prior to the start date, or the ability to bring forward the start date for an additional fee.

- Automated bulk plan transfers - to reduce risks (introduced in November 2017 by Scottish Widows and Standard Life). ${ }^{139}$

- Top-slice buy-ins - to target the highest value liabilities.

- Named-life longevity swap - if the named member lives longer than expected, the insurer pays out the difference (examples being the $£ 400 \mathrm{~m}$ Bentley plan or an unnamed plan with 90 named pensioners valued at $£ 50 \mathrm{~m}$ ).

- Tranching by age - to reduce costs; according to consultant Punter Southall, a buy-in for pensioners up to age 70 will make a subsequent buy-out within the following 10 years cheaper than a buy-in for the over $70 \mathrm{s.}{ }^{140}$

- Longevity swaps for small pension plans with liabilities of $£ 50-100 \mathrm{~m}$ - previously only available for medium ( $£ 100-500 \mathrm{~m})$ and large plans (above $£ 500 \mathrm{~m}$ ).

- Novation - the ability to transfer a longevity hedge from one provider to another, thereby introducing some liquidity into what had previously been a completely illiquid market. An example would be the reinsurance of a small bulk annuity transaction. Contract simplicity is a desirable feature of such arrangements.

- Longevity swap to buy-in conversions - as pioneered by Phoenix Life in December 2016 for its parent company's pension plan. Solvency II incentivises buy-in providers to hold longevity insurance, otherwise they pay an additional risk margin. This encourages buy-in providers to seek out plans which already have a longevity hedge and encourage them to do a buy-in. Another driver is longevity swap providers that are not currently active in the market - such as J. P. Morgan and Credit Suisse - but are still responsible for running off their existing swaps. They might have an incentive to encourage the associated pension plan to novate the swap to a buy-in provider and hence extinguish their liability. ${ }^{141}$

- Insuring away the extreme tail of liabilities in a closed plan after a specified term, such as 5 or 10 years - to reduce costs.

- Increasing optionality in contracts to improve flexibility - for example, the option to switch the indexation measure for pensions in payment from the Retail Price Index to the Consumer Price Index if government legislation changes; or the option to secure discretionary benefits, such as actual inflation above a $5 \%$ cap; or surrender options.

139 Michael Klimes (2017) How the first automated bulk scheme transfers happened, Professional Pensions, 10 November.

140 James Phillips (2017) DB schemes insuring wrong tranche of members in buy-ins, Professional Pensions, 14 August.

${ }^{141}$ Stephanie Baxter (2017) Converting longevity swaps into bulk annuities: The next de-risking innovation?, Professional Pensions, 13 April. 
- Combining liability management solutions (such as interest rate and inflation swaps, and ETV, FRO and PIE exercises) and bulk annuities in a buy-out - so instead of completing liability management before considering a buy-out, plans do this in a single exercise.

- "Buy-out aware" investment portfolios - used to reduce buy-out price volatility and close the funding shortfall, with the buy-out price locked to the value of the buy-out aware funds once a target shortfall has been reached and whilst the contract documentation for a buy-out is being completed.

- Improved arrangements for handling data errors that arise after a deal has been executed - to reduce pre-deal negotiation requirements and post-deal transaction uncertainty. Common data errors include member gender, date of birth and benefit amounts for both member and partner. A simplified data error process could deal with these issues in the following way: locking down benefits, removing the need for re-pricing; mechanistically adjusting demographic errors; and using due diligence to check for systematic errors with the data. ${ }^{142}$

- Arrangements to handle deferred members - to improve insurer appetite to assume the additional risk and cost involved. Deferred lives make up almost half $(45 \%)$ of the membership of UK DB plans in the UK. ${ }^{143}$ They are much more expensive to hedge for a number of reasons. First, there can be problems with their existence and identification. Second, they enjoy a large number of options which need to be priced. ${ }^{144}$ Third, their longevity risk is greater, because the longevity improvement assumption used for pricing has greater reliance on the assumed long-run trend. ${ }^{145}$ Fourth, as a direct consequence of the previous points, more capital is needed and this, in turn, increases the demand for reinsurance. These issues can be at least partially mitigated as follows: a robust existence checking procedure is needed involving electronic tracing, assuming a fixed percentage of the pension is exchanged for tax-free cash, setting the assumed retirement date to the plan's normal retirement date, assuming no pension is exchanged for additional partner pension, restricting the age profile to older deferred members, and restricting the proportion of deferred members in the transaction. ${ }^{146}$

11.53. These are all innovations in the space linking pension plans and insurance companies designed to ease the transfer of pension liabilities (or at least the longevity risk in them) from pension plans to insurance companies. But there is now an increasing sign of long-term capacity constraints within insurance companies. ${ }^{147}$ As one consultant said: "Given the market has historically completed only 150-200 deals in any one year, there is a real risk of capacity constraints in the market, not just from an insurer capital perspective, but also from a resource and expertise perspective." 148

142 Andrew Murphy (2017) Developments in longevity swaps, Pacific Life Re, 23 November, IFoA Life Conference. Provided due diligence has been carried out at the outset, subsequent data errors tend to be unbiased in terms of their impact and so average out close to zero.

143 That is $4.9 \mathrm{~m}$ members (The Pension Regulator and the Pension Protection Fund, Purple Book 2015).

144 For example, lump sum commutation, trivial commutation, early/late retirement, increasing a partner's benefits at the expense of the member's benefits, and pension increase exchanges.

145 Valuation and risk assessment of a deferred annuity can be broken down into five overlapping components: survival to retirement; the socio-economic group of the pensioner at the date of retirement; the base mortality table at the time of retirement for that socio-economic group; general mortality improvements (e.g. age $65+$ ) up to the date of retirement; and the mortality improvement rate after retirement. Uncertainty in the probability of survival to retirement will typically be quite small in relation to the other risks.

146 Andrew Murphy (2017) Developments in longevity swaps, Pacific Life Re, 23 November, IFoA Life Conference.

147 As mentioned in paragraph 11.47, there does not appear to be an immediate capacity constraint.

148 Martyn Phillips, Mercer (quoted in Professional Pensions (2016) Risk reduction and the extent of trust in pension scheme advisers and providers, June, p.28). 
11.54. In April 2017, the International Monetary Fund (IMF) released a new edition of its Global Financial Stability Report. Chapter 2 ("Low Growth, Low Interest Rates, And Financial Intermediation") suggests that DB pension funds across the globe might have to cut benefits "significantly" in the long term because of ultra-low interest rates. Attempts to increase returns by changing asset allocations "appears feasible only by taking potentially unacceptable levels of risk." In the face of such low rates, the IMF argues that "life insurers and pension funds would face a long-lasting transitional challenge to profitability and solvency, which is likely to require additional capital" or would require a "very high" level of volatility risk to meet their funding goals. However, a combination of risk aversion and regulatory constraints was likely to deter the vast majority from taking this second path. The IMF instead believes that the current situation might work to the benefit of insurers backing buy-ins and buy-outs. With investors increasingly monitoring the size of DB liabilities and the effects on company share prices, profits and dividends, the IMF said offloading these liabilities to insurers "is an attractive option" and "may represent a market-efficient arrangement" and that "regulation could play an important role in this area by facilitating such transactions."

\section{A Look into the Future: Potential Longevity Risk Transfer Solutions}

\subsection{Overview}

A number of potential solutions were suggested in the 2006 Living with Mortality paper:

- Longevity bond types (e.g. zero-coupon longevity bonds, deferred longevity bonds, principal-atrisk longevity bonds and longevity spread bonds).

- Mortality, longevity and annuity futures.

- Mortality options, longevity caplets and floorlets.

- Mortality swaptions.

These were direct translations from already existing capital market instruments, but so far none of these, apart from a single longevity spread bond (i.e. Kortis) and a few longevity bull call spreads constructed using longevity caplets and floorlets (e.g. the 2013 Aegon deal with Société Générale), have been introduced in the longevity risk transfer market. In this section, we look at two potential new solutions that might have a greater chance of being introduced in the near term.

\subsection{Potential New Solution: Longevity-Linked Securities}

12.2.1. A perceived problem with the EIB/BNP Paribas longevity bond was that the reference index might not be sufficiently highly correlated with a hedger's own mortality experience (as a result of population basis risk). An alternative instrument - denoted a longevity-linked security (LLS) ${ }^{149}-$ deals, at least partly, with this problem. The concept was inspired by the design of mortgage-backed securities.

12.2.2. The LLS is built around a special purpose vehicle. Individual hedgers on one side of the contract (e.g. a pension plan or an annuity provider) arrange longevity swaps with the SPV using their own mortality experience at rates that are negotiated with the SPV manager. The swapped

149 These were first discussed in Cairns et al. (2008). 


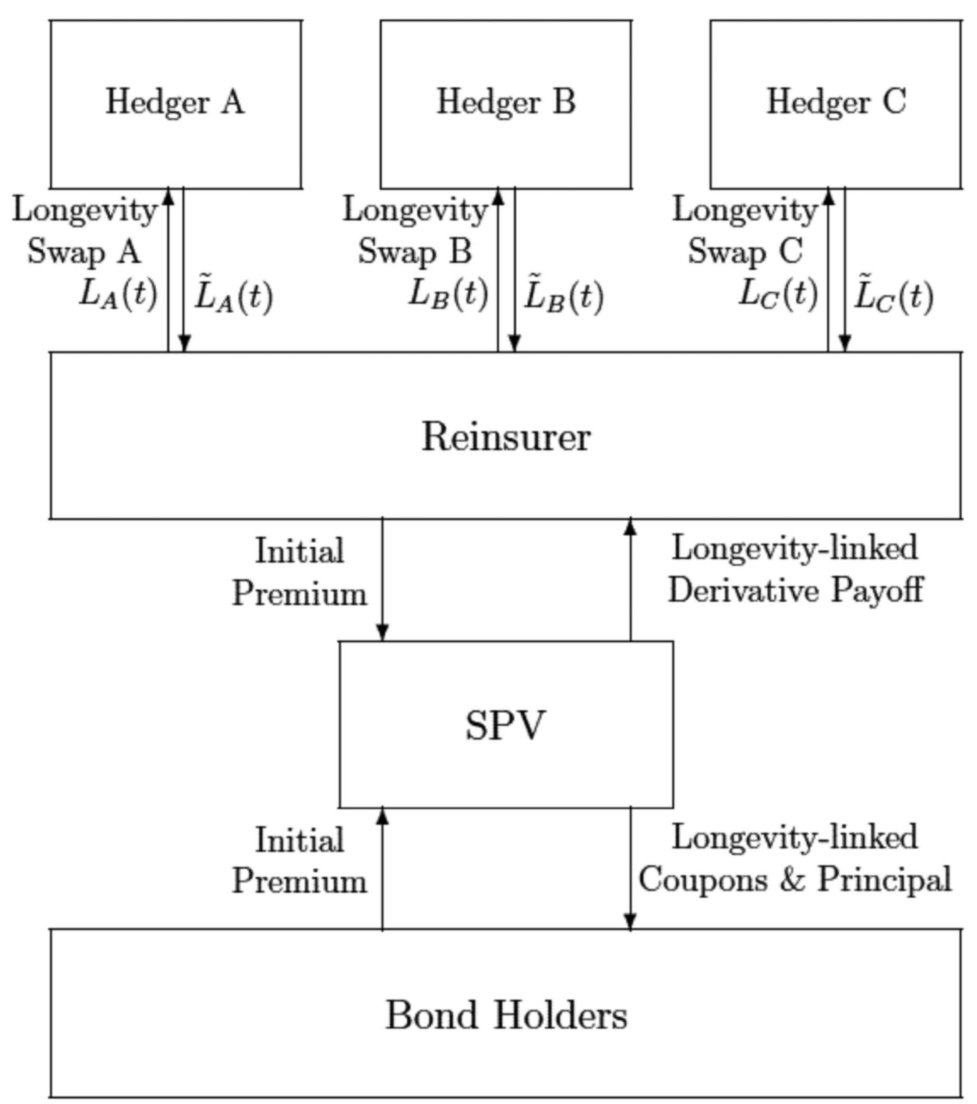

Figure 17. Cash flows under a LLS

cashflows are then aggregated and passed on to the market. Bondholders gain if mortality is heavier than anticipated.

12.2.3. It might be felt that the aggregate cashflows themselves lack transparency ${ }^{150}$ in which case the SPV might link cashflows to an accepted reference index. The difference between this and the aggregated swap cashflows is a basis risk that is borne by the SPV manager.

12.2.4. This type of arrangement is illustrated in Figure 17 where the intermediary in this case is a reinsurer, which transacts customised longevity swaps with a set of hedgers. In this example, there are three hedgers, A, B and C (but there could, of course, be many more). Hedger A wishes to swap the risky longevity-linked cashflows $L_{A}(t)$ for a series of pre-determined cashflows. The agreement with the SPV manager is to swap floating $L_{A}(t)$ for fixed $\tilde{L}_{A}(t)$ for $t=1, \ldots, T$, with the fixed leg set at a level that results in the swap initially having zero value at time 0 . Similarly, hedger B swaps floating $L_{B}(t)$ for fixed $\tilde{L}_{B}(t)$, and hedger C floating $L_{C}(t)$ for fixed $\tilde{L}_{C}(t)$. The SPV itself invests in

150 Although this did not seem to be a problem with mortgage-backed securities until the emergence of the GFC in 2007. 
AAA-rated, fixed-interest securities of appropriate duration or uses floating rate notes plus an interest-rate swap.

12.2.5. The LLS bond holders pay an initial premium that is used to buy the fixed-interest securities and to pay an initial commission to the SPV manager. The bond holders in return receive coupons and, possibly, a final repayment of principal that is linked to a reference index, $X(t)$, that matches ${ }^{151}$ as closely as possible the combined cashflows, rather than to $L_{A}(t), L_{B}(t)$ or $L_{C}(t)$. Any differences accrue to or are paid by the SPV manager. The bond holders will not normally be hedgers themselves, so they will expect a fair premium over market fixed-interest rates in return for assuming the longevity risk.

12.2.6. Finally, the LLS might take the form of a catastrophe (or cat) bond (similar to the Kortis bond). In this case, the repayment of principal would be determined by the value of an index-based underlying, with appropriate attachment and exhaustion points.

12.2.7. To be more concrete, the underlying index $X(t)$ that the LLS makes reference to is derived from, e.g. national population mortality rates, and is constructed in a way to achieve the optimal balance between hedge effectiveness for the reinsurer, within the cat bond structure, and the riskreturn profile to investors. For a cat bond with attachment and exhaustion points AP and EP, the payoff at maturity will be the full bond nominal, $N$, if $X(T)<A P, N(1-(X(T)-A P) /(E P-A P))$ if $A P \leq X(T)<E P$, and 0 if $E P \leq X(T)$.

12.2.8. The hedge is most likely to be effective if the reinsurer takes on a balanced and well diversified group of transactions with the primary hedgers (A, B and $\mathrm{C}$ above). For example, if the primary reinsurance transactions are wholly with blue collar pension plans, then an index-based LLS will be much less effective for the reinsurer. A low level of population basis risk turns out not to require exact matching of the national population (e.g. the aggregation of A, B and C). For example, Cairns et al. (2017a) demonstrate that an aggregated portfolio that covers $80 \%$ of the population but is also heavily skewed in value terms towards wealthier and healthier people can have a correlation with the national population that is well above $95 \%$.

12.2.9. The marketing of LLS to ILS investors has great potential, following the introduction of comprehensive UK regulations for ILS in 2017, particularly if it takes the cat bond structure familiar to such investors, according to consultants Hymans Robertson. This is because longevity risk is becoming better understood and its volatility and correlation with other asset classes is low. Hymans Robertson argues that "Bulk annuity insurers could use [ILS] to provide additional capital to finance large deals (particularly where reinsurance is expensive or difficult to obtain) or to optimise their capital positions by rebalancing the risks on their balance sheets." With the ILS investor base broadening all the time and an increasing amount of capital flowing into the market from other sophisticated investor sources, there is a growing pool of capital for which longevity or bulk-annuity linked risks might be attractive. ${ }^{152}$

151 The match might be expressed in cashflow terms or in value terms. In the latter case, the value of $X(t)$, is intended to hedge the value of the liability at a specified maturity.

152 Artemis (2017) ILS has potential in UK longevity and backing annuity deals: Hymans Robertson;www. artemis.bm/BLOG/2017/08/21/ILS-HAS-POTENTIAL-IN-UK-LONGEVITY-BACKING-ANNUITY-DEALSHYMANS-ROBERTSON/ 


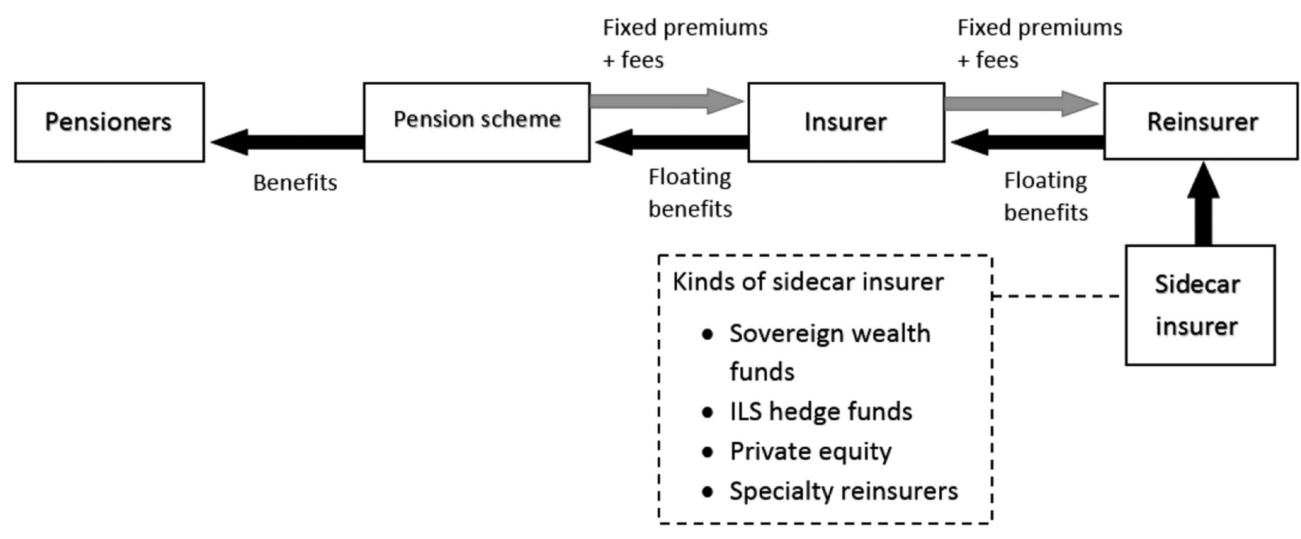

Figure 18. Typical sidecar structure

Source: PFI.

\subsection{Potential New Solution: Reinsurance Sidecars}

12.3.1. Another potential solution is the reinsurance sidecar - which is a way to share risks with new investors when the latter are concerned about the ceding reinsurer having an informational advantage.

12.3.2. Formally, a reinsurance sidecar is a financial structure established to allow external investors to take on the risk and benefit from the return of specific books of insurance or reinsurance business. It is typically set up by existing (re)insurers that are looking to either partner with another source of capital or set up an entity to enable them to accept capital from third-party investors (Kessler et al., 2016).

12.3.3. It is established as a SPV, with a maturity of 2-3 years. It is capitalised by specialist insurance funds, usually by preference shares, though sometimes in the form of debt instruments. It reinsures a defined pre-agreed book of business or categories of risk. Liability is limited to assets of the SPV and the vehicle is unrated.

12.3.4. The benefit to insurers is that sidecars can provide protection against exposure to peak longevity risks, ${ }^{153}$ help with capital management by providing additional capacity without the need for permanent capital, and can provide an additional source of income by leveraging underwriting expertise. The benefit to investors is that they enjoy targeted non-correlated returns relating to specific short-horizon risks and have an agreed procedure for exiting; investors can also take advantage of temporary price hikes, but without facing legacy issues that could affect an investment in a typical insurer.

\subsubsection{Figure 18 shows a typical sidecar structure.}

12.3.6. There are a number of challenges to the use of sidecars in the longevity risk transfer market. There is the tension between the long-term nature of longevity risk and investor preference for a short-term investment horizon. There are also regulatory requirements on cedants, affecting their

153 That is, specific individual cashflows that give rise to the greatest uncertainty in value terms 
ability to generate a return. These include: the posting of prudent collateral, the underlying assets in the SPV must generate matching cash flows, the risk transfer must be genuine, and the custodian/ trustee must be financially strong. There is also a risk to cedants of losing capital relief if regulatory requirements are not met or they change.

\subsection{Why Could These Potential Solutions Be Successful Now?}

The principal reason why these solutions might be more successful now in a way that they were not a decade ago is the capacity constraint in the (re)insurance industry - it does not have the capital or experienced personnel to take on unlimited longevity risk. The only long-term solution to this capacity constraint is to bring in new investors from the capital markets (i.e. to transfer the risk to the capital markets). These investors will include ILS investors, hedge funds, private equity investors, sovereign wealth funds, endowments, family offices and other investors seeking asset classes that have low correlation with existing financial assets. However, two issues need to be resolved. First, the hedger needs assurance that the solution sold to these investors provides an effective hedge. Second, these investors need some assurance that they are not going to be sold a "lemon." 154 There have been many attempts over the last decade to provide both types of assurance - without any real success. This time it might be - and certainly needs to be - different. An early sign of success for the reinsurance sidecar structure came at the beginning of 2018 when RGA Re and RenaissanceRe, announced a new start-up named Langhorne Re, which will target in-force life and annuity business. The new company has secured $\$ 780 \mathrm{~m}$ of equity capital from RGA, RenaissanceRe and third-party sidecar investors, including pension funds and other life companies. ${ }^{155}$

\section{Conclusions}

13.1. As Michaelson \& Mulholland (2014) point out:

the longevity risk inherent in the world's aggregate retirement obligations is far in excess of the amount of risk capital the global insurance industry could realistically bring to bear against this risk. ${ }^{156}$ Seen in this light, it becomes painfully obvious that vast sums of additional risk capital must be dedicated to adequately managing longevity risk. It is similarly evident that the only source capable of providing such quantities of capital, and thus assuming a meaningful amount of the world's longevity risk, are the global capital markets... The mission is clear longevity risk must be successfully turned into an asset class capable of attracting these vast pools of capital, or else the world's retirement systems will struggle to significantly reduce their longevity exposures in an efficient manner. However, developing capital markets solutions that are readily acceptable by a wide spectrum of institutional investors - given the complexity

154 Originally a "lemon" was a defective second-hand car offered for sale on an "as good as new" basis. It now refers to any product where the seller has more information about its true worth than any potential buyer. In other words, the seller has an informational advantage and needs to find a way of demonstrating the true value to the potential buyer in order to secure a sale (see Akerlof, 1970). The most effective way of achieving this for the reinsurer is to "keep some skin in the game" by agreeing to co-share downside risks with the new sidecar investors (as explained in Biffis \& Blake, 2014).

155 https://www.reinsurancene.ws/langhorne-re-launched-rga-renre-force-life-annuity-reinsurer/

156 Total global reinsurer capital was just \$595bn at 31 December 2016 (Aon Benfield, Reinsurance Market Outlook April 2017). 
and uncertainty in modelling this long-term risk - requires innovative solutions from dedicated and experienced financial institutions.

There are four major challenges.

13.2. First, in order to expand the investor base, there is a need to close the gap between the preferences of stakeholders: buyers and sellers of longevity protection. Currently, long-term capitalmarket investors prefer bonds, while, as the paper has outlined, the most successful solutions have been longevity swaps. While short-term mortality bonds have been a success, long-term longevity bonds have not been similarly successful so far. So more creative approaches that develop a carefully structured risk management chain are needed to meet the differing requirements and risk appetites of stakeholders. However, the Swiss Re strategy of gradual iteration from a successful innovation - as exemplified in the Kortis longevity spread bond which was a modest adaptation of the Vita mortality bond in terms of design and maturity - appears to show a way forward, as do elements of the recent NN Life transaction in the Netherlands. The two key prizes, if successful, are a much bigger investor base and much greater market liquidity.

13.3. Second, there needs to be a common agreement between market participants on which mortality model to use for the design and pricing of each longevity-linked deal. One of the main reasons why Aegon's deal with Société Générale went ahead in 2013 was that all parties agreed to use the same mortality model. Even if a mortality model produces the wrong forecasts - which it is bound to $\mathrm{do}-$ as long as those forecasts are not systematically biased, then it becomes a potential candidate for use in this market.

13.4. Third, a number of operational issues need to be dealt with. These include basis risk, credit risk, collateral and liquidity. Not only will this require market participants to work out the optimal trade-offs between basis risk and liquidity and between credit risk and collateral, it will also require the regulator to be willing to grant fair levels of regulatory capital relief for index-based hedge solutions that are compatible with current solvency capital requirements and consistent with levels of capital relief for customised longevity hedges, thereby putting both types of hedge on a level footing.

13.5. Fourth, it is important to engage with the regulator. This was the key message of Richard Sandor, a serial starter of new markets, such as the financial futures, climate exchange and Ameribor markets, ${ }^{157}$ when he spoke at the Longevity 12 conference in September $2016 .{ }^{158}$ He said that he always worked closely with the regulator when he was introducing a new product or market, so that there would be no surprises on the launch date. Failure to do this in the case of some of the early Dutch tail-risk protection deals meant that the Dutch regulator did not give the capital relief that was anticipated at the design stage. Regulators can also have big unintended consequences if, instead of engaging with them, there are attempts to circumvent them. For example, regulatory responses to the Global Financial Crisis (such as the US Dodd-Frank Act) had a significant effect in slowing down the establishment of longevity-linked capital market securities - which had nothing to do with the crisis itself. Regulations restricting the risk-taking activities of investment banks and new bank capital rules (Basel III) severely limited the role that banks could play in the development of this market. For example, it became virtually impossible for them to warehouse risk while matching longevity hedgers and longevity investors; and it even became unattractive for them to intermediate, standing in the

\footnotetext{
157 http://www.futuresmag.com/2016/03/21/inventing-new-market

158 https://www.cass.city.ac.uk/longevity-12
} 
middle between hedgers and investors, because the long-dated, illiquid credit exposure associated with longevity transactions now carried increased capital requirements. ${ }^{159}$ While significant parts of the Dodd-Frank Act are in the process of being repealed, there is little sign that investment banks the traditional conduit for introducing new capital from global investors, such as sovereign wealth funds - are returning to the longevity risk market.

13.6. These four challenges will need to be addressed in the next stage of the development of this market. But innovation has been an important feature of the longevity market since 2006 and there is every reason to believe that this will continue as the different players in the industry seek to meet the growing demand for longevity risk transfers, while reducing costs, optimising capital and managing risks.

\section{Acknowledgements}

The authors acknowledge funding from the Actuarial Research Centre of the Institute and Faculty of Actuaries through the "Modelling Measurement and Management of Longevity and Morbidity Risk" research programme, the Society of Actuaries and the Canadian Institute of Actuaries. The authors would also like to thank the two scrutineers of the paper for their extremely helpful and detailed comments on an earlier version of the paper.

\section{References}

Akerlof, G.A. (1970). The market for 'lemons': quality uncertainty and the market mechanism. Quarterly Journal of Economics, 84(3), 488-500.

Alai, D.H., Arnold (-Gaille), S. \& Sherris, M. (2014a). Modelling cause-of-death mortality and the impact of cause-elimination. Annals of Actuarial Science, 9(1), 167-186.

Alai, D.H. \& Sherris, M. (2014b). Rethinking age-period-cohort mortality trend models. Scandinavian Actuarial Journal, 2014(3), 208-227.

Aleksic, M.-C. \& Börger, M. (2012). Coherent projections of age, period, and cohort dependent mortality improvements, Discussion Paper, University of Ulm.

Bauer, D., Benth, F.E. \& Kiesel, R. (2010). Modeling the forward surface of mortality, Discussion Paper, University of Ulm.

Bauer, D., Börger, M., Ruß, J. \& Zwiesler, H.J. (2008). The volatility of mortality. Asia-Pacific Journal of Risk and Insurance, 3, 172-199.

Baxter, S. \& Wooley, A. (2017). All Annuitants Were Made Equal... but Some Are More Equal Than Others, Presentation at the IFoA Life Conference, Birmingham, 24 November 2017.

Berkum, F.V., Antonio, K. \& Vellekoop, M.H. (2016). The impact of multiple structural changes on mortality predictions. Scandinavian Actuarial Journal, 2016(7), 581-603.

Biffis, E. (2005). Affine processes for dynamic mortality and actuarial valuations. Insurance: Mathematics and Economics, 37, 443-468.

Biffis, E. \& Blake, D. (2014). Keeping some skin in the game: how to start a capital market in longevity risk transfers. North American Actuarial Journal, 18(1), 14-21.

159 In April 2012, a number of investment banks - UBS, Credit Suisse and Nomura - pulled out of the Life Market as a result of the additional capital requirements under Basel III. But new insurers and reinsurers entered: Munich Re, SCOR and PICA. 
Biffis, E., Blake, D., Pitotti, L. \& Sun, A. (2016). The cost of counterparty risk and collateralization in longevity swaps. Journal of Risk and Insurance, 83(2), 387-419.

Biffis, E., Denuit, M. \& Devolder, P. (2010). Stochastic mortality under measure changes. Scandinavian Actuarial Journal, 2010, 284-311.

Blake, D. \& Burrows, W. (2001). Survivor bonds: helping to hedge mortality risk. Journal of Risk and Insurance, 68(2), 339-348.

Blake, D., Boardman, T. \& Cairns, A.J.G. (2014). Sharing longevity risk: why governments should issue longevity bonds. North American Actuarial Journal, 18(1), 258-277.

Blake, D., Cairns, A.J.G. \& Dowd, K. (2006a). Living with mortality: longevity bonds and other mortality-linked securities. British Actuarial Journal, 12, 153-197.

Blake, D., Cairns, A.J.G. \& Dowd, K. (2008). Longevity risk and the Grim Reaper's toxic tail: the survivor fan charts. Insurance: Mathematics and Economics, 42, 1062-1066.

Blake, D., Cairns, A.J.G., Dowd, K. \& MacMinn, R. (2006b). Longevity bonds: financial engineering, valuation and hedging. Journal of Risk and Insurance, 73, 647-672.

Booth, H., Maindonald, J. \& Smith, L. (2002a). Applying Lee-Carter under conditions of variable mortality decline. Population Studies, 56, 325-336.

Booth, H., Maindonald, J. \& Smith, L. (2002b). Age-time interactions in mortality projection: applying Lee-Carter to Australia, Working Papers in Demography, Australian National University.

Börger, M. \& Ruß, J. (2012). It takes two: why mortality trend modeling is more than modeling one mortality trend, Discussion Paper, University of Ulm.

Börger, M., Fleischer, D. \& Kuksin, N. (2013). Modeling mortality trend under modern solvency regimes. ASTIN Bulletin, 44, 1-38.

Brouhns, N., Denuit, M. \& Van Keilegom, I. (2005). Bootstrapping the Poisson log-bilinear model for mortality forecasting. Scandinavian Actuarial Journal, 2005, 212-224.

Brouhns, N., Denuit, M. \& Vermunt, J.K. (2002a). A Poisson log-bilinear regression approach to the construction of projected lifetables. Insurance: Mathematics and Economics, 31, 373-393.

Brouhns, N., Denuit, M. \& Vermunt, J. (2002b). Measuring the longevity risk in mortality projections. Bulletin of the Swiss Association of Actuaries, 2, 105-130.

Cairns, A.J.G. (2014). Modeling and management of longevity risk, in Recreating Sustainable Retirement: Resilience, Solvency, and Tail Risk (Eds: P. B. Hammond, R. Maurer, and O. S. Mitchell). Oxford, Oxford University Press, pp. 71-88.

Cairns, A.J.G., Blake, D. \& Dowd, K. (2006). A two-factor model for stochastic mortality with parameter uncertainty: theory and calibration. Journal of Risk and Insurance, 73, 687-718.

Cairns, A.J.G., Blake, D. \& Dowd, K. (2008). Modelling and management of mortality risk: a review. Scandinavian Actuarial Journal, 108, 79-113.

Cairns, A.J.G., Blake, D., Dowd, K., Coughlan, G.D., Epstein, D. \& Khalaf-Allah, M. (2011a). Mortality density forecasts: an analysis of six stochastic mortality models. Insurance: Mathematics and Economics, 48, 355-367.

Cairns, A.J.G., Blake, D., Dowd, K., Coughlan, G.D., Epstein, D. \& Khalaf-Allah, M. (2011b). Bayesian stochastic mortality modelling for two populations. ASTIN Bulletin, 41, 29-59.

Cairns, A.J.G., Blake, D., Dowd, K., Coughlan, G.D., Epstein, D., Ong, A. \& Balevich, I. (2009). A quantitative comparison of stochastic mortality models using data from England \& Wales and the United States. North American Actuarial Journal, 13, 1-35.

Cairns, A.J.G., Blake, D., Dowd, K. \& Coughlan, G.D. (2014). Longevity hedge effectiveness: a decomposition. Quantitative Finance, 14, 217-235.

Cairns, A.J.G., Blake, D., Dowd, K. \& Kessler, A. (2016). Phantoms never die: living with unreliable population data. Journal of the Royal Statistical Society (Series A), 179, 975-1005. 
Cairns, A.J.G. \& El Boukfaoui, G. (2018). Basis risk in index based longevity hedges: a guide for longevity hedgers. To appear in North American Actuarial Journal.

Cairns, A.J.G., Kallestrup-Lamb, M., Rosenskjold, C.P.T., Blake, D. \& Dowd, K. (2017a). Modelling socio-economic differences in the mortality of Danish males using a new affluence index, Working Paper, Heriot-Watt University.

Cairns, A.J.G., Blake, D. \& Dowd, K. (2017b). A flexible and robust approach to modelling single population mortality. Presentation at the Longevity 13 Conference, Taipei, September 2017.

Chen, H., MacMinn, R.D. \& Sun, T. (2015). Multi-population mortality models: a factor copula approach. Insurance: Mathematics and Economics, 63, 135-146.

Chen, L., Cairns, A.J.G. \& Kleinow, T. (2017). Small population bias and sampling effects in stochastic mortality modelling. European Actuarial Journal, 7, 193-230.

Coelho, E. \& Nunes, L.C. (2011). Forecasting mortality in the event of a structural change. Journal of the Royal Statistical Society: Series A (Statistics in Society), 174, 713-736.

Coughlan, G. (2007a). Longevity risk and mortality-linked securities, Risk and Innovation, Pension Universe Conference, London (27 September).

Coughlan, G.D., Epstein, D., Sinha, A. \& Honig, P. (2007b). q-Forwards: Derivatives for Transferring Longevity and Mortality Risks, J. P. Morgan Pension Advisory Group, London (July).

Coughlan, G., Epstein, D., Ong, A., Sinha, A., Hevia-Portocarrero, J., Gingrich, E., Khalaf-Allah, M. \& Joseph, P. (2007c). LifeMetrics: a toolkit for measuring and managing longevity and mortality risks. J. P. Morgan Pension Advisory Group, London (13 March), available at https://www.jpmorgan.com/cm/BlobServer/lifemetrics_technical.pdf?blobkey=id\&blobwhere= 1158472448701\&blobheader=application\%2Fpdf\&blobcol=urldata\&blobtable=MungoBlobs

Coughlan, G.D., Khalaf-Allah, M., Ye, Y., Kumar, S., Cairns, A.J.G., Blake, D. \& Dowd, K. (2011). Longevity hedging 101: a framework for longevity basis risk analysis and hedge effectiveness. North American Actuarial Journal, 15, 150-176.

Currie, I.D. (2016). On fitting generalized linear and non-linear models of mortality. Scandinavian Actuarial Journal, 2016, 356-383.

Currie, I.D., Durban, M. \& Eilers, P.H.C. (2004). Smoothing and forecasting mortality rates. Statistical Modelling, 4, 279-298.

Czado, C., Delwarde, A. \& Denuit, M. (2005). Bayesian Poisson log-linear mortality projections. Insurance: Mathematics and Economics, 36, 260-284.

D’Amato, V., Di Lorenzo, E., Haberman, S., Russolillo, M. \& Sibillo, M. (2011). The Poisson logbilinear Lee-Carter model: applications of efficient bootstrap methods to annuity analyses. North American Actuarial Journal, 15, 315-333.

D’Amato, V., Haberman, S., Piscopo, G. \& Russolillo, M. (2012a). Modelling dependent data for longevity projections. Insurance Mathematics and Economics, 51, 694-701.

D’Amato, V., Haberman, S., Piscopo, G., Russolillo, M. \& Trapani, L. (2014). Detecting common longevity trends by a multiple population approach. North American Actuarial Journal, 18(1), 139-149.

D’Amato, V., Haberman, S. \& Russolillo, M. (2012b). The stratified sampling bootstrap: an algorithm for measuring the uncertainty in forecast mortality rates in the Poisson Lee-Carter setting. Methodology and Computing in Applied Probability, 14(1), 135-148.

Danesi, I.L., Haberman, S. \& Millossovich, P. (2015). Forecasting mortality in subpopulations using Lee-Carter Type Models: a comparison. Insurance: Mathematics and Economics, 62, 151161.

Darkiewicz, G. \& Hoedemakers, T. (2004). How the co-integration analysis can help in mortality forecasting, Discussion Paper, Catholic University of Leuven. 
Dawson, P., Blake, D., Cairns, A.J.G. \& Dowd, K. (2010). Survivor derivatives: a consistent pricing framework. Journal of Risk and Insurance, 77, 579-596.

Debonneuil, E. (2010). Simple model of mortality trends aiming at Universality: Lee Carter + Cohort, Quantitative Finance Papers, 1003:1802, arXiv.org.

Delwarde, A., Denuit, M. \& Eilers, P. (2007). Smoothing the Lee-Carter and Poisson log-bilinear models for mortality forecasting: a penalised log-likelihood approach. Statistical Modelling, 7, $29-48$.

Dowd, K. (2003). Survivor bonds: a comment on Blake and Burrows. Journal of Risk and Insurance, 70(2), 339-348.

Dowd, K., Blake, D. \& Cairns, A.J.G. (2010a). Facing up to the uncertainty of life: the longevity fan charts. Demography, 47, 67-78.

Dowd, K., Blake, D., Cairns, A.J.G. \& Dawson, P. (2006). Survivor swaps. Journal of Risk and Insurance, 73, 1-17.

Dowd, K., Cairns, A.J.G., Blake, D., Coughlan, G.D., Epstein, D. \& Khalaf-Allah, M. (2010b). Backtesting stochastic mortality models: an ex-post evaluation of multi-period-ahead density forecasts. North American Actuarial Journal, 14, 281-298.

Dowd, K., Cairns, A.J.G., Blake, D., Coughlan, G.D., Epstein, D. \& Khalaf-Allah, M. (2010c). Evaluating the goodness of fit of stochastic mortality models. Insurance: Mathematics and Economics, 47, 255-265.

Dowd, K., Cairns, A.J.G., Blake, D., Coughlan, G.D. \& Khalaf-Allah, M. (2011). A gravity model of mortality rates for two related populations. North American Actuarial Journal, 15, 334-356.

Enchev, V., Kleinow, T. \& Cairns, A.J.G. (2017). Multi-population mortality models: fitting, forecasting and comparisons. Scandinavian Actuarial Journal, 2017, 319-342.

Gaille, S. \& Sherris, M. (2011). Modelling mortality with common stochastic long-run trends. Geneva Papers on Risk and Insurance - Issues and Practice, 36, 595-621.

Gourieroux, C. \& Lu, Y. (2015). Love and death: a Freund model with frailty. Insurance: Mathematics and Economics, 63, 191-203.

Gourieroux, C. \& Monfort, A. (2008). Quadratic stochastic intensity and prospective mortality tables. Insurance: Mathematics and Economics, 43, 174-184.

Haberman, S. \& Renshaw, A. (2009). On age-period-cohort parametric mortality rate projections. Insurance: Mathematics and Economics, 45, 255-270.

Haberman, S. \& Renshaw, A. (2011). A comparative study of parametric mortality projection models. Insurance: Mathematics and Economics, 48, 35-55.

Haberman, S. \& Renshaw, A. (2012). Parametric mortality improvement rate modelling and projecting. Insurance: Mathematics and Economics, 50, 309-333.

Haberman, S. \& Renshaw, A. (2013). Modelling and projecting mortality improvement rates using a cohort perspective. Insurance: Mathematics and Economics, 53, 150-168.

Hainaut, D. (2012). Multidimensional Lee-Carter model with switching mortality processes. Insurance: Mathematics and Economics, 50, 236-246.

Hanewald, K. (2011). Explaining mortality dynamics: the role of macroeconomic fluctuations and cause of death trends. North American Actuarial Journal, 15, 290-314.

Hari, N., De Waegenaere, A., Melenberg, B. \& Nijman, T. (2008). Estimating the term structure of mortality. Insurance: Mathematics and Economics, 42, 492-504.

Harrison, D. \& Blake, D. (2013). A Healthier Way to De-risk: The Introduction of Medical Underwriting to the Defined Benefit De-risking Market, Pensions Institute; http://www. pensions-institute.org/reports/HealthierWayToDeRisk.pdf

Harrison, D. \& Blake, D. (2016). The Greatest Good for the Greatest Number: An Examination of Early Intervention Strategies for Trustees and Sponsoring Employers of Stressed Defined 
Benefit Schemes, Pensions Institute, available at http://www.pensions-institute.org/reports/ GreatestGood.pdf

Hatzopoulos, P. \& Haberman, S. (2009). A parameterized approach to modeling and forecasting mortality. Insurance: Mathematics and Economics, 44, 103-123.

Hatzopoulos, P. \& Haberman, S. (2011). A dynamic parameterization modeling for the age-periodcohort mortality. Insurance: Mathematics and Economics, 49, 155-174.

Hobcraft, J., Menken, J. \& Preston, S.H. (1982). Age, period and cohort effects in demography: a review. Population Index, 48(1), 4-43.

Hunt, A. \& Blake, D. (2014). A general procedure for constructing mortality models. North American Actuarial Journal, 18(1), 116-138.

Hunt, A. \& Blake, D. (2015). Modelling longevity bonds: analysing the Swiss Re Kortis bond. Insurance: Mathematics and Economics, 63, 12-29.

Hunt, A. \& Blake, D. (2016). The Good, the Bad and the Healthy: The Medical Underwriting Revolution in the Defined Benefit De-risking Market, Pensions Institute, available at http:// www.pensions-institute.org/reports/GoodBadHealthy.pdf

Hunt, A. \& Blake, D. (2018). Identifiability, cointegration and the gravity model. Insurance: Mathematics and Economics, 78, 360-368.

Hunt, A. \& Villegas, A.M. (2015). Robustness and convergence in the Lee-Carter model with cohort effects. Insurance Mathematics and Economics, 64, 186-202.

Hyndman, R., Booth, H. \& Yasmeen, F. (2013). Coherent mortality forecasting the product-ratio method with functional time series models. Demography, 50, 261-283.

International Monetary Fund (IMF) (2017). Global Financial Stability Report (Chapter 2: Low Growth, Low Interest Rates, And Financial Intermediation), Washington DC, available at www.imf.org

Jacobsen, R., Keiding, N. \& Lynge, E. (2002). Long-term mortality trends behind low life expectancy of Danish women. Journal of Epidemiology and Community Health, 56, 205-208.

Jarner, S. r. F. \& Kryger, E.M. (2011). Modelling adult mortality in small populations: the SAINT model. ASTIN Bulletin, 41, 377-418.

Joint Forum (2013). Longevity Risk Transfer Markets: Market Structure, Growth Drivers and Impediments, and Potential Risks. Joint Forum of the Basel Committee on Banking Supervision, International Organization of Securities Commissions, and International Association of Insurance Supervisors, c/o Bank for International Settlements, Basel, Switzerland, December, available at www.bis.org/publ/joint34.pdf

Kessler, A., Bugler, N., Nicenko, V. \& Gillis, C. (2016). Sidecars: Alternative Capital or Reinsurance? Presentation at the Longevity 12 Conference, Chicago, 29 September.

Kleinow, T. (2015). A common age effect model for the mortality of multiple populations. Insurance: Mathematics and Economics, 63, 147-152.

Koissi, M., Shapiro, A. \& Hognas, G. (2006). Evaluating and extending the Lee-Carter model for mortality forecasting: bootstrap confidence interval. Insurance: Mathematics and Economics, $38,1-20$.

Kuang, D., Nielsen, B. \& Nielsen, J. (2008). Forecasting with the age-period-cohort model and the extended chain-ladder model. Biometrika, 95, 987-991.

Lee, R.D. \& Carter, L.R. (1992). Modeling and forecasting U.S. mortality. Journal of the American Statistical Association, 87, 659-675.

Legal \& General and Engaged Investor (2016). De-risking Journeys of Mid-sized Pension Schemes, June. 
Li, H., De Waegenaere, A. \& Melenberg, B. (2015a). The choice of sample size for mortality forecasting: a Bayesian learning approach. Insurance: Mathematics and Economics, 63, 153168.

Li, J., Tickle, L., Tan, C.-I. \& Li, J.S.-H. (2017). Assessing Basis Risk for Longevity Transactions Phase 2, Sessional research meeting, Institute and Faculty of Actuaries, December 2017. (See bit.ly/ifoalbr2).

Li, J.S.-H. \& Chan, W.-S. (2011). Time-simultaneous prediction bands: a new look at the uncertainty involved in forecasting mortality. Insurance: Mathematics and Economics, 49, 81-88.

Li, J.S.-H. \& Hardy, M.R. (2011). Measuring basis risk in longevity hedges. North American Actuarial Journal, 15, 177-200.

Li, J.S.-H., Hardy, M. \& Tan, K. (2009). Uncertainty in mortality forecasting: an extension to the classic Lee-Carter approach. ASTIN Bulletin, 39, 137-164.

Li, J.S.-H., Zhou, R. \& Hardy, M.R. (2015b). A step-by-step guide to building two-population stochastic mortality models. Insurance: Mathematics and Economics, 63, 121-134.

Li, N. \& Lee, R.D. (2005). Coherent mortality forecasts for a group of populations: an extension of the Lee-Carter method. Demography, 42, 575-594.

Lin, T. \& Tzeng, L. (2010). An additive stochastic model of mortality rates: an application to longevity risk in reserve evaluation. Insurance: Mathematics and Economics, 46, 423-435.

Loeys, J., Panigirtzoglou, N. \& Ribeiro, R.M. (2007). Longevity: A Market in the Making. London: J. P. Morgan Securities Ltd., London (2 July).

Longevity Basis Risk Working Group (2014). Longevity Basis Risk: A Methodology for Assessing Basis Risk, Institute \& Faculty of Actuaries (IFoA) and the Life and Longevity Markets Association (LLMA), London (Authors: Haberman, S., Kaishev, V., Villegas, A., Baxter, S., Gaches, A., Gunnlaugsson, S., and Sison, M.), available at www.actuaries.org.uk/arc

Luchinskaya, D., Simpson, P. \& Stoye, G. (2017). UK health and social care spending, Institute for Fiscal Studies, 7 February, available at https://www.ifs.org.uk/publications/8879

Lucida (2008). Lucida and J. P. Morgan First to Trade Longevity Derivative, Press Release (15 February).

Mayhew, L. \& Smith, D. (2014). Gender convergence in human survival and the postponement of death. North American Actuarial Journal, 18(1), 194-216.

Michaelson, A. \& Mulholland, J. (2014). Strategy for increasing the global capacity for longevity risk transfer: developing transactions that attract capital markets investors. Journal of Alternative Investments, 17(1), 18-27.

Milidonis, A., Lin, Y. \& Cox, S.H. (2011). Mortality regimes and pricing. North American Actuarial Journal, 15, 266-289.

Mitchell, D., Brockett, P., Mendoza-Arriaga, R. \& Muthuraman, K. (2013). Modeling and forecasting mortality rates. Insurance: Mathematics and Economics, 52, 275-285.

Morningstar (2013). The State of State Pension Plans 2013-A Deep Dive Into Shortfalls and Surpluses.

Murphy, M. (2010). Re-examining the dominance of birth cohort effects on mortality. Population and Development Review, 36, 365-390.

Nielsen, B. \& Nielsen, J. (2014). Identification and forecasting in mortality models, The Scientific World Journal, 2104: Article 347043.

Njenga, C.N. \& Sherris, M. (2011). Longevity risk and the econometric analysis of mortality trends and volatility. Asia-Pacific Journal of Risk and Insurance, 5(2), 1-54.

O’Hare, C. \& Li, Y. (2015). Identifying structural breaks in stochastic mortality models. ASME J. Risk Uncertainty Part B, 1(2), 021001. 
Organisation for Economic Co-Operation and Development (OECD) (2013). Pension Markets in Focus, available at www.oecd.org

Osmond, C. (1985). Using age, period and cohort models to estimate future mortality rates. International Journal of Epidemiology, 14, 124-129.

Pedroza, C. (2006). A Bayesian forecasting model: predicting US male mortality. Biostatistics, 7, 530-550.

Pension Protection Fund and the Pensions Regulator (2015). The Purple Book 2015, Pension Protection Fund and the Pensions Regulator, Croydon and Brighton.

Pigott, C. \& Walker, M. (2016). Longevity Swap Markets - Why Just the UK?, Presentation to the Institute and Faculty of Actuaries, November.

Plat, R. (2009). On stochastic mortality modeling. Insurance: Mathematics and Economics, 45, 393404.

Prudential Regulatory Authority (2015). Solvency II: Internal Model and Matching Adjustment Update. Letter from Executive Director, 9 March 2015.

Prudential Regulatory Authority (2016). Reflections on the 2015 Solvency II Internal Model Approval Process. Letter from Executive Director, 15 January 2016.

Punter Southall (2015). De-risking Bulletin, March.

Renshaw, A. \& Haberman, S. (2003a). Lee-Carter mortality forecasting: a parallel generalized linear modelling approach for England and Wales mortality projections. Journal of the Royal Statistical Society: Series C (Applied Statistics), 52, 119-137.

Renshaw, A. \& Haberman, S. (2003b). Lee-Carter mortality forecasting with age-specific enhancement. Insurance: Mathematics and Economics, 33, 255-272.

Renshaw, A.E. \& Haberman, S. (2006). A cohort-based extension to the Lee-Carter model for mortality reduction factors. Insurance: Mathematics and Economics, 38, 556-570.

Renshaw, A. \& Haberman, S. (2008). On simulation-based approaches to risk measurement in mortality with specific reference to Poisson Lee-Carter modelling. Insurance: Mathematics and Economics, 42, 797-816.

Richards, S.J. (2008). Applying survival models to pensioner mortality data. British Actuarial Journal, 14, 257-326.

Richards, S.J., Currie, I.D., Kleinow, T. \& Ritchie, G. (2017). A Stochastic Implementation of the APCI Model for Mortality Projections, IFoA Sessional Research Meeting, Staple Inn, London, 16 October 2017.

Russo, V., Giacometti, R., Ortobelli, S., Rachev, S. \& Fabozzi, F. (2011). Calibrating affine stochastic mortality models using term assurance premiums. Insurance: Mathematics and Economics, 49, 53-60.

Russolillo, M., Giordano, G. \& Haberman, S. (2011). Extending the Lee-Carter model: a three-way decomposition. Scandinavian Actuarial Journal, 2011(2), 96-117.

Social Security Administration (SSA) (2013). OASDI Trustees Report 2013, available at http://www. ssa.gov/OACT/tr/2013/IV_B_LRest.html\#267528

Sweeting, P.J. (2011). A trend-change extension of the Cairns-Blake-Dowd model. Annals of Actuarial Science, 5, 143-162.

Swiss Re Europe (2012). A Mature Market: Building a Capital Market for Longevity Risk, Swiss Re Europe Research.

Symmons, J. (2008). Lucida Guards against Longevity, 19 February, available at www. efinancialnews.com.

Towers Watson (2015). Corporate Briefing, April.

Trading Risk (2008). J. P. Morgan longevity swap unlocks UK annuity market, Trading Risk, Issue number 5 (September/October): 3, available at www.trading-risk.com 
Villegas, A.M. \& Haberman, S. (2014). On the modelling and forecasting of socio-economic mortality differentials: an application to deprivation and mortality in England. North American Actuarial Journal, 18, 168-193.

Villegas, A.M., Haberman, S., Kaishev, V. \& Millossovich, P. (2017). A comparative study of twopopulation models for the assessment of basis risk in longevity hedges. ASTIN Bulletin, 47, 631-679.

Wang, C.-W., Huang, H.-C. \& Liu, I.-C. (2011). A quantitative comparison of the Lee-Carter model under different types of non-Gaussian innovations. Geneva Papers on Risk and Insurance Issues and Practice, 36, 675-696.

Wang, H. \& Preston, S.H. (2009). Forecasting United States mortality using cohort smoking histories. Proceedings of the National Academy of Sciences of the United States of America, 106, 393-398.

Willis Towers Watson (WTW) (2017). Key Themes in the Longevity Hedging and Bulk Annuity Market: De-risking Report 2017.

Yang, S.S., Yue, J. \& Huang, H.-C. (2010). Modeling longevity risks using a principal component approach: a comparison with existing stochastic mortality models. Insurance: Mathematics and Economics, 46, 254-270.

Zelenko, I. (2014). Longevity risk and the stability of retirement systems: the Chilean longevity bond case. Journal of Alternative Investments, 17(1), 35-54.

Zhou, R., Wang, Y., Kaufhold, K., Li, J.S.-H. \& Tan, K.S. (2014). Modeling period effects in multipopulation mortality models: applications to Solvency II. North American Actuarial Journal, 18(1), 150-167.

\section{APPENDIX}

Table A1 lists UK pension buy-ins over $£ 100$ m between 2007 and 2016, while Table A2 lists the publicly announced longevity swaps that have been executed between 2007 and 2016 in the UK. 
Table A1. UK Pension Buy-ins over $£ 100$ m, 2007-2016

\begin{tabular}{|c|c|c|c|c|}
\hline Hedger Name & Size $(£ \mathrm{~m})$ & Sector & Insurer & Date \\
\hline Aggregate Industries & 305 & Mining & $\begin{array}{l}\text { Pension Insurance } \\
\text { Corporation }\end{array}$ & February 10 \\
\hline Aggregate Industries & 135 & Mining & $\begin{array}{l}\text { Just Retirement } \\
\text { Partnership }\end{array}$ & July 16 \\
\hline Aon & 150 & Financial Services & $\begin{array}{l}\text { MetLife (now Rothesay } \\
\text { Life) }\end{array}$ & June 09 \\
\hline Aon & 105 & Financial Services & $\begin{array}{l}\text { Pension Insurance } \\
\text { Corporation }\end{array}$ & March 12 \\
\hline Aon & 210 & Financial Services & $\begin{array}{l}\text { Pension Insurance } \\
\text { Corporation }\end{array}$ & October 14 \\
\hline Aon & 890 & Financial services & $\begin{array}{l}\text { Pension Insurance } \\
\text { Corporation }\end{array}$ & March 16 \\
\hline BBA Aviation & 270 & Aviation & Legal \& General & April 08 \\
\hline Cable \& Wireless & 1,050 & Communications & Prudential & September 08 \\
\hline Cadbury & 500 & Food Producer & $\begin{array}{l}\text { Pension Insurance } \\
\text { Corporation }\end{array}$ & December 09 \\
\hline $\mathrm{CDC}$ & 370 & Public & Rothesay Life & November 09 \\
\hline Civil Aviation Authority & 1,600 & Public & Rothesay Life & July 15 \\
\hline Cobham & 280 & $\begin{array}{l}\text { Aerospace } \& \\
\text { Defence }\end{array}$ & Rothesay Life & July 13 \\
\hline Cookson & 320 & Engineering & $\begin{array}{l}\text { Pension Insurance } \\
\text { Corporation }\end{array}$ & July 12 \\
\hline Dairy Crest & 150 & Food Producer & Legal \& General & December 08 \\
\hline Dairy Crest & 150 & Food Producer & Legal \& General & June 09 \\
\hline Friends Provident & 360 & Financial Services & Aviva & April 08 \\
\hline GKN & 125 & Engineering & Rothesay Life & January 14 \\
\hline GKN & 190 & Engineering & $\begin{array}{l}\text { Pension Insurance } \\
\text { Corporation }\end{array}$ & November 16 \\
\hline GlaxoSmithKline & 900 & Pharmaceutical & Prudential & November 10 \\
\hline Home Retail Group & 280 & Retail & Prudential & June 11 \\
\hline Hunting & 110 & Energy & $\begin{array}{l}\text { Paternoster (now } \\
\text { Rothesay Life) }\end{array}$ & January 07 \\
\hline ICI & 3,000 & Chemicals & Legal \& General & March 14 \\
\hline ICI & 600 & Chemicals & Prudential & March 14 \\
\hline ICI & 300 & Chemicals & Prudential & November 14 \\
\hline ICI & 500 & Chemicals & Legal \& General & March 15 \\
\hline ICI & 500 & Chemicals & Prudential & June 15 \\
\hline ICI & 500 & Chemicals & Legal \& General & June 15 \\
\hline ICI & 330 & Chemicals & Legal \& General & March 16 \\
\hline ICI & 630 & Chemicals & Scottish Widows & June 16 \\
\hline ICI & 750 & Chemicals & Legal \& General & July 16 \\
\hline ICI & 590 & Chemicals & Scottish Widows & September 16 \\
\hline ICI & 380 & Chemicals & Legal \& General & September 16 \\
\hline ICI Specialty Chemicals & 220 & Chemicals & Prudential & August 15 \\
\hline ICI Specialty Chemicals & 140 & Chemicals & $\begin{array}{l}\text { Pension Insurance } \\
\text { Corporation }\end{array}$ & November 16 \\
\hline Interserve & 300 & Construction & Aviva & July 14 \\
\hline JLT & 120 & Financial Services & Prudential & September 13 \\
\hline Kingfisher & 230 & Retail & Legal \& General & December 15 \\
\hline London Stock Exchange & 160 & Financial Services & $\begin{array}{l}\text { Pension Insurance } \\
\text { Corporation }\end{array}$ & May 11 \\
\hline
\end{tabular}


Table A1. (Continued)

\begin{tabular}{|c|c|c|c|c|}
\hline Hedger Name & Size $(£ \mathrm{~m})$ & Sector & Insurer & Date \\
\hline Meat \& Livestock Commission & 150 & Food Producer & Aviva & June 11 \\
\hline MNOPF & 500 & Shipping & $\begin{array}{l}\text { Lucida (now Legal \& } \\
\text { General) }\end{array}$ & September 09 \\
\hline MNOPF & 100 & Various & $\begin{array}{l}\text { Lucida (now Legal \& } \\
\text { General) }\end{array}$ & May 10 \\
\hline Morgan Crucible & 160 & Engineering & $\begin{array}{l}\text { Lucida (now Legal \& } \\
\text { General) }\end{array}$ & March 08 \\
\hline Next & 125 & Retail & Aviva & August 10 \\
\hline Northern Bank & 680 & Financial Services & Prudential & April 15 \\
\hline Ofcom & 150 & Public & Legal \& General & July 08 \\
\hline $\mathrm{P} \& \mathrm{O}$ & 800 & $\begin{array}{l}\text { UK Ports } \\
\text { Business }\end{array}$ & $\begin{array}{l}\text { Paternoster (now } \\
\text { Rothesay Life) }\end{array}$ & December 07 \\
\hline Pensions Trust & 225 & Charities & $\begin{array}{l}\text { Paternoster (now } \\
\text { Rothesay Life) }\end{array}$ & July 08 \\
\hline Philips & 480 & Technology & Rothesay Life & August 13 \\
\hline Philips & 300 & Technology & Prudential & June 14 \\
\hline Philips & 310 & Technology & Prudential & September 14 \\
\hline Pilkington & 230 & Manufacturing & $\begin{array}{l}\text { Pension Insurance } \\
\text { Corporation }\end{array}$ & August 16 \\
\hline Smith \& Nephew & 190 & Medical & Rothesay Life & January 13 \\
\hline Smiths Group & 250 & Engineering & Legal \& General & March 08 \\
\hline Smiths Group & 250 & Engineering & $\begin{array}{l}\text { Paternoster (now } \\
\text { Rothesay Life) }\end{array}$ & September 08 \\
\hline Smiths Group & 150 & Engineering & Rothesay Life & September 11 \\
\hline Smiths Group & 170 & Engineering & $\begin{array}{l}\text { Pension Insurance } \\
\text { Corporation }\end{array}$ & September 13 \\
\hline Smiths Group & 250 & Engineering & $\begin{array}{l}\text { Pension Insurance } \\
\text { Corporation }\end{array}$ & October 16 \\
\hline Tate \& Lyle & 350 & Food Producer & Legal \& General & December 12 \\
\hline Taylor Wimpey & 205 & Housebuilding & Partnership & December 14 \\
\hline The Church of England & 100 & Charities & Prudential & February 14 \\
\hline Total & 1,600 & Oil and Gas & $\begin{array}{l}\text { Pension Insurance } \\
\text { Corporation }\end{array}$ & June 14 \\
\hline Undisclosed & 145 & Undisclosed & Legal \& General & January 09 \\
\hline Undisclosed & 220 & Retail & Legal \& General & March 09 \\
\hline Undisclosed & 100 & Manufacturing & $\begin{array}{l}\text { MetLife (now Rothesay } \\
\text { Life) }\end{array}$ & January 10 \\
\hline Undisclosed & 100 & Retail & Aviva & March 10 \\
\hline Undisclosed & 185 & Banking & Aviva & December 10 \\
\hline Undisclosed & 120 & Undisclosed & Legal \& General & May 11 \\
\hline Undisclosed & 145 & Property & $\begin{array}{l}\text { MetLife (now Rothesay } \\
\text { Life) }\end{array}$ & November 11 \\
\hline Undisclosed & 250 & Media & Aviva & December 11 \\
\hline Undisclosed & 110 & Undisclosed & Aviva & December 11 \\
\hline Undisclosed & 250 & Undisclosed & Legal \& General & August 12 \\
\hline Undisclosed & 140 & Undisclosed & Prudential & August 12 \\
\hline Undisclosed & 120 & Undisclosed & $\begin{array}{l}\text { Pension Insurance } \\
\text { Corporation }\end{array}$ & November 12 \\
\hline Undisclosed & 100 & Undisclosed & $\begin{array}{l}\text { Pension Insurance } \\
\text { Corporation }\end{array}$ & December 12 \\
\hline
\end{tabular}


Table A1. (Continued)

\begin{tabular}{|c|c|c|c|c|}
\hline Hedger Name & Size $(£ \mathrm{~m})$ & Sector & Insurer & Date \\
\hline Undisclosed & 100 & Undisclosed & $\begin{array}{l}\text { Pension Insurance } \\
\text { Corporation }\end{array}$ & April 13 \\
\hline Undisclosed & 200 & Undisclosed & $\begin{array}{l}\text { Pension Insurance } \\
\text { Corporation }\end{array}$ & November 14 \\
\hline Undisclosed & 300 & Unknown & Aviva & June 15 \\
\hline Undisclosed & 120 & Undisclosed & Just Retirement & October 15 \\
\hline Undisclosed & 200 & Undisclosed & Scottish Widows & April 16 \\
\hline Undisclosed & 130 & Undisclosed & $\begin{array}{l}\text { Just Retirement } \\
\text { Partnership }\end{array}$ & July 16 \\
\hline Undisclosed & 150 & Undisclosed & $\begin{array}{l}\text { Pension Insurance } \\
\text { Corporation }\end{array}$ & September 16 \\
\hline Undisclosed & 100 & Undisclosed & $\begin{array}{l}\text { Pension Insurance } \\
\text { Corporation }\end{array}$ & September 16 \\
\hline Undisclosed & 245 & Unknown & $\begin{array}{l}\text { Pension Insurance } \\
\text { Corporation }\end{array}$ & November 16 \\
\hline Undisclosed & 105 & Undisclosed & $\begin{array}{l}\text { Pension Insurance } \\
\text { Corporation }\end{array}$ & November 16 \\
\hline Undisclosed* & 120 & Undisclosed & Rothesay Life & June 14 \\
\hline Unilever & 130 & Consumer goods & Legal \& General & September 14 \\
\hline Weir Group & 240 & Engineering & Legal \& General & December 07 \\
\hline West Ferry Printers & 130 & Printing & Aviva & September 08 \\
\hline $\begin{array}{l}\text { West Midlands Integrated Transport } \\
\text { Authority }\end{array}$ & 270 & Transport & Prudential & April 12 \\
\hline Western United & 115 & Mining & Rothesay Life & November 12 \\
\hline Western United & 110 & Food Producer & Rothesay Life & March 14 \\
\hline Wiggins Teape & 400 & Manufacturing & Scottish Widows & November 15 \\
\hline
\end{tabular}

Source: LCP (Professional Pensions, 26 January 2017).

Notes: Information collected from insurance company data and publicly announced transactions in H2 2016.

*This deal was completed during Q3 2014. 
Table A2. UK Longevity Swaps, 2007-2017

\begin{tabular}{|c|c|c|c|c|c|c|}
\hline Date & Hedger & Type & $\begin{array}{l}\text { Size } \\
(£ \mathrm{~m})\end{array}$ & $\begin{array}{l}\text { Term } \\
\text { (years) }\end{array}$ & Format & $\begin{array}{l}\text { Receiver or } \\
\text { Intermediary }\end{array}$ \\
\hline April 2007 & Friends' Provident & Ins & 1,700 & Run-off & Reinsurance contract & Swiss $\operatorname{Re}$ \\
\hline February 2008 & Lucida & Ins & N/A & 10 & $\begin{array}{l}\text { Index-based hedge; } \\
\text { exposure placed with } \\
\text { capital market investors }\end{array}$ & J. P. Morgan \\
\hline September 2008 & Canada Life & Ins & 500 & 40 & $\begin{array}{l}\text { Exposure placed with } \\
\text { capital market investors }\end{array}$ & J. P. Morgan \\
\hline February 2009 & Abbey Life & Ins & 1,500 & Run-off & Reinsurance contract & Deutsche Bank \\
\hline March 2009 & Aviva & Ins & 475 & 10 & $\begin{array}{l}\text { Exposure placed with } \\
\text { capital market investors \& } \\
\text { Partner RE }\end{array}$ & RBS \\
\hline May 2009 & Babcock & $\mathrm{PF}$ & $500-750$ & 50 & $\begin{array}{l}\text { Reinsurance contract with } \\
\text { Pac Life Re }\end{array}$ & Credit Suisse \\
\hline July 2009 & RSA & Ins & 1,900 & Run-off & $\begin{array}{l}\text { Reinsurance contract with } \\
\text { Rothesay Life; combined } \\
\text { with inflation \& interest } \\
\text { rate swaps }\end{array}$ & $\begin{array}{l}\text { Goldman Sachs/ } \\
\text { Rothesay }\end{array}$ \\
\hline December 2009 & $\begin{array}{r}\text { Berkshire } \\
\text { Council }\end{array}$ & PF & 1,000 & Run-off & Reinsurance contract & Swiss $\operatorname{Re}$ \\
\hline February 2010 & BMW & $\mathrm{PF}$ & 3,000 & Run-off & Reinsurance contract & $\begin{array}{l}\text { Deutsche Bank, } \\
\text { Paternoster }\end{array}$ \\
\hline July 2010 & British Airways & $\mathrm{PF}$ & 1,300 & NA & $\begin{array}{l}\text { Synthetic buy-in (longevity } \\
\text { swap + asset swap) }\end{array}$ & $\begin{array}{l}\text { Goldman Sachs/ } \\
\text { Rothesay }\end{array}$ \\
\hline February 2011 & Pall (UK) & $\mathrm{PF}$ & 70 & 10 & $\begin{array}{l}\text { Index-based hedge; } \\
\text { exposure placed with } \\
\text { capital market investors }\end{array}$ & J. P. Morgan \\
\hline August 2011 & ITV & $\mathrm{PF}$ & 1,700 & NA & Reinsurance contract & Credit Suisse \\
\hline November 2011 & Rolls Royce & PF & 3,000 & NA & $\begin{array}{l}\text { Pensioner bespoke longevity } \\
\text { swap }\end{array}$ & Deutsche Bank \\
\hline December 2011 & British Airways & $\mathrm{PF}$ & 1,300 & NA & $\begin{array}{l}\text { Pensioner bespoke longevity } \\
\text { swap }\end{array}$ & $\begin{array}{l}\text { Goldman Sachs/ } \\
\text { Rothesay }\end{array}$ \\
\hline December 2011 & Pilkington & $\mathrm{PF}$ & 1,000 & NA & $\begin{array}{l}\text { Pensioner bespoke longevity } \\
\text { swap }\end{array}$ & Legal \& General \\
\hline April 2012 & $\begin{array}{r}\text { Berkshire } \\
\text { Council }\end{array}$ & $\mathrm{PF}$ & 100 & Run-off & Insurance contract & Swiss $\operatorname{Re}$ \\
\hline May 2012 & Akzo Nobel & $\mathrm{PF}$ & 1,400 & NA & Insurance contract & Swiss Re \\
\hline July 2012 & $\begin{array}{l}\text { Pension Insurance } \\
\text { Corp }\end{array}$ & Ins & 300 & NA & Insurance contract & Munich Re \\
\hline December 2012 & $\mathrm{LV}=$ & Ins & 800 & NA & Insurance contract & Swiss $\operatorname{Re}$ \\
\hline December 2012 & $\begin{array}{l}\text { Pension Insurance } \\
\text { Corp }\end{array}$ & Ins & 400 & NA & Insurance contract & Munich Re \\
\hline February 2011 & Pall (UK) & $\mathrm{PF}$ & 70 & 10 & $\begin{array}{l}\text { Index-based hedge; } \\
\text { exposure placed with } \\
\text { capital market investors }\end{array}$ & J. P. Morgan \\
\hline August 2011 & ITV & PF & 1,700 & NA & Reinsurance contract & Credit Suisse \\
\hline November 2011 & Rolls Royce & $\mathrm{PF}$ & 3,000 & NA & $\begin{array}{l}\text { Pensioner bespoke longevity } \\
\text { swap }\end{array}$ & Deutsche Bank \\
\hline December 2011 & British Airways & $\mathrm{PF}$ & 1,300 & NA & $\begin{array}{l}\text { Pensioner bespoke longevity } \\
\text { swap }\end{array}$ & $\begin{array}{l}\text { Goldman Sachs/ } \\
\text { Rothesay }\end{array}$ \\
\hline
\end{tabular}


Table A2. (Continued)

\begin{tabular}{|c|c|c|c|c|c|c|}
\hline Date & Hedger & Type & $\begin{array}{l}\text { Size } \\
(£ \mathrm{~m})\end{array}$ & $\begin{array}{l}\text { Term } \\
\text { (years) }\end{array}$ & Format & $\begin{array}{l}\text { Receiver or } \\
\text { Intermediary }\end{array}$ \\
\hline December 2011 & Pilkington & $\mathrm{PF}$ & 1,000 & NA & $\begin{array}{l}\text { Pensioner bespoke longevity } \\
\text { swap }\end{array}$ & Legal \& General \\
\hline April 2012 & $\begin{array}{l}\text { Berkshire } \\
\text { Council }\end{array}$ & $\mathrm{PF}$ & 100 & Run-off & Insurance contract & Swiss $\operatorname{Re}$ \\
\hline May 2012 & Akzo Nobel & $\mathrm{PF}$ & 1,400 & NA & Insurance contract & Swiss $\mathrm{Re}$ \\
\hline July 2012 & $\begin{array}{l}\text { Pension Insurance } \\
\text { Corp }\end{array}$ & Ins & 300 & NA & Insurance contract & Munich Re \\
\hline March 2014 & $\begin{array}{l}\text { Aviva Staff } \\
\text { Pension Scheme }\end{array}$ & PF & 5,000 & NA & Insurance contract & $\begin{array}{l}\text { Munich Re, Scor } \\
\text { and Swiss Re }\end{array}$ \\
\hline May 2014 & Royal London & Ins & 1,000 & NA & Insurance contract & $\begin{array}{l}\text { RGA } \\
\text { International }\end{array}$ \\
\hline July 2014 & $\begin{array}{l}\text { BT Pension } \\
\text { Scheme }\end{array}$ & $\mathrm{PF}$ & 16,000 & NA & Insurance contract & $\begin{array}{l}\text { Prudential } \\
\text { Insurance Co of } \\
\text { America }\end{array}$ \\
\hline August 2014 & Rothesay Life & Ins & 1,000 & NA & Insurance contract & $\begin{array}{l}\text { Prudential } \\
\text { Insurance Co of } \\
\text { America }\end{array}$ \\
\hline August 2014 & $\begin{array}{l}\text { Phoenix Group } \\
\text { Pension Scheme }\end{array}$ & $\mathrm{PF}$ & 900 & NA & Insurance contract & Phoenix Life \\
\hline October 2014 & Legal \& General & Ins & 1,350 & NA & Insurance contract & $\begin{array}{l}\text { Prudential } \\
\text { Retirement } \\
\text { Insurance and } \\
\text { Annuity } \\
\text { Company }\end{array}$ \\
\hline December 2014 & Rothesay Life & Ins & 1,000 & NA & Insurance contract & Pacific Life Re \\
\hline January 2015 & Rothesay Life & Ins & 300 & NA & Insurance contract & $\begin{array}{l}\text { Prudential } \\
\text { Insurance Co of } \\
\text { America }\end{array}$ \\
\hline January 2015 & $\begin{array}{l}\text { Merchant Navy } \\
\text { Officers' } \\
\text { Pension Fund }\end{array}$ & $\mathrm{PF}$ & 1,500 & NA & Insurance contract & Pacific Life Re \\
\hline February 2015 & Scottish Power & $\mathrm{PF}$ & 2,000 & NA & Insurance contract & Abbey Life \\
\hline $\begin{array}{l}\text { April } 2015 \text { and } \\
\text { June } 2015\end{array}$ & $\begin{array}{l}\text { Pension Insurance } \\
\text { Corp }\end{array}$ & Ins & $>1,600$ & NA & Insurance contract & $\begin{array}{l}\text { Prudential } \\
\text { Insurance Co of } \\
\text { America }\end{array}$ \\
\hline July 2015 & $\begin{array}{l}\text { AXA UK Pension } \\
\text { Scheme }\end{array}$ & $\mathrm{PF}$ & 2,800 & NA & Insurance contract & $\begin{array}{l}\text { RGA } \\
\text { International }\end{array}$ \\
\hline August 2015 & Legal \& General & Ins & 1,850 & NA & Insurance contract & $\begin{array}{l}\text { Prudential } \\
\text { Insurance Co of } \\
\text { America }\end{array}$ \\
\hline September 2015 & $\begin{array}{l}\text { Scottish \& } \\
\text { Newcastle }\end{array}$ & $\mathrm{PF}$ & 2,400 & NA & Insurance contract & $\begin{array}{l}\text { Friends Life, } \\
\text { Swiss Re }\end{array}$ \\
\hline November 2015 & RAC (2003) & $\mathrm{PF}$ & 600 & NA & Insurance contract & SCOR Se \\
\hline December 2015 & Unnamed & $\mathrm{PF}$ & 90 & NA & Insurance contract & $\begin{array}{l}\text { Zurich, Pacific } \\
\text { Life Re }\end{array}$ \\
\hline April 2016 & Legal \& General & Ins & NA & NA & Reinsurance contract & Prudential \\
\hline August 2016 & Scottish Power & $\mathrm{PF}$ & 1,000 & NA & Reinsurance contract & Abbey Life \\
\hline August 2016 & Pirelli & $\mathrm{PF}$ & 600 & NA & Reinsurance contract & $\begin{array}{l}\text { Zurich, Pacific } \\
\text { Life Re }\end{array}$ \\
\hline
\end{tabular}


Table A2. (Continued)

\begin{tabular}{|c|c|c|c|c|c|c|}
\hline Date & Hedger & Type & $\begin{array}{l}\text { Size } \\
(£ \mathrm{~m})\end{array}$ & $\begin{array}{l}\text { Term } \\
\text { (years) }\end{array}$ & Format & $\begin{array}{l}\text { Receiver or } \\
\text { Intermediary }\end{array}$ \\
\hline January 2017 & NA & $\mathrm{PF}$ & 300 & NA & Reinsurance contract & Zurich, SCOR \\
\hline August 2017 & SSE & $\mathrm{PF}$ & 800 & NA & Reinsurance contract & Legal \& General \\
\hline September 2017 & British Airways & PF & 1,600 & NA & Reinsurance contract & $\begin{array}{l}\text { Partner Re, } \\
\quad \text { Canada Life Re }\end{array}$ \\
\hline September 2017 & $\begin{array}{l}\text { Marsh \& } \\
\text { McLennan }\end{array}$ & $\mathrm{PF}$ & 3,400 & NA & Reinsurance contract & $\begin{array}{l}\text { Canada Life Re, } \\
\text { Prudential } \\
\text { Insurance Co of } \\
\text { America }\end{array}$ \\
\hline November 2017 & $\begin{array}{l}\text { Pension Insurance } \\
\text { Corp }\end{array}$ & Ins & 900 & NA & Reinsurance contract & $\begin{array}{l}\text { Prudential } \\
\text { Insurance Co of } \\
\text { America }\end{array}$ \\
\hline December 2017 & Legal \& General & Ins & 600 & NA & Reinsurance contract & $\begin{array}{l}\text { Prudential } \\
\text { Insurance Co of } \\
\text { America }\end{array}$ \\
\hline
\end{tabular}

Note: Ins - hedger is insurance company; PF - hedger is pension fund, http://www.artemis.bm/library/ longevity_swaps_risk_transfers.html 